\title{
Supplementary Content Discovery of a Covalent Inhibitor of KRAS G12C (AMG 510) for the Treatment of Solid Tumors
}

Brian A. Lanman, ${ }^{*}{ }^{\dagger}$ Jennifer R. Allen, ${ }^{\dagger}$ John G. Allen, ${ }^{\dagger}$ Albert K. Amegadzie, ${ }^{\dagger}$ Kate S. Ashton, ${ }^{\dagger}$ Shon K. Booker, ${ }^{\dagger}$ Jian Jeffrey Chen, ${ }^{\dagger}$ Ning Chen, ${ }^{\dagger}$ Michael J. Frohn, ${ }^{\dagger}$ Guy Goodman, ${ }^{\dagger}$ David J. Kopecky, ${ }^{\dagger}$ Longbin Liu, ${ }^{\dagger}$ Patricia Lopez, ${ }^{\dagger}$ Jonathan D. Low ${ }^{\dagger} \mathrm{Vu} \mathrm{Ma},{ }^{\dagger}$ Ana E. Minatti, ${ }^{\dagger}$ Thomas T. Nguyen, ${ }^{\dagger}$ Nobuko Nishimura, ${ }^{\dagger}$ Alexander J. Pickrell, ${ }^{\dagger}$ Anthony B. Reed, ${ }^{\dagger}$ Youngsook Shin,${ }^{\dagger}$ Aaron C. Siegmund, ${ }^{\dagger}$ Nuria A. Tamayo, ${ }^{\dagger}$ Christopher M. Tegley, ${ }^{\dagger}$ Mary C. Walton, ${ }^{\dagger}$ Hui-Ling Wang, ${ }^{\dagger}$ Ryan P. Wurz, ${ }^{\dagger}$ May Xue, ${ }^{\dagger}$ Kevin C. Yang, ${ }^{\dagger}$ Pragathi Achanta,${ }^{\dagger}$ Michael D. Bartberger,${ }^{\S}$ Jude Canon, ${ }^{\ddagger}$ L. Steven Hollis, ${ }^{\|}$John D. McCarter, "Christopher Mohr, ${ }^{\S}$ Karen Rex, ${ }^{\ddagger}$ Anne Y. Saiki, ${ }^{\ddagger}$ Tisha San Miguel, ${ }^{\complement}$ Laurie P. Volak, ${ }^{\#}$ Kevin H. Wang, ${ }^{\perp}$ Douglas A. Whittington, ${ }^{\perp}$ Stephan G. Zech, ${ }^{\prime}$ J. Russell Lipford, ${ }^{\star}$ Victor J. Cee ${ }^{\dagger}$

Departments of ${ }^{\dagger}$ Medicinal Chemistry, ${ }^{\star}$ Oncology Research, ${ }^{\S}$ Molecular Engineering, "Discovery Technologies, and "Pharmacokinetics and Drug Metabolism, Amgen Research, One Amgen Center Drive, Thousand Oaks, California 91320, United States

Departments of 'Discovery Attribute Sciences and ${ }^{\perp}$ Molecular Engineering, Amgen Research, 360 Binney Street, Cambridge, Massachusetts 02142, United States

\section{Table of Contents}

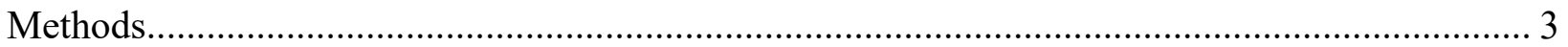

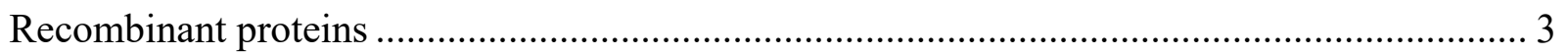

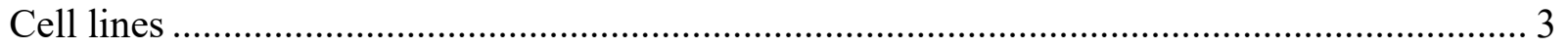

Coupled nucleotide exchange assay ......................................................................... 3

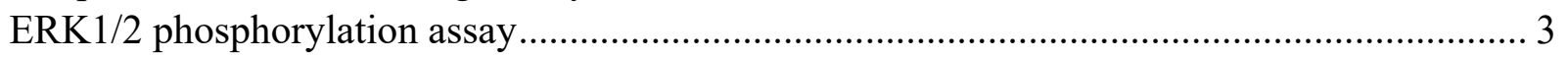

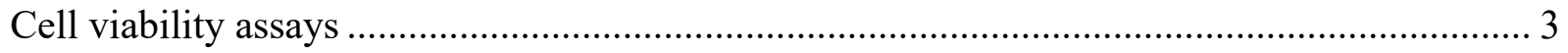

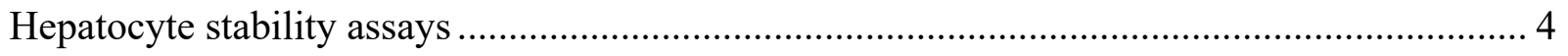

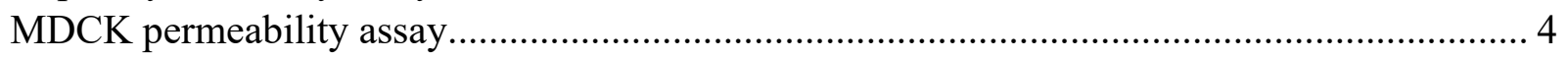

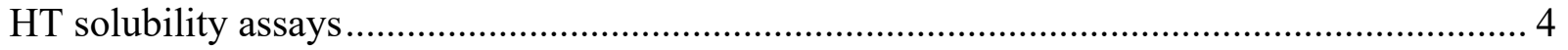

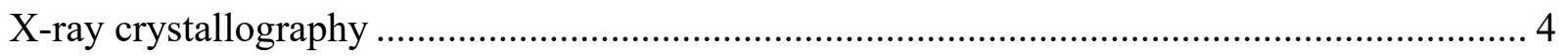

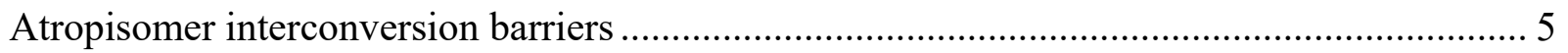

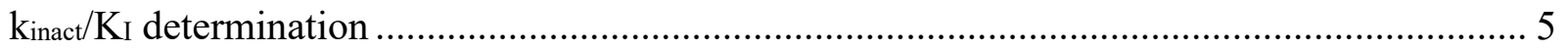

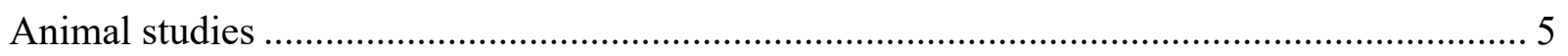

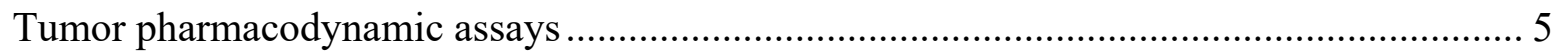

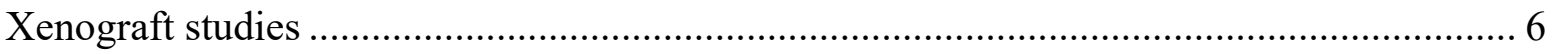

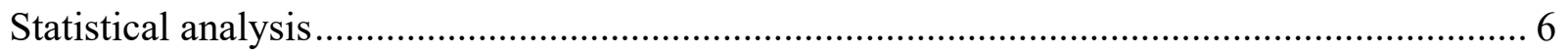

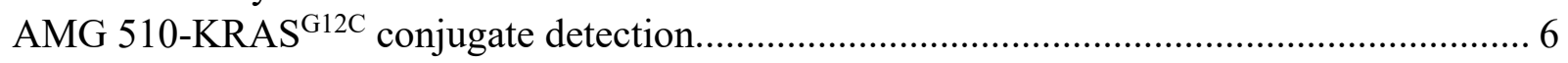

Procedures for the syntheses of AMG $510((R)-38)$ and related analogs ................................. 6

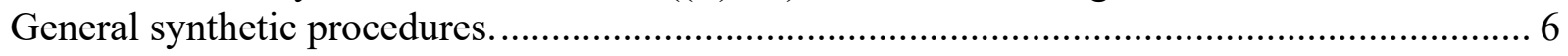

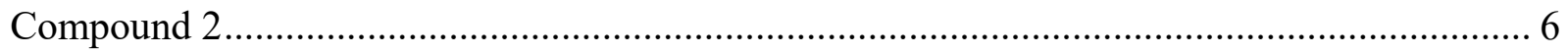

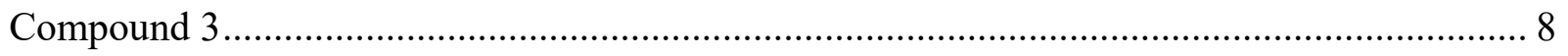

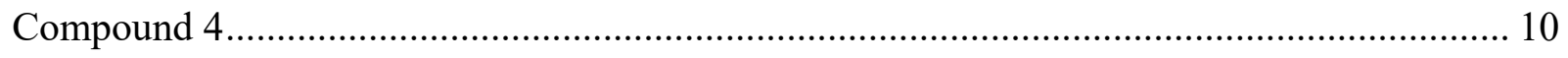

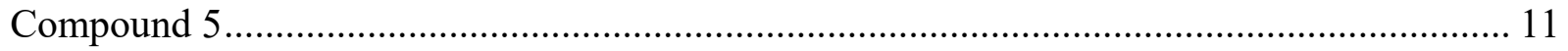


Compound 6

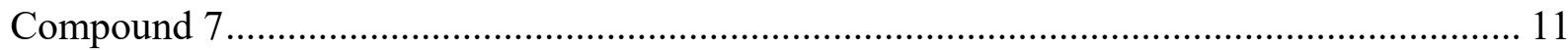

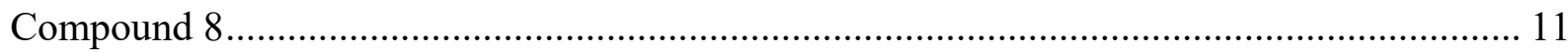

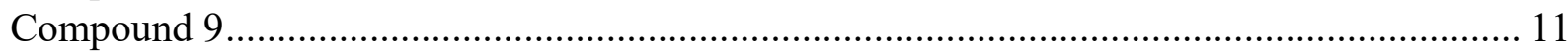

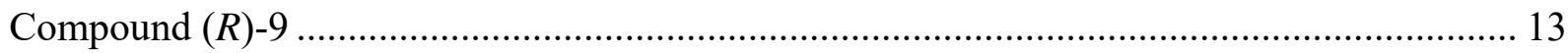

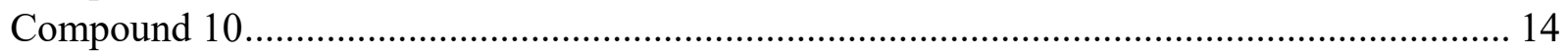

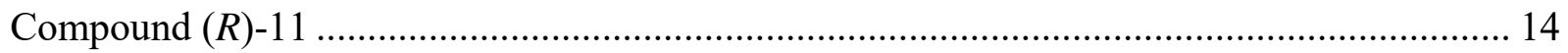

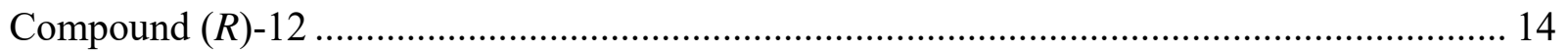

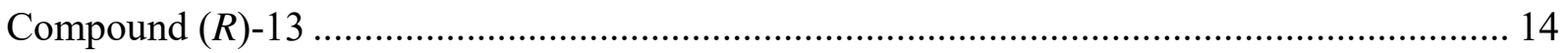

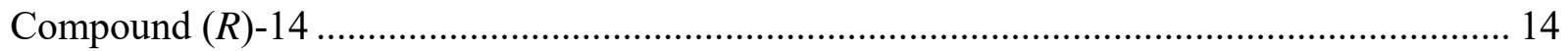

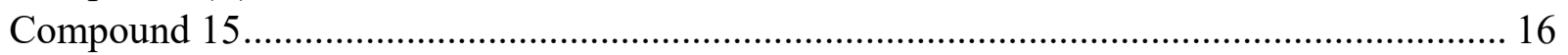

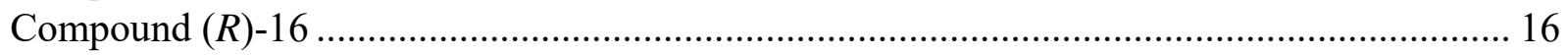

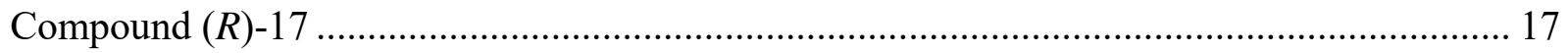

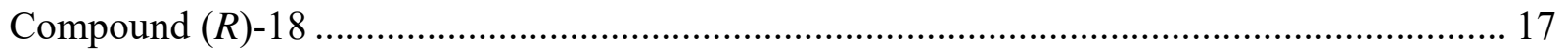

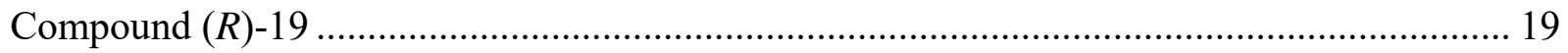

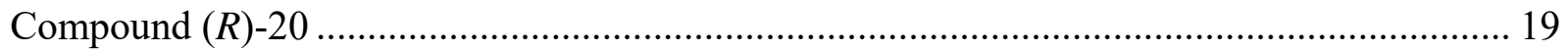

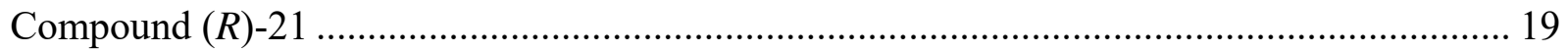

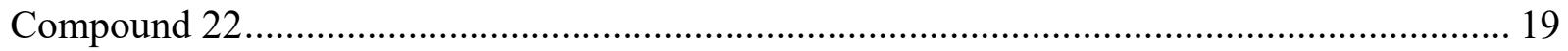

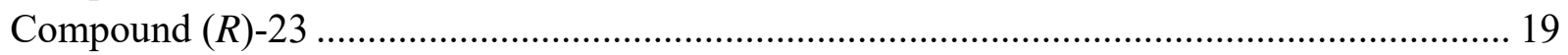

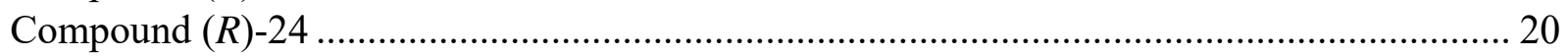

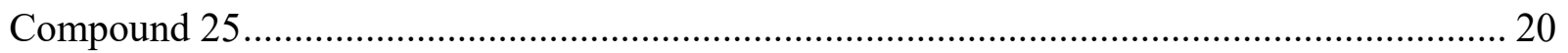

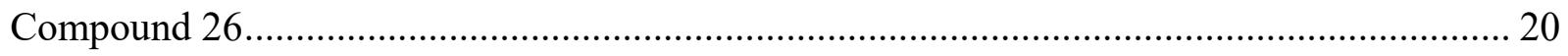

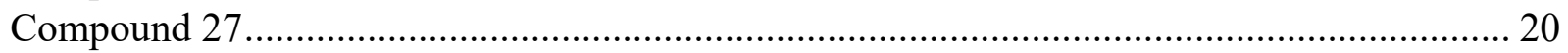

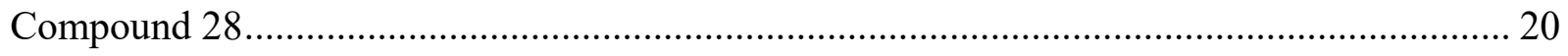

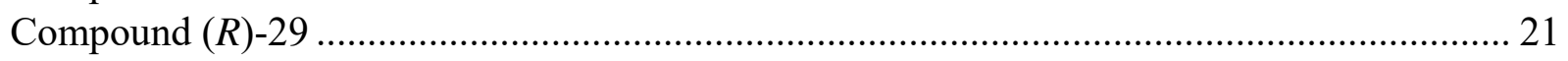

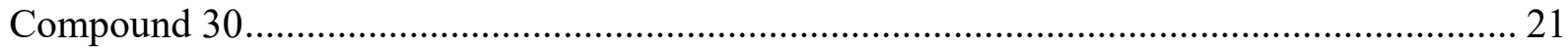

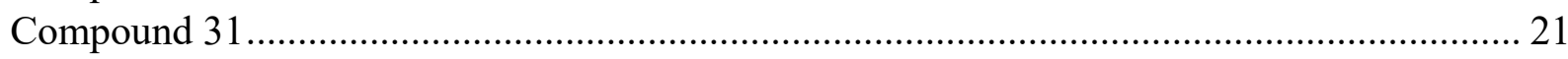

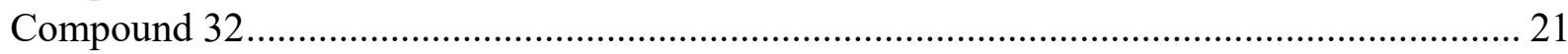

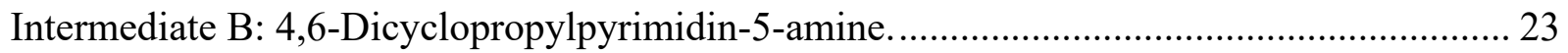

Intermediate C: (S)-1-(3-Methylpiperazin-1-yl)prop-2-en-1-one TFA salt............................... 23

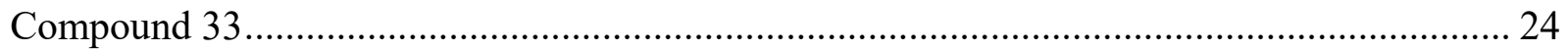

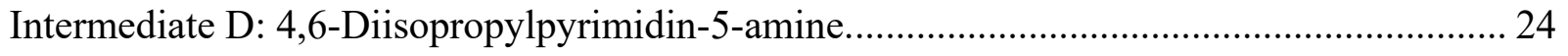

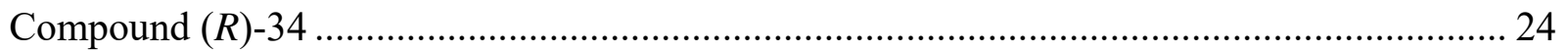

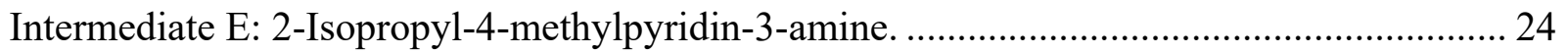

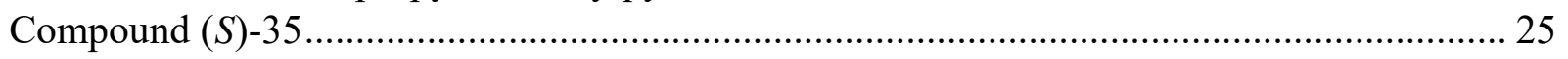

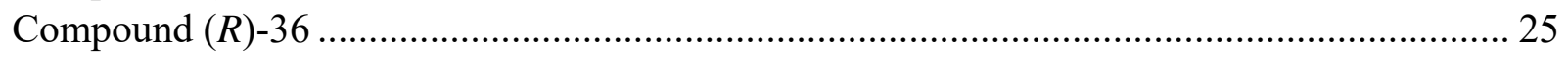

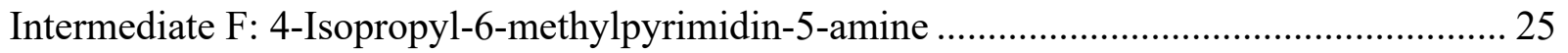

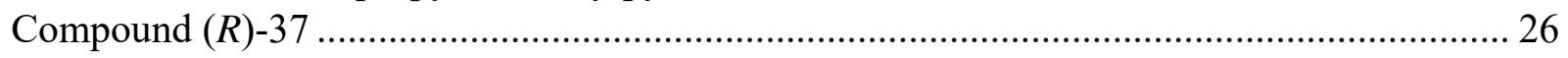

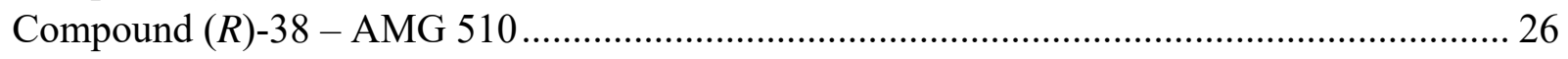

Intermediate G: (2-Fluoro-6-hydroxyphenyl)potassium trifluoroborate. ................................. 28

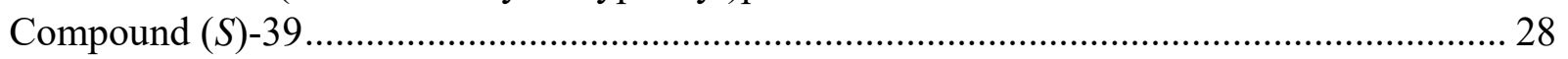

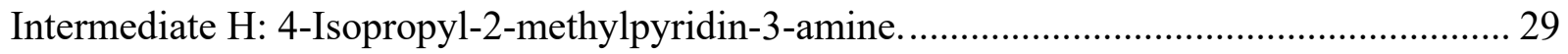

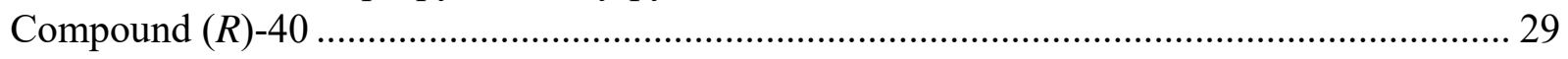




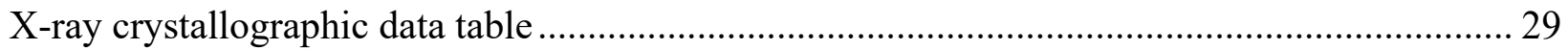

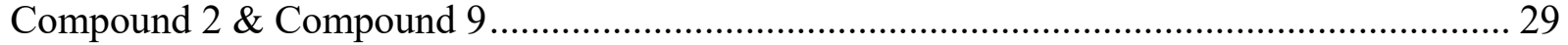

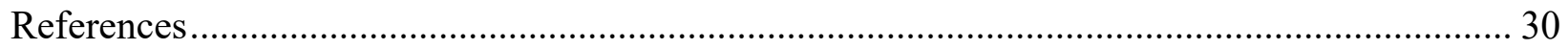

\section{Methods}

\section{Recombinant proteins}

Recombinant His-tagged human KRAS ${ }^{\text {G12C/C118A }}(1-169)$ and GST-human c-RAF (1-149) were expressed in Escherichia coli and purified using affinity chromatography and size-exclusion chromatography. Recombinant His-tagged human SOS1 (564-1049, insect codon optimized) was expressed in Trichoplusia ni and purified using affinity chromatography; after removal of the His-tag, it was further purified by size-exclusion chromatography. A "cysteine-light" mutant construct was used for co-crystallization studies based on the work of Ostrem, et al. ${ }^{1}$ Recombinant His-tagged human $\mathrm{KRAS}^{\mathrm{G} 12 \mathrm{C} / \mathrm{C} 51 \mathrm{~S} / \mathrm{C} 80 \mathrm{~L} / \mathrm{C} 118 \mathrm{~S}}$ (1-169) was expressed in E. coli and purified using affinity, ion-exchange, and size-exclusion chromatography. The His-tag was removed for crystallization.

\section{Cell lines}

MIA PaCa-2 and A549 cells were purchased from American Type Culture Collection (ATCC). Cell lines were authenticated by short tandem repeat (STR) profiling. To improve in vivo growth kinetics, MIA PaCa-2 T2 cells were generated by passaging MIA PaCa-2 cells in mice. All cell lines were cultured in RPMI 1640 medium supplemented with $10 \%$ fetal bovine serum and $1 \mathrm{x}$ penicillin/streptomycin/L-glutamine at $37^{\circ} \mathrm{C}, 5 \% \mathrm{CO}_{2}$ in a humidified incubator.

\section{Coupled nucleotide exchange assay}

The inhibition of the SOS1-catalyzed nucleotide exchange activity of KRAS ${ }^{\mathrm{G12C} / \mathrm{C} 118 \mathrm{~A}}$ was measured using Alpha (Amplified Luminescent Proximity Homogeneous Assay) technology. $20 \mathrm{nM}$ GDP-bound human KRAS ${ }^{\mathrm{G} 12 \mathrm{C} / \mathrm{C} 118 \mathrm{~A}}$ protein was incubated with two-fold serially-diluted test compound or DMSO for 5 minutes at ambient temperature in reaction buffer (25 mM HEPES, pH 7.4; $10 \mathrm{mM} \mathrm{MgCl} 2 ; 0.01 \%$ Triton X-100). For all subsequent steps, DTT was added to the reaction buffer at a final concentration of $1 \mathrm{mM}$. Next, GTP and SOS-1 were added in DTT-reaction buffer at final concentrations of $1.25 \mathrm{mM}$ or $500 \mathrm{nM}$, respectively, and incubated at RT for 30 minutes. Finally, c-RAF RBD (50 nM final), Alpha glutathione donor beads (PerkinElmer; $20 \mu \mathrm{g} / \mathrm{mL}$ final), and AlphaLISA ${ }^{\circledR}$ nickel chelate acceptor beads (PerkinElmer; $20 \mu \mathrm{g} / \mathrm{mL}$ final), all diluted in DTT-reaction buffer, were added. The reaction mixture was incubated at RT for $5 \mathrm{~min}$, and then the plates were read on an EnVision ${ }^{\circledR}$ Multilabel Reader using the AlphaScreen protocol. Luminescence signal was measured at $570 \mathrm{~nm}$ following a $180 \mathrm{~ms}$ excitation at $680 \mathrm{~nm}$. Signal intensity corresponded with the association of c-RAF RBD with GTP-bound KRAS ${ }^{\mathrm{G} 12 \mathrm{C} / \mathrm{C} 118 \mathrm{~A}}$ and was normalized to DMSO control.

\section{ERK1/2 phosphorylation assay}

For cellular assays, $2.5 \mathrm{E}+04$ MIA PaCa-2 cells were seeded per well in 96 -well plates and incubated at $37{ }^{\circ} \mathrm{C}, 5 \% \mathrm{CO}_{2}$, overnight. The following day, 3-fold serially-diluted compound or DMSO was added to the cells, and the plates were incubated at $37{ }^{\circ} \mathrm{C}, 5 \% \mathrm{CO}_{2}$ for 2 hours. Following treatment, the cells were stimulated with $10 \mathrm{ng} / \mathrm{mL}$ EGF (Roche) for 10 min, washed with ice-cold PBS, and lysed in RIPA lysis buffer $(50 \mathrm{mM}$ Tris- $\mathrm{HCl}, \mathrm{pH} 7.5 ; 1 \%$ Igepal; $0.5 \%$ sodium deoxycholate; $150 \mathrm{mM} \mathrm{NaCl} ; 0.1 \%$ sodium dodecyl sulfate) containing protease and phosphatase inhibitors. ERK1/2 phosphorylation levels were measured in treated cell lysates using phospho-ERK1/2 whole cell lysate kits (Meso Scale Discovery) according to the manufacturer's protocol. Signal intensity corresponded with phospho-ERK1/2 levels and was normalized to DMSO control.

For tumor cell lysates from in vivo pharmacodynamic assays, $50 \mu \mathrm{g}$ of total protein per sample was analyzed using phospho-ERK1/2 and total ERK1/2 whole cell lysate kits (Meso Scale Discovery) according to the manufacturer's protocol. Phospho-ERK1/2 signal was normalized to total ERK1/2 signal for a given sample, and $\%$ p-ERK inhibition was calculated relative to the vehicle group.

\section{Cell viability assays}

For adherent viability assays, $0.5-1.0 \mathrm{E}+03$ cells were seeded per well in 384 -well plates and incubated at $37^{\circ} \mathrm{C}, 5 \% \mathrm{CO}_{2}$, overnight. The following day, serially-diluted compound or DMSO was added to the cells, and the plates were incubated at 
$37{ }^{\circ} \mathrm{C}, 5 \% \mathrm{CO}_{2}$ for 72 hours. Cell viability was measured using a CellTiter-Glo ${ }^{\circledR}$ Luminescent Cell Viability Assay kit (Promega) according to the manufacturer's protocol. The luminescence signal of treated samples was normalized to DMSO control.

\section{Hepatocyte stability assays}

Compounds were prepared as $50 \mu \mathrm{M}$ stock solutions in (1:1) $\mathrm{CH}_{3} \mathrm{CN} /$ water and added (8 $\mu \mathrm{L} /$ well) to thawed cryopreserved hepatocytes high-glucose DMEM $\left(0.5 \times 10^{6}\right.$ total cells $/ \mathrm{mL} ; 800 \mu \mathrm{L} /$ well $)$ in deep-welled 96 -well plates for a final test compound concentration of $0.5 \mu \mathrm{M}$. Following pipette aspiration and mixing, aliquots $(6 \times 100 \mu \mathrm{L})$ of the resulting mixtures were transferred to incubation plates and incubated $\left(37^{\circ} \mathrm{C}, 5 \% \mathrm{CO}_{2}\right)$ with vigorous intermittent shaking $(1400 \mathrm{rpm}$ for $5 \mathrm{~s}$, every $3 \mathrm{~min})$. Analytical samples were withdrawn periodically $(0,10,20,30,45$, and $60 \mathrm{~min})$, diluted with $100 \mu \mathrm{L}$ $\mathrm{CH}_{3} \mathrm{CN}+$ internal standard $(1 \mu \mathrm{M}$ tolbutamide $)$, and centrifuged $\left(>3000 \times \mathrm{g}\right.$ for $\left.30 \mathrm{~min}, 2-8{ }^{\circ} \mathrm{C}\right)$. Supernatants were analyzed by LCMS to determine compound half-lives and intrinsic clearance rates $\left(\mathrm{CL}_{\text {int }}\right)$ using the substrate depletion method. Reported values are the average of triplicate measurements.

\section{MDCK permeability assay}

Transcellular permeability studies with MDCK-II (Madin Darby Canine Kidney Epithelial Cells) cell monolayers were performed as described in Schinkel et al, $1995^{2}$ and Booth-Genthe et al, 2006, ${ }^{3}$ with slight modification: MDCK-II cells were seeded on 24-well transwell plates (Millicell-PCF, $0.4 \mu \mathrm{m}, 0.7 \mathrm{~cm}^{2}$; EMD-Millipore Corp., Billerica, MA) at a density of 250,000 cells/well and cultured in media consisting of Dulbecco's Modified Eagle Medium (DMEM), high glucose, supplemented with $10 \%(\mathrm{v} / \mathrm{v})$ fetal bovine serum; GlutaMAX ${ }^{\mathrm{TM}} ; 1 \mathrm{mM}$ sodium pyruvate; 1X MEM non-essential amino acids; and hygromycin B $(500 \mu \mathrm{g} / \mathrm{mL})$ (media and all supplements were purchased from Thermo Fisher Scientific). Five days after seeding, medium was aspirated and cells were washed with $0.4 \mathrm{~mL}$ Hank's Balanced Salt solution (HBSS) containing $10 \mathrm{mM}$ Hepes, $\mathrm{pH} 7.4$ (HHBSS). MDCK cells were pre-incubated with HHBSS for 30 minutes in both apical and basolateral compartments. After pre-incubation, buffer was aspirated, dosing solution containing 10 or $50 \mu \mathrm{M}$ test compound was added into the apical compartment, and HHBSS buffer was added to the basal compartment. Each incubation was performed in triplicate. The plates were re-assembled and incubated $\left(37^{\circ} \mathrm{C}, 5 \% \mathrm{CO}_{2}\right)$ on a plate shaker $(100 \mathrm{RPM}$, Heidolph Titramax 100, Cinnaminson, NJ) for two hours. At the end of incubation, samples from the receiver and donor compartments were collected and analyzed by LC-MS/MS, and the apparent permeability coefficient ( $\left.\mathrm{P}_{\mathrm{AB}}\right)$ of tested compounds was calculated: $\left.\mathrm{P}_{\mathrm{AB}}=(d Q / d t) /(A * C)\right)$, where $d Q / d t$ is the apical-to-basal penetration rate of the agent $(\mu \mathrm{m} / \mathrm{s}), A$ is the surface area of the cell monolayer on the Transwell $\left(0.7 \mathrm{~cm}^{2}\right)$, and $C_{0}$ is the initial concentration of the test compound $(\mu \mathrm{M})$.

\section{HT solubility assays}

Compounds were transferred to deep-welled 96-well plates in DMSO (10 $\mu \mathrm{L}$ of $10 \mathrm{mM}$ stock), and DMSO was removed via Genevac (full vacuum, $30{ }^{\circ} \mathrm{C}, 2.5 \mathrm{~h}$ ). Media (200 $\mu \mathrm{L}$ of DMSO, PBS (pH 7.4), 0.01N HCl (pH 2.0), or FaSSIF (fastedstate simulated intestinal fluid)) was added, and plates were sealed. Plates were agitated (orbital shaker, $1500 \mathrm{rpm}, 1 \mathrm{~h}$ ), then allowed to stand at $\mathrm{rt}$ for 48-72 h. Undissolved material was precipitated by centrifugation (4000 rpm, $30 \mathrm{~min})$, and wells were analyzed for compound by LCMS (Halo C18 column $(2.7 \mu \mathrm{m}, 3 \times 50 \mathrm{~mm}), 0.1 \%$ TFA in water/0.1\% TFA in $\mathrm{CH}_{3} \mathrm{CN}, 95: 5 \rightarrow 5: 95$ gradient $\left.(1.5 \mathrm{~min}), 2.0 \mathrm{~mL} / \mathrm{min}, 40^{\circ} \mathrm{C}\right)$. Media solubility was determined by peak area ratio, using DMSO wells as a standard $(500 \mu \mathrm{M})$. PBS buffer (Gibco ${ }^{\circledR}$ DPBS) was purchased from Thermo Fisher Scientific. FaSSIF was prepared from $5 \mathrm{mM}$ taurocholic acid sodium salt, $1.5 \mathrm{mM}$ granular lecithin in $0.029 \mathrm{M}$ potassium phosphate (monobasic), and $0.22 \mathrm{M}$ potassium chloride, $\mathrm{pH} 6.8$.

\section{X-ray crystallography}

Purified un-tagged KRAS ${ }^{\mathrm{G} 12 \mathrm{C} / \mathrm{C} 51 \mathrm{~S} / \mathrm{C} 80 \mathrm{~L} / \mathrm{C} 118 \mathrm{~S}}$ (“KRAS”) in $20 \mathrm{mM}$ HEPES pH 7.5, $150 \mathrm{mM} \mathrm{NaCl}$ was concentrated to 40 $\mathrm{mg} / \mathrm{mL}$ and added to a two-fold molar excess of solid compound dissolved in DMSO. The protein-complex samples were placed on a mixer at RT for 16 hours, and subsequently spin-filtered. Co-crystallization was performed using sitting drop vapor diffusion method. The protein-complex samples were mixed 1:1 with crystallization buffer using a Mosquito robot (TTP Labtech). "KRAS"-compound 2 crystallized in $0.2 \mathrm{M}$ ammonium acetate, $0.1 \mathrm{M}$ sodium citrate (pH 5.6), 32\% w/v polyethylene glycol 4000, $5 \mathrm{mM}$ magnesium chloride at $20{ }^{\circ} \mathrm{C}$. Crystals of "KRAS"-compound 9 were grown in $0.2 \mathrm{M}$ calcium acetate, $25 \% \mathrm{w} / \mathrm{v}$ polyethylene glycol 3350 at $20{ }^{\circ} \mathrm{C}$.

For data collection, each crystal was equilibrated in cryoprotectant prior to freezing in liquid nitrogen. The data set of "KRAS"-compound 2 was collected on a Rayonix MX300HS CCD detector at the Advanced Photon Source SER-CAT Beamline 22-ID. The data were integrated and scaled using HKL2000. ${ }^{4}$ The crystal belongs to the orthorhombic space group P21 212 with unit cell dimensions of $a=79.6, b=106.3, c=33.7, \alpha=90^{\circ}, \beta=90^{\circ}, \gamma=90^{\circ}$, and contains two protein 
molecules in the asymmetric unit. The data set of "KRAS"-compound 9 was collected on a Pilatus3 6M silicon pixel detector at the Advanced Light Source Beamline 5.0.2. The data were integrated and scaled using XDS. ${ }^{5}$ The crystal belongs to the triclinic space group P1 with unit cell dimensions of $a=33.4, b=39.6, c=62.5, \alpha=76.9^{\circ}, \beta=81.4^{\circ}, \gamma=77.3^{\circ}$, and contains two protein molecules in the asymmetric unit.

The molecular replacement solutions were achieved with Phaser $^{6}$ from the CCP4 program suite, ${ }^{7}$ with an apo KRAS structure as a search model. Iterative refinement cycles were performed using Refmac $5,{ }^{8}$ and model building was performed using the graphics program Coot. ${ }^{9}$ The ligands were generated using PRODRG ${ }^{10}$ and the PHENIX ${ }^{11}$ module eLBOW. $^{12}$ The structure of "KRAS" bound to GDP and compound 2 was refined to $1.60 \AA$ with an R-factor of $21.7 \%$ and Rfree of 23.1\%. Ligand B was not bound in the Switch II pocket and was solvent exposed. Amino acid residues A: 61-67 and B: 32-38, 59-68 were unresolved in the crystal structure. The structure of "KRAS" bound to GDP and compound 9 was refined to $1.50 \AA$ with an $\mathrm{R}$-factor of $19.0 \%$ and $\mathrm{R}_{\text {free }}$ of $21.7 \%$. The atomic coordinates and structure factors have been deposited in the Protein Data Bank respectively (PDB ID codes: 6PGO, 6PGP). See X-ray crystallographic data table (pp. 29) for more details on data collection and refinement statistics.

\section{Atropisomer interconversion barriers}

Test compound (ca. $5 \mathrm{mg}$ ) was dissolved in $0.7 \mathrm{~mL}$ of DMSO-d 6 (Cambridge Isotope Laboratories, Inc., Tewksbury, MA, USA) and placed in a $5 \mathrm{~mm}$ NMR tube. ${ }^{1} \mathrm{H}$ NMR spectra were collected as a function of time and temperature on a 500-MHz Bruker Avance II NMR spectrometer (Bruker Biospin Corp., Billerica, MA, USA) equipped with a BBFO probe capable of achieving sample temperatures up to $150{ }^{\circ} \mathrm{C}$. The VT unit was calibrated with $80 \%$ ethylene glycol in DMSO$d_{6}$. Slowly interchanging atropisomers were monitored by kinetic experiments at constant temperature (i.e. NMR spectra were collected as function of time, monitoring the conversion of purified atropisomer into a racemic mixture). Relative amounts of $R$ - and $S$-atropisomers were determined by integration and fitted to a mono-exponential function to deduce halflives. When single atropisomers could not be purified, interconversion was monitored by VT NMR using mixtures of $R$ and $S$-atropisomers. Exchange rates were estimated from line-shape analysis or coalescence temperatures. The activation free energy $\left(\Delta \mathrm{G}^{\ddagger}\right)$ for atropisomer interconversion was calculated from the exchange rates using the methods reported in Org. Biomol. Chem. 2013, 11, 110-118. ${ }^{13}$

\section{$\mathrm{k}_{\text {inact }} / \mathrm{K}_{\text {I }}$ determination}

Covalent adduction formation between $\mathrm{KRAS}^{\mathrm{G} 12 \mathrm{C}}$ and AMG 510 was measured by mass spectrometry, as previously described. ${ }^{14}$ Inhibitor relative percent bound values at different times $(6,12,24$, and $60 \mathrm{~s}$; 3-5 replicates per time-point, except where adduct formation was essentially complete) were fit to an exponential equation (Prism 7.04, GraphPad Software, San Diego, CA, USA) for each of various inhibitor concentrations $(5,10,20,50,100 \mu \mathrm{M})$ to generate $\mathrm{k}_{\text {obs }}$ values for each concentration. The resulting $\mathrm{k}_{\mathrm{obs}}$ values were plotted versus inhibitor concentration and fit to the Michaelis-Menten equation as previously described ${ }^{15}$ to produce $\mathrm{k}_{\text {inact }}$ and $\mathrm{K}_{\mathrm{I}}$ values.

\section{Animal studies}

All animal experimental procedures were conducted in accordance with the guidelines of the Amgen Animal Care and Use Committee and the Association for Assessment and Accreditation of Laboratory Animal Care standards. All studies utilized 4-7 week-old female athymic nude or female BALB/c mice (Charles River Laboratories). The athymic nude mice were housed five per filter-capped cage in sterile housing, and the BALB/c mice were housed five per filter-capped cage, non-sterile housing in an environmentally controlled room (temperature $23 \pm 2{ }^{\circ} \mathrm{C}$, relative humidity $50 \pm 20 \%$ ) on a 12 hour light/dark cycle. The mice were fed commercial rodent chow.

\section{Tumor pharmacodynamic assays}

The effect of (R)-24, ARS-1620, and AMG 510 on ERK1/2 phosphorylation was evaluated in MIA PaCa-2 T2 tumorbearing mice. MIA PaCa-2 T2 tumor cells (5.0E+06 cells) were injected subcutaneously into the flank of female athymic nude mice in a mixture with Matrigel (BD Bioscience, San Jose, CA). Mice received a single oral dose of vehicle, $(R)-\mathbf{2 4}$ $(10,30$, and $100 \mathrm{mg} / \mathrm{kg})$, ARS-1620 (100 mg/kg), or AMG $510(0.3,1,3,10,30$ and $100 \mathrm{mg} / \mathrm{kg})$ when the average tumor size reached $\sim 300-600 \mathrm{~mm}^{3}$ ( $n=3$ /group) and were harvested 2 hours later. A single dose level of AMG 510 orally (10 $\mathrm{mg} / \mathrm{kg}$ ) was used for the time-course studies. For all studies, blood and tumor were collected to determine exposure levels. Tumor samples were also collected at the indicated times, snap frozen in liquid nitrogen and processed for PK or pulverized using a cryoPREP ${ }^{\circledR}$ Dry Impactor (Covaris). Samples were resuspended in RIPA lysis buffer containing protease and phosphatase inhibitors and homogenized. Cleared lysates were then assayed for ERK1/2 phosphorylation levels as described above and also for covalent modification of $\mathrm{KRAS}^{\mathrm{G} 12 \mathrm{C}}$ by mass spectrometry. 


\section{Xenograft studies}

MIA PaCa-2 T2 cells (5.0E+06 cells with a mixture of Matrigel) were injected subcutaneously in the flank of female athymic nude mice ( $n=10$ /group). Treatment began when tumors were established and approximately $170 \mathrm{~mm}^{3}$. In the dose response studies, mice received (orally) either vehicle (QD), $(R)-24(10,30,60$, and $100 \mathrm{mg} / \mathrm{kg}$ QD), or AMG $\mathbf{5 1 0}$ (10, 30 and $100 \mathrm{mg} / \mathrm{kg}$ QD). Tumor dimensions were assessed twice weekly with Pro-Max electronic digital caliper (Japan Micrometer Mfg. Co. LTD), and tumor volume was calculated using the formula: length $\mathrm{x}$ width $\mathrm{x}$ height and expressed as $\mathrm{mm}^{3}$. Data are expressed as mean $\pm \mathrm{SEM}$.

\section{Statistical analysis}

Pharmacodynamic experiments were analyzed by One-way ANOVA followed by Dunnett's post-hoc. For efficacy studies, repeated measures analysis of variance (RMANOVA) was conducted followed by Dunnett's post-hoc test using GraphPad Prism 7.04. Regression analysis was conducted by paired t-test.

\section{AMG 510-KRASG12C conjugate detection}

Anti-human RAS (anti-RAS) antibody was purchased from Abcam and biotinylated with EZ-Link NHS-PEG4-Biotin (Thermo Fisher Scientific) using the protocol described by the vendor. Residual biotin was removed, and the resulting biotinanti-RAS was loaded onto Dynabeads ${ }^{\circledR}$ MyOneTM Streptavidin $C 1$ beads (Thermo Fisher Scientific) at a 1:1 ratio for an hour at RT with shaking. Lysates from in vitro-treated cells or in vivo-treated tumor cells described previously were incubated with biotinylated anti-RAS beads for 3 hours at RT with shaking. Using a magnet, beads were washed with PBST $(3 \mathrm{x})$, followed by PBS (1x), and then water (1x). Samples were eluted from the beads using $2 \%$ aqueous formic acid $/ 10 \%$ aqueous $\mathrm{ACN}$, followed by incubation at RT with shaking for $10 \mathrm{~min}$. The supernatant was transferred to a 96 -well plate and dried. Samples were resuspended in a denaturation buffer $(10 \mathrm{mM}$ TCEP, $8 \mathrm{M}$ urea $)$ and incubated at $65^{\circ} \mathrm{C}$ with shaking for 15 minutes. Iodoacetamide $(40 \mathrm{mM})$ was added and incubated at $37^{\circ} \mathrm{C}$ for 30 minutes, protected from light. $50 \mathrm{mM}$ $\mathrm{NH}_{4} \mathrm{HCO}_{3}$ and trypsin $(0.01 \mu \mathrm{g} / \mu \mathrm{L})$ were added, and samples were digested overnight at $37{ }^{\circ} \mathrm{C}$ for $\sim 16-20$ hours, then finally quenched with formic acid to give a final concentration of $1 \%(\mathrm{v}: \mathrm{v})$. Samples were then analyzed by mass spectrometry, and occupancy was calculated as a percentage of AMG 510 modified-KRAS ${ }^{\mathrm{G} 12 \mathrm{C}}$ peptide normalized to the sum of unmodified and modified KRAS ${ }^{\mathrm{G} 12 \mathrm{C}}$ peptide.

\section{Procedures for the syntheses of AMG $510((R)-38)$ and related analogs}

\section{General synthetic procedures.}

All materials were obtained from commercial suppliers and used without further purification unless otherwise noted. Anhydrous solvents were obtained from Sigma-Aldrich and used directly. Reactions involving air- or moisture-sensitive reagents were performed under a nitrogen or argon atmosphere. Silica gel chromatography was performed using pre-packed silica gel cartridges (RediSep ${ }^{\circledR}$ Rf, Teledyne ISCO). Reverse-phase HPLC purification was performed using Gilson (Middleton, WI) workstations. NMR spectra were acquired on Bruker Avance 400, 500, or $600 \mathrm{MHz}$ spectrometers equipped with $5 \mathrm{~mm}$ BBFO probes. All final compounds were purified to $>95 \%$ purity as determined by LC-MS using an Agilent 1100 or 1260 multi-wavelength detector (215 nm detection) and an Advanced Materials Technology HALO C18 column $(50 \times 3.0 \mathrm{~mm}, 2.7 \mu \mathrm{m})$ at $40{ }^{\circ} \mathrm{C}$ with a $2.0 \mathrm{~mL} / \mathrm{min}$ flow rate using a $5-95 \%$ gradient of acetonitrile/water with $0.1 \%$ trifluoracetic acid over $1.5 \mathrm{~min}$. Low-resolution MS data were obtained concurrently with UV chromatography using an Agilent G1956B MSD SL, 6120B, 6130B, or 6140A quadrupole MS in positive electrospray ionization mode. Resolved atropisomers were purified to $>95 \%$ ee (or de) using a Thar 80, 200, or 350 preparative SFC. Enantiomeric, and diastereomeric excesses were determined by SFC (Waters Acquity UPC2 or Agilent 1260 Infinity analytical systems).

\section{Compound 2}

\section{2-(1-(4-Acryloyl-1-piperazinyl)-7-chloro-4-phenyl-6-phthalazinyl)-3-fluorophenol.}




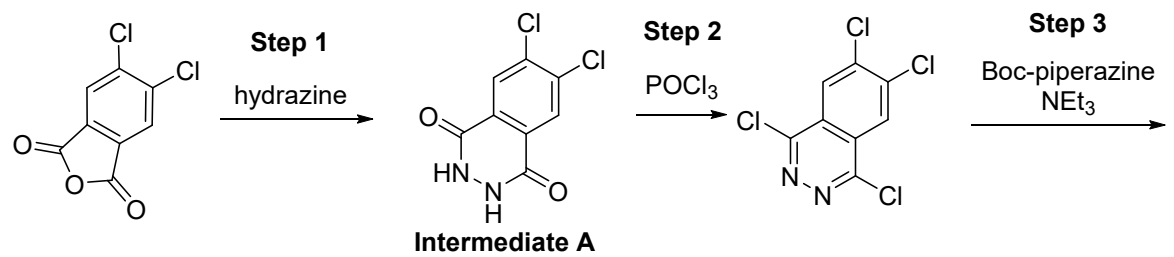<smiles>CC(C)(C)OC(=O)N1CCN(c2nnc(-c3ccccc3)c3cc(Cl)c(Cl)cc23)CC1</smiles><smiles>C=CC(=O)N1CCN(c2nnc(-c3ccccc3)c3cc(Cl)c(Cl)cc23)CC1</smiles>
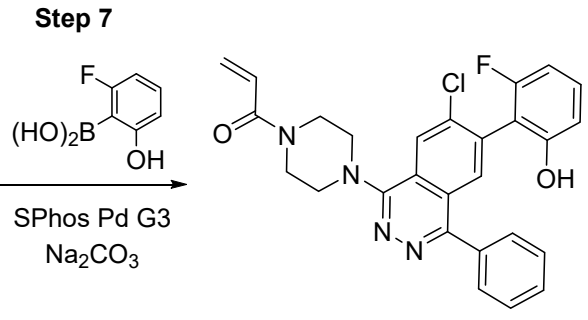

Compound 2

Step 1: 6,7-Dichloro-2,3-dihydrophthalazine-1,4-dione (Intermediate A). Hydrazine (0.23 mL, 10.1 mmol) was added to a mixture of 5,6-dichloroisobenzofuran-1,3-dione ( $2.00 \mathrm{~g}, 9.22 \mathrm{mmol}$, TCI America) and ethanol (30 $\mathrm{mL})$, and the resulting mixture was stirred at reflux for $2 \mathrm{~h}$ before being cooled to $\mathrm{rt}$. The resulting precipitate was collected by filtration and washed with water to give 6,7-dichloro-2,3-dihydrophthalazine-1,4-dione $(1.62 \mathrm{~g}, 76 \%$ yield, Intermediate A) as a white solid. $m / z(E S I,+v e) 231.1(\mathrm{M}+\mathrm{H})^{+}$.

Step 2: 1,4,6,7-Tetrachlorophthalazine. ${ }^{16}$ Pyridine $(431 \mu \mathrm{L}, 5.28 \mathrm{mmol})$ was added to a stirred mixture of 6,7-dichloro2,3-dihydrophthalazine-1,4-dione $(610 \mathrm{mg}, 2.64 \mathrm{mmol}$, Intermediate A) in phosphorus oxychloride (2.4 mL, $26.4 \mathrm{mmol})$. The reaction mixture was stirred to $100{ }^{\circ} \mathrm{C}$ for $2 \mathrm{~h}$, cooled, and poured slowly into rapidly stirred water $(75 \mathrm{~mL})$ at $\sim 10{ }^{\circ} \mathrm{C}$. The resulting suspension was filtered, and the collected solid was washed with water to give 1,4,6,7-tetrachlorophthalazine (543 mg, 77\% yield) as a yellow solid. ${ }^{1} \mathrm{H}$ NMR (400 MHz, CDCl $) \delta 8.43(2 \mathrm{H}, \mathrm{s}) . \mathrm{m} / \mathrm{z}(\mathrm{ESI},+\mathrm{ve}) 266.9(\mathrm{M}+\mathrm{H})^{+}$.

Step 3: tert-Butyl 4-(4,6,7-trichlorophthalazin-1-yl)piperazine-1-carboxylate. 1-Boc-piperazine (340 mg, 1.82 mmol) was added to a stirred mixture of 1,4,6,7-tetrachlorophthalazine $(543 \mathrm{mg}, 2.03 \mathrm{mmol})$ and triethylamine $(0.846 \mathrm{~mL}$, $6.08 \mathrm{mmol})$ in DCM $(8 \mathrm{~mL})$. The reaction mixture was stirred at $\mathrm{rt}$ for 2 days. Additional 1-Boc-piperazine (340 mg, 1.82 mmol) was added, and the reaction mixture was stirred at $\mathrm{rt}$ for $23 \mathrm{~h}$. The reaction mixture was quenched with saturated aqueous sodium bicarbonate $(20 \mathrm{~mL})$ and extracted with DCM $(30 \mathrm{~mL})$. The organic layer was separated, washed with brine $(20 \mathrm{~mL})$, dried over $\mathrm{MgSO}_{4}$, filtered, and concentrated in vacuo. Chromatographic purification of the residue (silica gel, 0-50\% EtOAc/heptane) gave tert-butyl 4-(4,6,7-trichlorophthalazin-1-yl)piperazine-1-carboxylate (398 mg, 47\% yield) as an off-white solid. ${ }^{1} \mathrm{H}$ NMR $\left(400 \mathrm{MHz}, \mathrm{CDCl}_{3}\right) \delta 8.35(1 \mathrm{H}, \mathrm{s}) 8.12(1 \mathrm{H}, \mathrm{s}) 3.68-3.75(4 \mathrm{H}, \mathrm{m}) 3.45-3.52(4 \mathrm{H}, \mathrm{m}) 1.51$ $(9 \mathrm{H}, \mathrm{s}) . \mathrm{m} / \mathrm{z}(\mathrm{ESI},+\mathrm{ve}) 417.0(\mathrm{M}+\mathrm{H})^{+}$.

Step 4: tert-Butyl 4-(6,7-dichloro-4-phenylphthalazin-1-yl)piperazine-1-carboxylate. A mixture of tert-butyl 4(4,6,7-trichlorophthalazin-1-yl)piperazine-1-carboxylate (95 $\mathrm{mg}, 0.23 \mathrm{mmol}$ ), tetrakis(triphenylphosphine)palladium (26 $\mathrm{mg}, 0.023 \mathrm{mmol})$, phenylboronic acid $(28 \mathrm{mg}, 0.23 \mathrm{mmol})$, and sodium carbonate ( $2 \mathrm{M}$ aqueous, $0.34 \mathrm{~mL}, 0.68 \mathrm{mmol}) \mathrm{in}$ 1,4-dioxane $(1 \mathrm{~mL})$ was stirred at $40{ }^{\circ} \mathrm{C}$ for $24 \mathrm{~h}$. Additional tetrakis(triphenylphosphine)palladium $(26 \mathrm{mg}, 0.023 \mathrm{mmol})$ and phenylboronic acid (13 mg, $0.11 \mathrm{mmol})$ were added, and the reaction mixture was stirred at $40{ }^{\circ} \mathrm{C}$ for $24 \mathrm{~h}$. The reaction mixture was quenched with saturated aqueous sodium bicarbonate $(20 \mathrm{~mL})$ and extracted with EtOAc $(25 \mathrm{~mL})$. The organic layer was separated, washed with brine $(20 \mathrm{~mL})$, dried over $\mathrm{MgSO}_{4}$, filtered, and concentrated in vacuo. Chromatographic purification of the residue (silica gel, 0-100\% EtOAc/heptane) gave tert-butyl 4-(6,7-dichloro-4-phenylphthalazin-1yl)piperazine-1-carboxylate $\left(68 \mathrm{mg}, 65 \%\right.$ yield) as a white solid. ${ }^{1} \mathrm{H}$ NMR $\left(400 \mathrm{MHz}, \mathrm{CDCl}_{3}\right) \delta 8.13(1 \mathrm{H}, \mathrm{s}) 8.07(1 \mathrm{H}, \mathrm{s})$ 7.62-7.67 (2 H, m) 7.50-7.55 (3 H, m) 3.65-3.74 (4 H, m) 3.44-3.53 (4 H, m) 1.47 (9 H, s). m/z (ESI, +ve) 459.1 (M+H) .

Step 5: 6,7-Dichloro-1-phenyl-4-(piperazin-1-yl)phthalazine. tert-Butyl 4-(6,7-dichloro-4-phenylphthalazin-1yl)piperazine-1-carboxylate $(68 \mathrm{mg}, 0.15 \mathrm{mmol})$ was stirred in trifluoroacetic acid $(1 \mathrm{~mL}, 13 \mathrm{mmol})$ at $\mathrm{rt}$ for $20 \mathrm{~min}$. The reaction mixture was quenched with saturated aqueous sodium bicarbonate $(20 \mathrm{~mL})$ and extracted with $\mathrm{DCM}(2 \times 25 \mathrm{~mL})$. 
The organic layer was separated, dried over $\mathrm{MgSO}_{4}$, filtered, and concentrated in vacuo to give crude 6,7-dichloro-1-phenyl4-(piperazin-1-yl)phthalazine as an off-white solid that was used directly in the next step. $\mathrm{m} / \mathrm{z}(\mathrm{ESI},+\mathrm{ve}) 359.0(\mathrm{M}+\mathrm{H})^{+}$.

Step 6: 1-(4-(6,7-Dichloro-4-phenylphthalazin-1-yl)piperazin-1-yl)prop-2-en-1-one. Acryloyl chloride (13 $\mu \mathrm{L}, 0.16$ $\mathrm{mmol})$ was added to a stirred mixture of 6,7-dichloro-1-phenyl-4-(piperazin-1-yl)phthalazine $(53 \mathrm{mg}, 0.15 \mathrm{mmol})$ and triethylamine $(62 \mu \mathrm{L}, 0.44 \mathrm{mmol})$ in DCM $(1 \mathrm{~mL})$. The reaction mixture was stirred at $\mathrm{rt}$ for 30 min. The reaction mixture was quenched with saturated aqueous sodium bicarbonate $(15 \mathrm{~mL})$ and extracted with DCM $(20 \mathrm{~mL})$. The organic layer was separated, dried over $\mathrm{MgSO}_{4}$, filtered, and concentrated in vacuo. Chromatographic purification of the residue (silica gel, 0-100\% EtOAc/heptane) gave 1-(4-(6,7-dichloro-4-phenylphthalazin-1-yl)piperazin-1-yl)prop-2-en-1-one (43 mg, $71 \%$ yield $)$ as a yellow solid. ${ }^{1} \mathrm{H}$ NMR $\left(400 \mathrm{MHz}, \mathrm{CDCl}_{3}\right) \delta 8.20(1 \mathrm{H}, \mathrm{s}) 8.14(1 \mathrm{H}, \mathrm{s}) 7.66-7.75(2 \mathrm{H}, \mathrm{m}) 7.54-7.62(3 \mathrm{H}$, m) $6.66(1 \mathrm{H}, \mathrm{dd}, J=16.63,10.37 \mathrm{~Hz}) 6.37(1 \mathrm{H}, \mathrm{dd}, J=16.82,1.96 \mathrm{~Hz}) 5.78(1 \mathrm{H}, \mathrm{dd}, J=10.56,1.96 \mathrm{~Hz}) 3.85-4.04(1$ $\mathrm{H}, \mathrm{m}) 3.53-3.72(1 \mathrm{H}, \mathrm{m}) . \mathrm{m} / \mathrm{z}(\mathrm{ESI},+\mathrm{ve}) 431.2(\mathrm{M}+\mathrm{H})^{+}$.

Step 7: 2-(1-(4-Acryloyl-1-piperazinyl)-7-chloro-4-phenyl-6-phthalazinyl)-3-fluorophenol (2). 1-(4-(6,7-Dichloro4-phenylphthalazin-1-yl)piperazin-1-yl)prop-2-en-1-one (43 $\mathrm{mg}, 0.10 \mathrm{mmol})$, 2-fluoro-6-hydroxyphenylboronic acid (18 $\mathrm{mg}, 0.11 \mathrm{mmol}$, Combi-Blocks, Inc.), SPhos Pd G3 (9 mg, $10 \mu \mathrm{mol})$, and sodium carbonate $(2 \mathrm{M}$ aqueous, $0.16 \mathrm{~mL}, 0.31$ $\mathrm{mmol})$ in 1,2-dimethoxyethane $(0.5 \mathrm{~mL})$ was stirred at $60{ }^{\circ} \mathrm{C}$ for $3 \mathrm{~h}$. Additional 2-fluoro-6-hydroxyphenylboronic acid (9 $\mathrm{mg}, 0.06 \mathrm{mmol})$ and SPhos Pd G3 (9 mg, $10 \mu \mathrm{mol})$ were added, and the reaction mixture was stirred at $60^{\circ} \mathrm{C}$ for $2 \mathrm{~h}$. The reaction mixture was quenched with saturated aqueous sodium bicarbonate $(15 \mathrm{~mL})$ and extracted with EtOAc $(20 \mathrm{~mL})$. The organic layer was separated, washed with brine $(10 \mathrm{~mL})$, dried over $\mathrm{MgSO}_{4}$, filtered, and concentrated in vacuo. Chromatographic purification of the residue (silica gel, 0-100\% EtOAc/heptane) gave a mixture of the two regioisomeric products. Reverse phase preparative chromatography (XBridge Prep $\mathrm{C}_{18}, 5 \mu \mathrm{m}, \mathrm{OBD}, 150 \times 30 \mathrm{~mm} ; 35-55 \%$ water/MeCN $(0.1 \% \mathrm{TFA}), 30 \mathrm{~mL} / \mathrm{min})$ gave the separated regioisomeric products. The fractions containing the desired first-eluting regioisomer were neutralized with saturated aqueous sodium bicarbonate, extracted with DCM, and the organic extracts were concentrated in vacuo to give impure 2-(1-(4-acryloyl-1-piperazinyl)-7-chloro-4-phenyl-6-phthalazinyl)-3fluorophenol. The desired regioisomer was further purified by column chromatography (silica gel, 0-100\% EtOAc/heptane) to give 2-(1-(4-acryloyl-1-piperazinyl)-7-chloro-4-phenyl-6-phthalazinyl)-3-fluorophenol (3 mg, 6\% yield) as an off-white solid. ${ }^{1} \mathrm{H}$ NMR $\left(400 \mathrm{MHz}, \mathrm{CDCl}_{3}\right) \delta 8.21(1 \mathrm{H}, \mathrm{s}) 8.06(1 \mathrm{H}, \mathrm{s}) 7.62-7.69(2 \mathrm{H}, \mathrm{m}) 7.45-7.51(3 \mathrm{H}, \mathrm{m}) 7.24-7.32(1 \mathrm{H}, \mathrm{m})$ $6.81-6.90(1 \mathrm{H}, \mathrm{m}) 6.75(1 \mathrm{H}, \mathrm{t}, J=8.41 \mathrm{~Hz}) 6.65(1 \mathrm{H}, \mathrm{dd}, J=16.82,10.56 \mathrm{~Hz}) 6.38(1 \mathrm{H}, \mathrm{dd}, J=16.82,1.76 \mathrm{~Hz}) 5.79(1$ $\mathrm{H}, \mathrm{dd}, J=10.56,1.76 \mathrm{~Hz}) 3.86-4.02(4 \mathrm{H}, \mathrm{m}) 3.57-3.76(4 \mathrm{H}, \mathrm{m}) . \mathrm{m} / \mathrm{z}(\mathrm{ESI},+\mathrm{ve}) 489.0(\mathrm{M}+\mathrm{H})^{+}$.

\section{Compound 3}

1-(4-(7-Chloro-6-(2-fluoro-6-hydroxyphenyl)-4-(o-tolyl)phthalazin-1-yl)piperazin-1-yl)prop-2-en-1-one. 


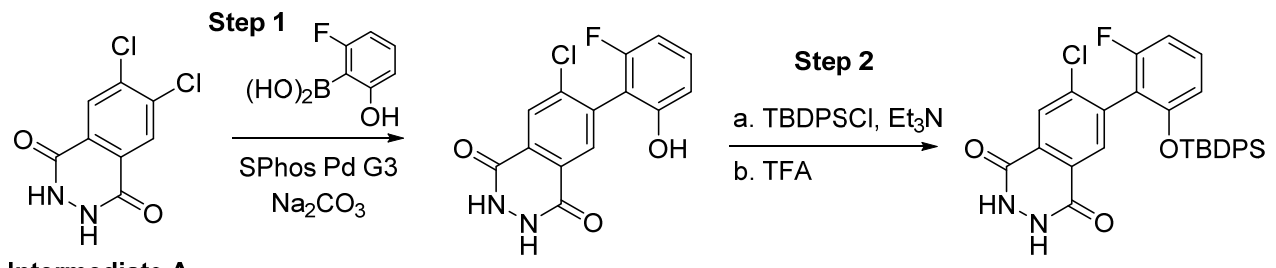

Intermediate A<smiles>O=[R16]c1cccc(F)c1-c1cc2c(Cl)nnc(Cl)c2cc1Cl</smiles>

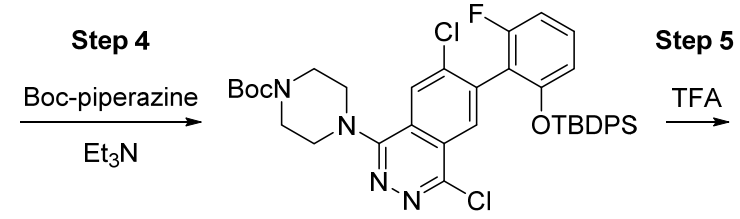<smiles>CC(C)(C)COc1cccc(F)c1-c1cc2c(Cl)nnc(N3CCNCC3)c2cc1Cl</smiles><smiles></smiles><smiles>C=CC(=O)N1CCN(c2nnc(Cl)c3cc(-c4c(O)cccc4F)c(Cl)cc23)CC1</smiles>

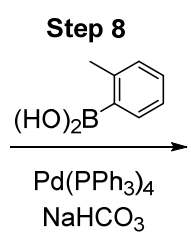<smiles>C=CC(=O)N1CCN(c2nnc(-c3ccccc3C)c3cc(-c4c(O)cccc4F)c(Cl)cc23)CC1</smiles>

Step 1: 6-Chloro-7-(2-fluoro-6-hydroxyphenyl)-2,3-dihydrophthalazine-1,4-dione. A mixture of 6,7-dichloro-2,3dihydrophthalazine-1,4-dione (3.80 g, $16.45 \mathrm{mmol}$, Intermediate A), 2-fluoro-6-hydroxyphenylboronic acid (10.3 g, 65.8 mmol, Combi-Blocks Inc.), SPhos Pd G3 (1.42 g, $1.65 \mathrm{mmol}$ ), and $\mathrm{Na}_{2} \mathrm{CO}_{3}$ (2 M aqueous; $32.9 \mathrm{~mL}, 65.8 \mathrm{mmol}$ ) in DME $(60 \mathrm{~mL})$ was stirred at $80^{\circ} \mathrm{C}$ for $16 \mathrm{~h}$. The reaction mixture was cooled to rt and diluted with water $(200 \mathrm{~mL})$ and EtOAc $(300 \mathrm{~mL})$. The aqueous layer was separated, acidified with $5 \mathrm{~N} \mathrm{HCl}$, and extracted with EtOAc $(300 \mathrm{~mL})$. The combined organic layers were washed with brine $(200 \mathrm{~mL})$, dried over $\mathrm{MgSO}_{4}$, filtered, and concentrated in vacuo. The residue was suspended in DCM $(50 \mathrm{~mL})$ and collected by filtration to give 6-chloro-7-(2-fluoro-6-hydroxyphenyl)-2,3dihydrophthalazine-1,4-dione $(2.77 \mathrm{~g}, 55 \%$ yield $)$ as an off-white solid. $\mathrm{m} / \mathrm{z}(\mathrm{ESI},+\mathrm{ve}) 307.0(\mathrm{M}+\mathrm{H})^{+}$.

Step 2: 6-(2-((tert-Butyldiphenylsilyl)oxy)-6-fluorophenyl)-7-chloro-2,3-dihydrophthalazine-1,4-dione. tertButyl(chloro)diphenylsilane $(2.67 \mathrm{~mL}, 10.3 \mathrm{mmol})$ was added to an ice-cooled mixture of 6-chloro-7-(2-fluoro-6hydroxyphenyl)-2,3-dihydrophthalazine-1,4-dione (2.62 g, $8.54 \mathrm{mmol})$ and TEA (4.75 $\mathrm{mL}, 34.2 \mathrm{mmol})$ in acetonitrile (40 $\mathrm{mL}$ ), and the resulting mixture was stirred at $0{ }^{\circ} \mathrm{C}$ for $15 \mathrm{~min}$, then warmed to $\mathrm{rt}$ and stirred for $1.5 \mathrm{~h}$. Additional tertbutyl(chloro)diphenylsilane $(2.67 \mathrm{~mL}, 10.3 \mathrm{mmol})$ was added, and the resulting mixture was stirred at $\mathrm{rt}$ for $16 \mathrm{~h}$. The reaction mixture was subsequently diluted with water $(300 \mathrm{~mL})$, acidified with $5 \mathrm{~N} \mathrm{HCl}$, and extracted with EtOAc $(300$ $\mathrm{mL})$. The organic layer was separated, washed with brine $(250 \mathrm{~mL})$, dried over $\mathrm{MgSO}_{4}$, filtered, and concentrated in vacuo. The residue was taken up in DCM $(200 \mathrm{~mL})$; TFA $(20 \mathrm{~mL})$ was added, and the resulting mixture was stirred at $\mathrm{rt}$ for $45 \mathrm{~min}$. The reaction mixture was then diluted with saturated aqueous $\mathrm{NaHCO}_{3}(200 \mathrm{~mL})$ and extracted with $\mathrm{DCM}(2 \times 250 \mathrm{~mL})$. The combined organic extracts were dried over $\mathrm{MgSO}_{4}$, filtered, and concentrated in vacuo to give crude 6-(2-((tertbutyldiphenylsilyl)oxy)-6-fluorophenyl)-7-chloro-2,3-dihydrophthalazine-1,4-dione that was used directly in the next step assuming $100 \%$ yield. $\mathrm{m} / \mathrm{z}(\mathrm{ESI},+\mathrm{ve}) 545.2(\mathrm{M}+\mathrm{H})^{+}$.

Step 3: 6-(2-((tert-Butyldiphenylsilyl)oxy)-6-fluorophenyl)-1,4,7-trichlorophthalazine. ${ }^{16}$ Pyridine $(1.45 \mathrm{~mL}, 17.1$ mmol) was added to a mixture of 6-(2-((tert-butyldiphenylsilyl)oxy)-6-fluorophenyl)-7-chloro-2,3-dihydrophthalazine-1,4dione (4.66 g, $8.55 \mathrm{mmol})$ and phosphorus oxychloride $(6.39 \mathrm{~mL}, 68.4 \mathrm{mmol})$, and the resulting mixture was stirred at 100 ${ }^{\circ} \mathrm{C}$ for $1.5 \mathrm{~h}$. The reaction mixture was then cooled to $\mathrm{rt}$ and slowly poured into stirred water $(300 \mathrm{~mL})$ while maintaining an internal temperature of $<10^{\circ} \mathrm{C}$. After stirring for $15 \mathrm{~min}$, the resulting mixture was extracted with EtOAc (400 mL), and the organic extract was washed with brine $(250 \mathrm{~mL})$, dried over $\mathrm{MgSO}_{4}$, filtered, and concentrated in vacuo. Chromatographic purification of the residue (silica gel, 0-25\% EtOAc/heptane) provided impure 6-(2-((tert- 
butyldiphenylsilyl)oxy)-6-fluorophenyl)-1,4,7-trichlorophthalazine (5.21 g, 105\%) as a white solid. $\mathrm{m} / \mathrm{z}(\mathrm{ESI},+\mathrm{ve}) 581.1$ $(\mathrm{M}+\mathrm{H})^{+}$.

Step 4: tert-Butyl 4-(6-(2-((tert-butyldiphenylsilyl)oxy)-6-fluorophenyl)-4,7-dichlorophthalazin-1-yl)piperazine-1carboxylate. 1-Boc-piperazine $(5.00 \mathrm{~g}, 26.9 \mathrm{mmol})$ was added to a mixture of impure 6-(2-((tert-butyldiphenylsilyl)oxy)6-fluorophenyl)-1,4,7-trichlorophthalazine (5.21 g, $8.95 \mathrm{mmol})$ and triethylamine $(3.77 \mathrm{~mL}, 26.9 \mathrm{mmol}) \mathrm{in} \mathrm{DCM}(35 \mathrm{~mL})$, and the resulting mixture was stirred at $\mathrm{rt}$ for $19 \mathrm{~h}$. The reaction mixture was then partitioned between DCM (300 $\mathrm{mL})$ and saturated aqueous $\mathrm{NaHCO}_{3}(200 \mathrm{~mL})$. The organic layer was separated, dried over $\mathrm{MgSO}_{4}$, filtered, and concentrated in vacuo. Chromatographic purification of the residue (silica gel, 0-50\% EtOAc/heptane) gave a mixture of tert-butyl 4-(6(2-((tert-butyldiphenylsilyl)oxy)-6-fluorophenyl)-4,7-dichlorophthalazin-1-yl)piperazine-1-carboxylate and tert-butyl 4-(7(2-((tert-butyldiphenylsilyl)oxy)-6-fluorophenyl)-4,6-dichlorophthalazin-1-yl)piperazine-1-carboxylate. Regioisomeric separation (chiral SFC: OJ-H, $\left.30 \times 250 \mathrm{~mm}, 5 \mu \mathrm{m}, 15 \% \mathrm{MeOH}(\mathrm{w} / 20 \mathrm{mM} \mathrm{NH} 3) / \mathrm{CO}_{2}\right)$ provided tert-butyl 4-(6-(2-((tertbutyldiphenylsilyl)oxy)-6-fluorophenyl)-4,7-dichlorophthalazin-1-yl)piperazine-1-carboxylate (1.21 g, 9\% yield) as the second-eluting isomer and a white solid. ${ }^{1} \mathrm{H} \mathrm{NMR}\left(400 \mathrm{MHz}, \mathrm{CDCl}_{3}\right) \delta 8.27(\mathrm{~s}, 1 \mathrm{H}) 8.17(\mathrm{~s}, 1 \mathrm{H}) 7.56-7.61(\mathrm{~m}, 4 \mathrm{H}) 7.40-$ $7.46(\mathrm{~m}, 2 \mathrm{H}) 7.31-7.37(\mathrm{~m}, 4 \mathrm{H}) 6.99-7.07(\mathrm{~m}, 1 \mathrm{H}) 6.77(\mathrm{t}, J=8.61 \mathrm{~Hz}, 1 \mathrm{H}) 6.42(\mathrm{~d}, J=8.22 \mathrm{~Hz}, 1 \mathrm{H}) 3.72-3.77(\mathrm{~m}, 4 \mathrm{H})$ 3.53-3.59 (m, 4H) $1.51(\mathrm{~s}, 9 \mathrm{H}) 0.66(\mathrm{~s}, 9 \mathrm{H}) . \quad \mathrm{m} / \mathrm{z}(\mathrm{ESI},+\mathrm{ve}) 731.2(\mathrm{M}+\mathrm{H})^{+}$.

Step 5: 6-(2-((tert-Butyldiphenylsilyl)oxy)-6-fluorophenyl)-4,7-dichloro-1-(piperazin-1-yl)phthalazine. Trifluoroacetic acid ( $2 \mathrm{~mL}, 27 \mathrm{mmol})$ was added to a stirred solution of tert-butyl 4-(6-(2-((tert-butyldiphenylsilyl)oxy)-6fluorophenyl)-4,7-dichlorophthalazin-1-yl)piperazine-1-carboxylate (1.21 g, $1.65 \mathrm{mmol})$ in DCM (10 mL), and the resulting mixture was stirred at $\mathrm{rt}$ for $1.5 \mathrm{~h}$. The reaction mixture was then diluted with saturated aqueous $\mathrm{NaHCO}_{3}(75 \mathrm{~mL})$ and extracted with DCM $(2 \times 100 \mathrm{~mL})$. The combined organic extracts were dried over $\mathrm{MgSO}_{4}$, filtered, and concentrated in vacuo to give crude 6-(2-((tert-butyldiphenylsilyl)oxy)-6-fluorophenyl)-4,7-dichloro-1-(piperazin-1-yl)phthalazine as a light yellow solid that was used directly in the next step assuming $100 \%$ yield. $\mathrm{m} / \mathrm{z}(\mathrm{ESI},+\mathrm{ve}) 631.3(\mathrm{M}+\mathrm{H})^{+}$.

Step 6: 1-(4-(6-(2-((tert-Butyldiphenylsilyl)oxy)-6-fluorophenyl)-4,7-dichlorophthalazin-1-yl)piperazin-1-yl)prop2-en-1-one. Acryloyl chloride $(0.15 \mathrm{~mL}, 1.8 \mathrm{mmol})$ was added to a mixture of 6-(2-((tert-butyldiphenylsilyl)oxy)-6fluorophenyl)-4,7-dichloro-1-(piperazin-1-yl)phthalazine $(1.04 \mathrm{~g}, 1.65 \mathrm{mmol})$ and triethylamine $(0.69 \mathrm{~mL}, 4.9 \mathrm{mmol}) \mathrm{in}$ $\mathrm{DCM}(10 \mathrm{~mL})$, and the resulting mixture was stirred at $\mathrm{rt}$ for $45 \mathrm{~min}$. Saturated aqueous $\mathrm{NaHCO}_{3}(75 \mathrm{~mL})$ was added, and the resulting mixture was extracted with $\mathrm{DCM}(3 \times 100 \mathrm{~mL})$. The combined organic extracts were dried over $\mathrm{MgSO}_{4}$, filtered, and concentrated in vacuo to give crude 1-(4-(6-(2-((tert-butyldiphenylsilyl)oxy)-6-fluorophenyl)-4,7dichlorophthalazin-1-yl)piperazin-1-yl)prop-2-en-1-one as a tan solid that was used directly in the next step assuming $100 \%$ yield. $m / z\left(\right.$ ESI, +ve) $685.1(\mathrm{M}+\mathrm{H})^{+}$.

Step 7: 1-(4-(4,7-Dichloro-6-(2-fluoro-6-hydroxyphenyl)phthalazin-1-yl)piperazin-1-yl)prop-2-en-1-one. TBAF (1 $\mathrm{M}$ in THF, $3.30 \mathrm{~mL}, 3.30 \mathrm{mmol})$ was added to a solution of crude 1-(4-(6-(2-((tert-butyldiphenylsilyl)oxy)-6-fluorophenyl)4,7-dichlorophthalazin-1-yl)piperazin-1-yl)prop-2-en-1-one (1.13 g, $1.65 \mathrm{mmol})$ in THF (10 mL), and the resulting mixture was stirred at $\mathrm{rt}$ for $15 \mathrm{~min}$. The reaction mixture was concentrated in vacuo, and the residue was purified by column chromatography (silica gel, 0-100\% EtOAc/heptane) to give 1-(4-(4,7-dichloro-6-(2-fluoro-6-hydroxyphenyl)phthalazin-1yl)piperazin-1-yl)prop-2-en-1-one (0.50 g, 68\% yield) as a yellow solid. ${ }^{1} \mathrm{H}$ NMR (400 MHz, DMSO- $\left.d_{6}\right) \delta 10.26$ (br s, $\left.1 \mathrm{H}\right)$ $8.31(\mathrm{~s}, 1 \mathrm{H}) 8.14(\mathrm{~s}, 1 \mathrm{H}) 7.31-7.40(\mathrm{~m}, 1 \mathrm{H}) 6.78-6.92(\mathrm{~m}, 3 \mathrm{H}) 6.17(\mathrm{dd}, J=16.63,2.35 \mathrm{~Hz}, 1 \mathrm{H}) 5.74(\mathrm{dd}, J=10.37,2.35$ $\mathrm{Hz}, 1 \mathrm{H}) 3.79-3.92(\mathrm{~m}, 4 \mathrm{H}) 3.46-3.55(\mathrm{~m}, 4 \mathrm{H}) . \mathrm{m} / \mathrm{z}(\mathrm{ESI},+\mathrm{ve}) 447.0(\mathrm{M}+\mathrm{H})^{+}$.

Step 8: 1-(4-(7-Chloro-6-(2-fluoro-6-hydroxyphenyl)-4-(o-tolyl)phthalazin-1-yl)piperazin-1-yl)prop-2-en-1-one (3). A mixture of 1-(4-(4,7-dichloro-6-(2-fluoro-6-hydroxyphenyl)phthalazin-1-yl)piperazin-1-yl)prop-2-en-1-one (25 mg, $0.056 \mathrm{mmol})$, 2-tolylboronic acid (30 mg, $0.22 \mathrm{mmol}$, Frontier Scientific, Inc.), $\mathrm{Pd}\left(\mathrm{PPh}_{3}\right)_{4}(6 \mathrm{mg}, 6 \mu \mathrm{mol})$, and $\mathrm{Na}_{2} \mathrm{CO} 3(2$ $\mathrm{M}$ aqueous; $84 \mu \mathrm{L}, 0.17 \mathrm{mmol})$ in 1,4-dioxane $(0.3 \mathrm{~mL})$ was stirred at $40{ }^{\circ} \mathrm{C}$ for $18 \mathrm{~h}$. The reaction mixture was then diluted with EtOAc $(20 \mathrm{~mL})$ and washed with water $(15 \mathrm{~mL})$. The organic layer was separated, washed with brine $(15 \mathrm{~mL})$, dried over $\mathrm{MgSO}_{4}$, filtered, and concentrated in vacuo. Chromatographic purification of the residue (silica gel, $0-100 \%$ EtOAc/heptane) furnished 1-(4-(7-chloro-6-(2-fluoro-6-hydroxyphenyl)-4-(o-tolyl)phthalazin-1-yl)piperazin-1-yl)prop-2en-1-one (12 mg, 43\% yield) as a white solid. ${ }^{1} \mathrm{H}$ NMR (400 MHz, DMSO-d $) \delta 10.15$ (br s, 1H) 8.33 (s, 1H) 7.36-7.45 $(\mathrm{m}, 2 \mathrm{H}) 7.24-7.36(\mathrm{~m}, 4 \mathrm{H}) 6.90(\mathrm{dd}, J=16.63,10.37 \mathrm{~Hz}, 1 \mathrm{H}) 6.70-6.80(\mathrm{~m}, 2 \mathrm{H}) 6.18(\mathrm{dd}, J=16.73,2.25 \mathrm{~Hz}, 1 \mathrm{H}) 5.75$ $(\mathrm{dd}, J=10.56,2.15 \mathrm{~Hz}, 1 \mathrm{H}) 3.83-3.97(\mathrm{~m}, 4 \mathrm{H}) 3.47-3.62(\mathrm{~m}, 4 \mathrm{H}) 1.98-2.06(\mathrm{~m}, 3 \mathrm{H}) . \mathrm{m} / \mathrm{z}(\mathrm{ESI},+\mathrm{ve}) 503.1(\mathrm{M}+\mathrm{H})^{+}$.

\section{Compound 4}

1-(4-(7-Chloro-4-(2-chlorophenyl)-6-(2-fluoro-6-hydroxyphenyl)-1-phthalazinyl)-1-piperazinyl)-2-propen-1-one was prepared according to the procedure described for Compound 3, using 2-chlorophenylboronic acid (Matrix Scientific) in Step 8 (34\% yield) to afford Compound 4 as a light yellow solid. ${ }^{1} \mathrm{H}$ NMR $\left(400 \mathrm{MHz}, \mathrm{MeOH}-d_{4}\right) \delta 8.40(1 \mathrm{H}$, s) $7.50-$ $7.70(4 \mathrm{H}, \mathrm{m}) 7.42(1 \mathrm{H}, \mathrm{s}) 7.22-7.30(1 \mathrm{H}, \mathrm{m}) 6.89(1 \mathrm{H}, \mathrm{dd}, J=16.73,10.66 \mathrm{~Hz}) 6.63-6.76(2 \mathrm{H}, \mathrm{m}) 6.30(1 \mathrm{H}, \mathrm{dd}, J=$ $16.73,1.86 \mathrm{~Hz}) 5.83(1 \mathrm{H}, \mathrm{dd}, J=10.56,1.96 \mathrm{~Hz}) 3.98-4.10(4 \mathrm{H}, \mathrm{m}) 3.62-3.76(4 \mathrm{H}, \mathrm{m}) . \mathrm{m} / \mathrm{z}(\mathrm{ESI},+\mathrm{ve}) 523.1(\mathrm{M}+\mathrm{H})^{+}$. 


\section{Compound 5}

1-(4-(7-Chloro-4-(2-ethylphenyl)-6-(2-fluoro-6-hydroxyphenyl)phthalazin-1-yl)piperazin-1-yl)prop-2-en-1-one was prepared according to the procedure described for Compound 3, using 2-ethylbenzeneboronic acid (Alfa Aesar) in Step $8\left(63 \%\right.$ yield) to afford Compound 5 as a white solid. ${ }^{1} \mathrm{H}$ NMR $\left(400 \mathrm{MHz}, \mathrm{MeOH}-d_{4}\right) \delta \mathrm{ppm} 8.44(1 \mathrm{H}, \mathrm{s}) 7.46-7.57(3 \mathrm{H}$, m) 7.26-7.44 (3 H, m) $6.94(1 \mathrm{H}, \mathrm{dd}, J=16.73,10.66 \mathrm{~Hz}) 6.77(1 \mathrm{H}, \mathrm{d}, J=8.22 \mathrm{~Hz}) 6.68-6.75(1 \mathrm{H}, \mathrm{m}) 6.35(1 \mathrm{H}, \mathrm{dd}, J=$ $16.73,1.86 \mathrm{~Hz}) 5.88(1 \mathrm{H}, \mathrm{dd}, J=10.76,1.96 \mathrm{~Hz}) 4.04-4.12(4 \mathrm{H}, \mathrm{m}) 3.67-3.76(4 \mathrm{H}, \mathrm{m}) 2.36-2.60(2 \mathrm{H}, \mathrm{m}) 1.06(3 \mathrm{H}, \mathrm{q}$, $J=7.63 \mathrm{~Hz}) . \mathrm{m} / \mathrm{z}(\mathrm{ESI},+\mathrm{ve}) 517.1(\mathrm{M}+\mathrm{H})^{+}$.

\section{Compound 6}

1-(4-(7-Chloro-6-(2-fluoro-6-hydroxyphenyl)-4-(2-methoxyphenyl)phthalazin-1-yl)piperazin-1-yl)prop-2-en-1one was prepared according to the procedure described for Compound 3, using 2-methoxybenzeneboronic acid (SigmaAldrich) in Step 8 (62\% yield) to afford Compound 6 as a light yellow solid. ${ }^{1} \mathrm{H}$ NMR $\left(400 \mathrm{MHz}, \mathrm{CDCl}_{3}\right) \delta 8.16-8.24(\mathrm{~m}$, 1H), 7.61-7.67 (m, 1H), 7.43-7.52 (m, 2H), 7.15-7.23 (m, 1H), 7.05-7.13 (m, 1H), 6.92-7.02 (m, 1H), 6.70-6.82 (m, 2H), 6.57-6.69 (m, 1H), 6.30-6.40 (m, 1H), 5.68-5.81 (m, 1H), 3.81-4.03 (m, 4H), 3.49-3.71 (m, 7H), 2.52-2.66 (m, $1 \mathrm{H}) .{ }^{19} \mathrm{~F}$ $\operatorname{NMR}\left(376 \mathrm{MHz}, \mathrm{CDCl}_{3}\right) \delta-112.17,-113.96(\mathrm{~s}, 2 \mathrm{~F}) . \mathrm{m} / \mathrm{z}(\mathrm{ESI},+\mathrm{ve}) 519(\mathrm{M}+\mathrm{H})^{+}$.

\section{Compound 7}

1-(4-(7-Chloro-4-(2-cyclopropylphenyl)-6-(2-fluoro-6-hydroxyphenyl)phthalazin-1-yl)piperazin-1-yl)prop-2-en1-one was prepared according to the procedure described for Compound 3, using 2-cyclopropylbenzeneboronic acid (CombiPhos Catalysts, Inc.) in Step 8 (34\% yield) to afford Compound 7 as a white solid. ${ }^{1} \mathrm{H} \mathrm{NMR}\left(400 \mathrm{MHz}, \mathrm{MeOH}-d_{4}\right)$ $\delta$ ppm $8.52(1 \mathrm{H}, \mathrm{s}) 7.55-7.63(2 \mathrm{H}, \mathrm{m}) 7.44-7.51(2 \mathrm{H}, \mathrm{m}) 7.35-7.43(1 \mathrm{H}, \mathrm{m}) 7.24(1 \mathrm{H}, \mathrm{t}, J=7.04 \mathrm{~Hz}) 7.02(1 \mathrm{H}, \mathrm{dd}, J=$ $16.73,10.66 \mathrm{~Hz}) 6.83-6.90(1 \mathrm{H}, \mathrm{m}) 6.76-6.83(1 \mathrm{H}, \mathrm{m}) 6.43(1 \mathrm{H}, \mathrm{dd}, J=16.73,1.66 \mathrm{~Hz}) 5.97(1 \mathrm{H}, \mathrm{dd}, J=10.66,1.66$ Hz) 4.13-4.19 (4 H, m) 3.76-3.82 (4 H, m) 1.56-1.70 (1 H, m) 0.70-0.92 (3 H, m) 0.55-0.68 (1 H, m). m/z (ESI, +ve) $529.1(\mathrm{M}+\mathrm{H})^{+}$.

\section{Compound 8}

1-(4-(7-Chloro-6-(2-fluoro-6-hydroxyphenyl)-4-(2-isopropylphenyl)phthalazin-1-yl)piperazin-1-yl)prop-2-en-1one was prepared according to the procedure described for Compound 3, using 2-isopropylphenylboronic acid (Alfa Aesar) in Step 8 (73\% yield) to afford Compound 8 as an off-white solid. ${ }^{1} \mathrm{H}$ NMR (400 MHz, MeOH- $\left.d_{4}\right) \delta$ ppm $8.34(1 \mathrm{H}$, s) 7.44-7.51 (2 H, m) $7.34(1 \mathrm{H}, \mathrm{d}, J=4.30 \mathrm{~Hz}) 7.27-7.32(1 \mathrm{H}, \mathrm{m}) 7.15-7.25(2 \mathrm{H}, \mathrm{m}) 6.83(1 \mathrm{H}, \mathrm{dd}, J=16.82,10.56 \mathrm{~Hz})$ $6.66(1 \mathrm{H}, \mathrm{d}, J=8.22 \mathrm{~Hz}) 6.57-6.64(1 \mathrm{H}, \mathrm{m}) 6.21-6.27(1 \mathrm{H}, \mathrm{m}) 5.77(1 \mathrm{H}, \mathrm{dd}, J=10.66,1.86 \mathrm{~Hz}) 3.93-4.02(4 \mathrm{H}, \mathrm{m})$ 3.56-3.65 (4 H, m) 2.46-2.56 (1 H, m) 0.98-1.13 (6 H, m). m/z (ESI, +ve) $531.2(\mathrm{M}+\mathrm{H})^{+}$.

\section{Compound 9}

4-(4-Acryloylpiperazin-1-yl)-6-chloro-7-(2-fluoro-6-hydroxyphenyl)-1-(2-isopropylphenyl)quinazolin-2(1H)-one 

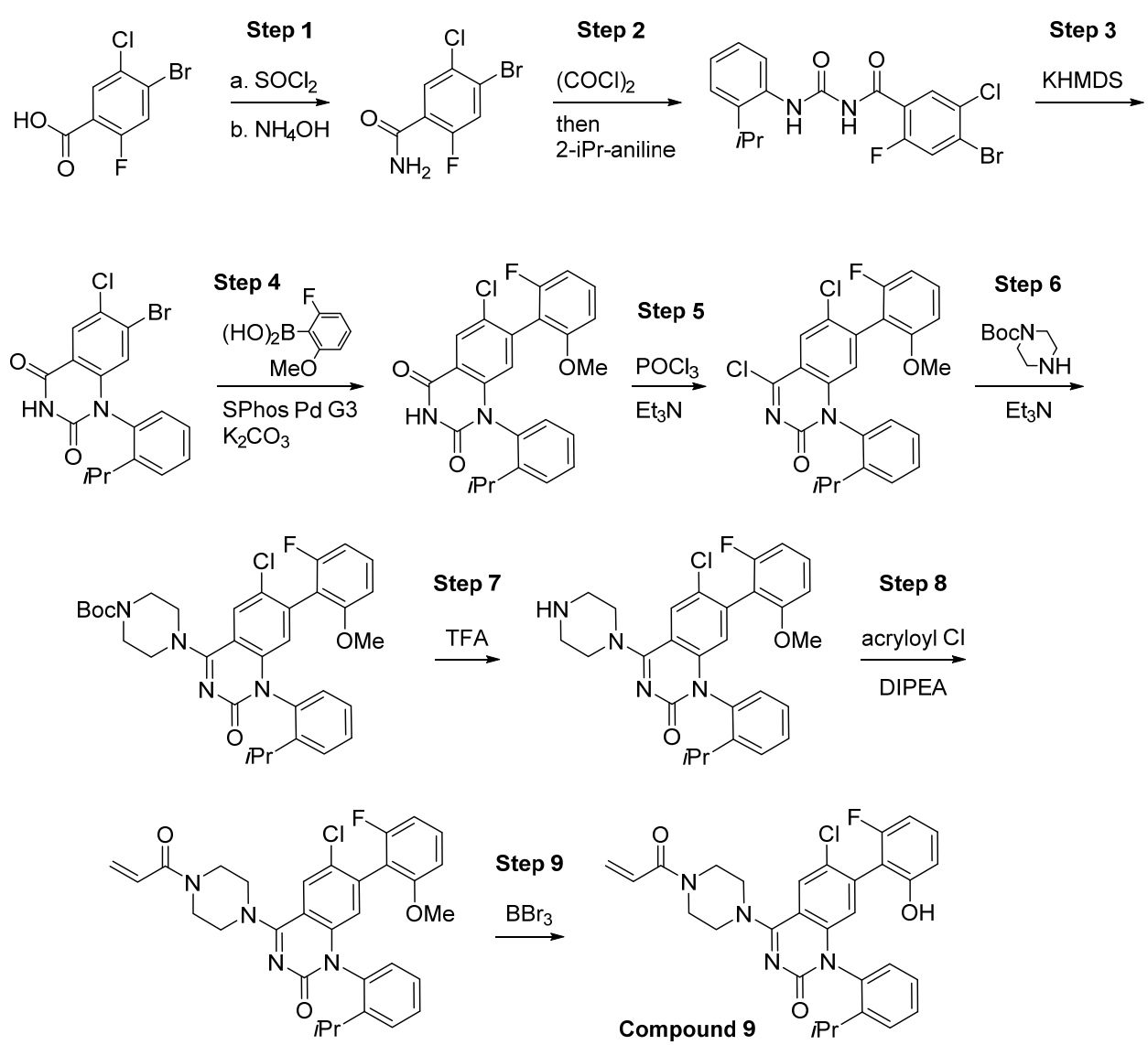

Step 1: 4-Bromo-5-chloro-2-fluorobenzamide. A mixture of 4-bromo-5-chloro-2-fluorobenzoic acid (23.3 g, 92 mmol) in thionyl chloride $(67 \mathrm{~mL}, 0.92 \mathrm{~mol})$ was stirred at $70{ }^{\circ} \mathrm{C}$ under a reflux condenser for $1 \mathrm{~h}$. The reaction mixture was then concentrated in vacuo, and the residue was taken up in 1,4-dioxane $(200 \mathrm{~mL})$, treated with ammonium hydroxide ( $30 \%$ aqueous, $82 \mathrm{~mL}, 0.64 \mathrm{~mol}$ ), and stirred at $\mathrm{rt}$ for $15 \mathrm{~min}$. The reaction mixture was concentrated in vacuo to give 4bromo-5-chloro-2-fluorobenzamide $\left(29.1 \mathrm{~g}\right.$, quantitative) as an off-white solid. $\mathrm{m} / \mathrm{z}(\mathrm{ESI},+\mathrm{ve}) 251.8(\mathrm{M}+\mathrm{H})^{+}$.

Step 2: 4-Bromo-5-chloro-2-fluoro- $N$-((2-isopropylphenyl)carbamoyl)benzamide. A mixture of 4-bromo-5-chloro2-fluorobenzamide (4.99 g, $19.8 \mathrm{mmol})$ and oxalyl chloride (2 M in DCM; $16.8 \mathrm{~mL}, 33.6 \mathrm{mmol})$ in DCE (100 mL) was stirred under a reflux condenser at $80{ }^{\circ} \mathrm{C}$ for $1 \mathrm{~h}$. The reaction mixture was then cooled to rt and 2-isopropylaniline (2.94 $\mathrm{mL}, 20.75 \mathrm{mmol}$ ) was added. The resulting mixture was stirred at $\mathrm{rt}$ for $15 \mathrm{~min}$, then cooled to $0{ }^{\circ} \mathrm{C}$. The precipitated solid was removed by filtration, and the collected filtrate was concentrated in vacuo to give 4-bromo-5-chloro-2-fluoro- $N$ - $((2-$ isopropylphenyl)carbamoyl)benzamide $\left(6.30 \mathrm{~g}, 77 \%\right.$ yield) as a white solid. ${ }^{1} \mathrm{H}$ NMR (400 MHz, DMSO-d6) $\delta 11.06$ (br. s., $1 \mathrm{H}) 10.31(\mathrm{~s}, 1 \mathrm{H}) 7.97-8.05(\mathrm{~m}, 2 \mathrm{H}) 7.82(\mathrm{~d}, J=7.2 \mathrm{~Hz}, 1 \mathrm{H}) 7.32-7.38(\mathrm{~m}, 1 \mathrm{H}) 7.14-7.25(\mathrm{~m}, 2 \mathrm{H}) 3.11(\mathrm{spt}, J=6.8 \mathrm{~Hz}$, 1H) $1.24(\mathrm{~d}, J=6.8 \mathrm{~Hz}, 6 \mathrm{H}) .{ }^{19} \mathrm{~F}$ NMR $\left(376 \mathrm{MHz}, \mathrm{DMSO}-\mathrm{d}_{6}\right) \delta-113.6(\mathrm{~s}, 1 \mathrm{~F}) . \mathrm{m} / \mathrm{z}(\mathrm{ESI},+\mathrm{ve}) 412.7 / 414.6(\mathrm{M}+\mathrm{H})^{+}$.

Step 3: 7-Bromo-6-chloro-1-(2-isopropylphenyl)quinazoline-2,4(1H,3H)-dione. KHMDS (1 M in THF, $8.30 \mathrm{~mL}$, $8.30 \mathrm{mmol})$ was added to a mixture of 4-bromo-5-chloro-2-fluoro- $N$-((2-isopropylphenyl)carbamoyl)benzamide (1.56 g, $3.77 \mathrm{mmol})$ in THF $(19 \mathrm{~mL})$ at $-20^{\circ} \mathrm{C}$, and the resulting mixture was allowed to warm to rt over1 h. The reaction mixture was then diluted with EtOAc $(150 \mathrm{~mL})$ and washed with saturated aqueous ammonium chloride $(2 \times 100 \mathrm{~mL})$. The organic layer was dried over $\mathrm{Na}_{2} \mathrm{SO}_{4}$, filtered, and concentrated in vacuo. The residue was suspended in DCM (5 mL), sonicated, collected by filtration, and dried in vacuo to give 7-bromo-6-chloro-1-(2-isopropylphenyl)quinazoline- $2,4(1 \mathrm{H}, 3 \mathrm{H})$-dione $\left(1.17 \mathrm{~g}, 79 \%\right.$ yield) as a white solid. ${ }^{1} \mathrm{H}$ NMR $\left(400 \mathrm{MHz}, \mathrm{CDCl}_{3}\right) \delta 9.43$ (br. s., $\left.1 \mathrm{H}\right) 8.29$ (s, 1H) 7.55-7.59 (m, 2H) 7.39$7.44(\mathrm{~m}, 1 \mathrm{H}) 7.16(\mathrm{~d}, J=7.8 \mathrm{~Hz}, 1 \mathrm{H}) 6.75(\mathrm{~s}, 1 \mathrm{H}) 2.59-2.77(\mathrm{~m}, 1 \mathrm{H}) 1.17-1.24(\mathrm{~m}, 3 \mathrm{H}) 1.11(\mathrm{~d}, \mathrm{~J}=6.8 \mathrm{~Hz}, 3 \mathrm{H}) . \quad m / z(\mathrm{ESI}$, +ve) $392.9 / 395.0(\mathrm{M}+\mathrm{H})^{+}$.

Step 4: 6-Chloro-7-(2-fluoro-6-methoxyphenyl)-1-(2-isopropylphenyl)quinazoline-2,4(1H,3H)-dione. A mixture of 7-bromo-6-chloro-1-(2-isopropylphenyl)quinazoline-2,4(1H,3H)-dione $\quad(1.17 \quad \mathrm{~g}, \quad 2.96 \quad \mathrm{mmol}), \quad$ (2-fluoro-6methoxyphenyl)boronic acid (2.02 g, $11.9 \mathrm{mmol})$, SPhos Pd G3 (0.128 g, $0.148 \mathrm{mmol})$, and potassium carbonate (2 M in water, $4.45 \mathrm{~mL}, 8.90 \mathrm{mmol})$ in DME $(30 \mathrm{~mL})$ was stirred at $85{ }^{\circ} \mathrm{C}$ for $16 \mathrm{~h}$. The reaction mixture was then diluted with EtOAc $(150 \mathrm{~mL})$ and washed with saturated aqueous $\mathrm{NaHCO}_{3}(3 \times 100 \mathrm{~mL})$. The organic layer was dried over $\mathrm{Na}_{2} \mathrm{SO}_{4}$, filtered, and concentrated in vacuo. Chromatographic purification of the residue (silica gel, 0-50\% EtOAc/heptane) gave 
6-chloro-7-(2-fluoro-6-methoxyphenyl)-1-(2-isopropylphenyl)quinazoline-2,4(1H,3H)-dione (866 $\mathrm{mg}, 67 \%$ yield). ${ }^{1} \mathrm{H}$ NMR (400 MHz, DMSO-d $) \delta 11.90(\mathrm{~d}, J=1.2 \mathrm{~Hz}, 1 \mathrm{H}) 8.11(\mathrm{~d}, J=3.3 \mathrm{~Hz}, 1 \mathrm{H}) 7.53-7.59(\mathrm{~m}, 1 \mathrm{H}) 7.48$ (tt, $J=7.0,2.2$ $\mathrm{Hz}, 1 \mathrm{H}) 7.38-7.44(\mathrm{~m}, 1 \mathrm{H}) 7.32-7.37(\mathrm{~m}, 2 \mathrm{H}) 6.93(\mathrm{dd}, J=8.4,4.3 \mathrm{~Hz}, 1 \mathrm{H}) 6.86(\mathrm{t}, J=8.7 \mathrm{~Hz}, 1 \mathrm{H}) 6.15(\mathrm{~s}, 1 \mathrm{H}) 3.66(\mathrm{~d}, J$ $=30 \mathrm{~Hz}, 3 \mathrm{H}) 2.73(\mathrm{dq}, J=14.2,7.0 \mathrm{~Hz}, 1 \mathrm{H}) 1.11(\mathrm{t}, J=7.1 \mathrm{~Hz}, 3 \mathrm{H}) 1.03(\mathrm{dd}, J=12.7,6.8 \mathrm{~Hz}, 3 \mathrm{H}) .{ }^{19} \mathrm{~F} \mathrm{NMR}(376 \mathrm{MHz}$, DMSO-d $) \delta-113.8(\mathrm{~s}, 1 \mathrm{~F})-115.2(\mathrm{~s}, 1 \mathrm{~F}) . \mathrm{m} / \mathrm{z}(\mathrm{ESI},+\mathrm{ve}) 439.1(\mathrm{M}+\mathrm{H})^{+}$.

Step 5: 4,6-Dichloro-7-(2-fluoro-6-methoxyphenyl)-1-(2-isopropylphenyl)quinazolin-2(1H)-one. ${ }^{16}$ To a solution of 6-chloro-7-(2-fluoro-6-methoxyphenyl)-1-(2-isopropylphenyl)quinazoline-2,4(1H,3H)-dione (395 $\mathrm{mg}, 0.900 \mathrm{mmol})$ and $\mathrm{Et}_{3} \mathrm{~N}(0.75 \mathrm{~mL}, 5.4 \mathrm{mmol})$ in acetonitrile $(9 \mathrm{~mL})$ was added phosphorus oxychloride $(0.50 \mathrm{~mL}, 5.4 \mathrm{mmol})$, and the resulting solution was stirred at $80{ }^{\circ} \mathrm{C}$ for $1.5 \mathrm{~h}$. The reaction mixture was concentrated in vacuo to give 4,6-dichloro-7-(2-fluoro-6methoxyphenyl)-1-(2-isopropylphenyl)quinazolin-2(1H)-one. $\mathrm{m} / \mathrm{z}(\mathrm{ESI},+\mathrm{ve}) 457.1(\mathrm{M}+\mathrm{H})^{+}$.

Step 6: tert-Butyl 4-(6-chloro-7-(2-fluoro-6-methoxyphenyl)-1-(2-isopropylphenyl)-2-oxo-1,2-dihydroquinazolin4-yl)piperazine-1-carboxylate. A solution of 4,6-dichloro-7-(2-fluoro-6-methoxyphenyl)-1-(2isopropylphenyl)quinazolin-2(1H)-one, tert-butyl piperazine-1-carboxylate $(0.335 \mathrm{~g}, 1.80 \mathrm{mmol})$, and $\mathrm{Et}_{3} \mathrm{~N}(0.75 \mathrm{~mL}, 5.4$ $\mathrm{mmol})$ in DCE $(9 \mathrm{~mL})$ was stirred at $60^{\circ} \mathrm{C}$ for $20 \mathrm{~min}$. The reaction mixture was diluted with EtOAc $(100 \mathrm{~mL})$ and washed with saturated aqueous $\mathrm{NaHCO}_{3}(3 \times 75 \mathrm{~mL})$. The organic layer was dried over $\mathrm{Na}_{2} \mathrm{SO}_{4}$ and concentrated in vacuo. Chromatographic purification of the residue (silica gel, 0-60\% (3:1) EtOAc-EtOH/heptane) provided tert-butyl 4-(6-chloro7-(2-fluoro-6-methoxyphenyl)-1-(2-isopropylphenyl)-2-oxo-1,2-dihydroquinazolin-4-yl)piperazine-1-carboxylate (352 mg, $64 \%$ yield over 2 steps $) . \quad m / z(E S I,+v e) 607.3(\mathrm{M}+\mathrm{H})^{+}$.

Step 7: 6-Chloro-7-(2-fluoro-6-methoxyphenyl)-1-(2-isopropylphenyl)-4-(piperazin-1-yl)quinazolin-2(1H)-one. A solution of tert-butyl 4-(6-chloro-7-(2-fluoro-6-methoxyphenyl)-1-(2-isopropylphenyl)-2-oxo-1,2-dihydroquinazolin-4yl)piperazine-1-carboxylate $(0.594 \mathrm{~g}, 0.978 \mathrm{mmol})$ in TFA $(4 \mathrm{~mL})$ was stirred at ambient temperature for $30 \mathrm{~min}$. The reaction mixture was concentrated in vacuo to give 6-chloro-7-(2-fluoro-6-methoxyphenyl)-1-(2-isopropylphenyl)-4(piperazin-1-yl)quinazolin-2(1H)-one. $\mathrm{m} / \mathrm{z}(\mathrm{ESI},+\mathrm{ve}) 507.2(\mathrm{M}+\mathrm{H})^{+}$.

Step 8: 4-(4-Acryloylpiperazin-1-yl)-6-chloro-7-(2-fluoro-6-methoxyphenyl)-1-(2-isopropylphenyl)quinazolin2(1H)-one. To an ice-cooled solution of 6-chloro-7-(2-fluoro-6-methoxyphenyl)-1-(2-isopropylphenyl)-4-(piperazin-1yl)quinazolin-2 $(1 \mathrm{H})$-one and DIPEA $(0.85 \mathrm{~mL}, 4.9 \mathrm{mmol})$ in DCM $(10 \mathrm{~mL})$ at $0{ }^{\circ} \mathrm{C}$ was added acryloyl chloride $(0.079 \mathrm{~mL}$, $0.98 \mathrm{mmol}$ ), and the resulting mixture was stirred at $0^{\circ} \mathrm{C}$ for $30 \mathrm{~min}$. The reaction mixture was diluted with EtOAc (100 $\mathrm{mL})$ and washed with saturated aqueous $\mathrm{NaHCO}_{3}(3 \times 75 \mathrm{~mL})$. The organic layer was dried over $\mathrm{Na}_{2} \mathrm{SO}_{4}$, decanted, and concentrated in vacuo. Chromatographic purification of the residue (silica gel, 0-100\% (3:1) EtOAc-EtOH/heptane) gave 4-(4-acryloylpiperazin-1-yl)-6-chloro-7-(2-fluoro-6-methoxyphenyl)-1-(2-isopropylphenyl)quinazolin-2(1H)-one (372 mg, $68 \%$ yield over 2 steps) as an off-white solid. ${ }^{1} \mathrm{H} \mathrm{NMR}\left(400 \mathrm{MHz}, \mathrm{CDCl}_{3}\right) \delta 7.86(\mathrm{~d}, J=1.2 \mathrm{~Hz}, 1 \mathrm{H}) 7.41-7.54(\mathrm{~m}, 2 \mathrm{H})$ 7.29-7.37 (m, 2H) $7.14(\mathrm{dt}, J=7.8,1.7 \mathrm{~Hz}, 1 \mathrm{H}) 6.70-6.79(\mathrm{~m}, 2 \mathrm{H}) 6.58-6.68(\mathrm{~m}, 1 \mathrm{H}) 6.50(\mathrm{~d}, J=7.4 \mathrm{~Hz}, 1 \mathrm{H}) 6.39(\mathrm{dd}, J$ $=16.8,1.8 \mathrm{~Hz}, 1 \mathrm{H}) 5.75-5.84(\mathrm{~m}, 1 \mathrm{H}) 3.79-4.06(\mathrm{~m}, 8 \mathrm{H}) 3.75(\mathrm{~s}, 2 \mathrm{H}) 3.66(\mathrm{~s}, 1 \mathrm{H}) 2.69(\mathrm{tt}, J=13.4,6.8 \mathrm{~Hz}, 1 \mathrm{H}) 1.20-1.24$ $(\mathrm{m}, 3 \mathrm{H}) 1.07(\mathrm{dd}, J=6.8,3.9 \mathrm{~Hz}, 3 \mathrm{H}) .{ }^{19} \mathrm{~F} \mathrm{NMR}\left(377 \mathrm{MHz}, \mathrm{CDCl}_{3}\right) \delta-113.05(\mathrm{~s}, 1 \mathrm{~F})-113.55(\mathrm{~s}, 1 \mathrm{~F}) . \mathrm{m} / \mathrm{z}(\mathrm{ESI},+\mathrm{ve}) 561.2$ $(\mathrm{M}+\mathrm{H})^{+}$.

Step 9: 4-(4-Acryloylpiperazin-1-yl)-6-chloro-7-(2-fluoro-6-hydroxyphenyl)-1-(2-isopropylphenyl)quinazolin2(1H)-one (9). $\mathrm{BBr}_{3}$ (1 M in DCE, $3.3 \mathrm{~mL}, 3.3 \mathrm{mmol}$ ) was added to an ice-cooled solution of 4-(4-acryloylpiperazin-1-yl)6-chloro-7-(2-fluoro-6-methoxyphenyl)-1-(2-isopropylphenyl)quinazolin-2(1H)-one (0.372 g, $0.663 \mathrm{mmol})$ in DCE (1.7 $\mathrm{mL}$ ), and the resulting mixture was stirred at $0{ }^{\circ} \mathrm{C}$ for $20 \mathrm{~min}$, then allowed to warm to rt and stir at $\mathrm{rt}$ for $2 \mathrm{~h}$. Saturated aqueous $\mathrm{NaHCO}_{3}$ was added to the reaction mixture, followed by EtOAc $(150 \mathrm{~mL})$. The organic layer was separated and washed with saturated aqueous $\mathrm{NaHCO}_{3}(3 \times 100 \mathrm{~mL})$. The organic layer was then dried over $\mathrm{Na}_{2} \mathrm{SO}_{4}$, filtered, and concentrated in vacuo. Chromatographic purification of the residue (silica gel, 0-100\% (3:1) EtOAc-EtOH/heptane) provided the title compound (277 mg, 76 yield) as a white solid. ${ }^{1} \mathrm{H}$ NMR (400 MHz, DMSO-d6) $\delta 10.06$ (br. d., $J=15.1$ $\mathrm{Hz}, 1 \mathrm{H}) 8.03(\mathrm{~d}, J=1.2 \mathrm{~Hz}, 1 \mathrm{H}) 7.51-7.56(\mathrm{~m}, 1 \mathrm{H}) 7.45(\mathrm{t}, J=7.6 \mathrm{~Hz}, 1 \mathrm{H}) 7.33(\mathrm{tdd}, J=7.5,7.5,3.8,1.4 \mathrm{~Hz}, 1 \mathrm{H}) 7.14-$ $7.25(\mathrm{~m}, 2 \mathrm{H}) 6.84(\mathrm{dd}, J=16.8,10.4 \mathrm{~Hz}, 1 \mathrm{H}) 6.62-6.74(\mathrm{~m}, 2 \mathrm{H}) 6.14-6.26(\mathrm{~m}, 2 \mathrm{H}) 5.71-5.78(\mathrm{~m}, 1 \mathrm{H}) 3.71-3.99(\mathrm{~m}, 8 \mathrm{H})$ 2.52-2.59 (m, 1H) 1.02-1.12 (m, 6H). ${ }^{19} \mathrm{~F}$ NMR (377 MHz, DMSO-d $) \delta-113.6(\mathrm{~s}, 1 \mathrm{~F})-114.8(\mathrm{~s}, 1 \mathrm{~F}) . \quad \mathrm{m} / \mathrm{z}(\mathrm{ESI},+\mathrm{ve})$ $547.1(\mathrm{M}+\mathrm{H})^{+}$.

\section{Compound $(R)-9$}

(R)-4-(4-Acryloylpiperazin-1-yl)-6-chloro-7-(2-fluoro-6-hydroxyphenyl)-1-(2-isopropylphenyl)quinazolin-2(1H)one. Atropisomer separation of Compound 9 (SFC: Chiralpak IC, $300 \times 15 \mathrm{~mm}, 5 \mu \mathrm{m}, 40 \% \mathrm{MeOH} / \mathrm{CO}_{2}(\mathrm{w} / 20 \mathrm{mM} \mathrm{NH}$ ), $135 \mathrm{~g} / \mathrm{min}, 188 \mathrm{bar})$ gave the title compound as the first-eluting isomer. ${ }^{1} \mathrm{H}$ NMR (400 MHz, DMSO-d $) \delta 10.06$ (br. d., $J$ $=15.1 \mathrm{~Hz}, 1 \mathrm{H}) 8.03(\mathrm{~d}, J=1.2 \mathrm{~Hz}, 1 \mathrm{H}) 7.51-7.56(\mathrm{~m}, 1 \mathrm{H}) 7.45(\mathrm{t}, J=7.6 \mathrm{~Hz}, 1 \mathrm{H}) 7.33(\mathrm{tdd}, J=7.5,7.5,3.8,1.4 \mathrm{~Hz}, 1$ H) 7.14-7.25 (m, 2 H) $6.84(\mathrm{dd}, J=16.8,10.4 \mathrm{~Hz}, 1 \mathrm{H}) 6.62-6.74(\mathrm{~m}, 2 \mathrm{H}) 6.14-6.26$ (m, $2 \mathrm{H}) 5.71-5.78$ (m, $1 \mathrm{H}) 3.71-$ $3.99(\mathrm{~m}, 8 \mathrm{H}) 2.52-2.59(\mathrm{~m}, 1 \mathrm{H}) 1.02-1.12(\mathrm{~m}, 6 \mathrm{H}) .{ }^{19} \mathrm{~F}$ NMR $\left(377 \mathrm{MHz}, \mathrm{DMSO}-d_{6}\right) \delta-113.6(\mathrm{~s}, 1 \mathrm{~F})-114.8(\mathrm{~s}, 1 \mathrm{~F})$. $\mathrm{m} / \mathrm{z}(\mathrm{ESI},+\mathrm{ve}) 547.1(\mathrm{M}+\mathrm{H})^{+}$. The atropisomer configuration of $(R)-9$ was assigned by analogy based on in vitro potency: 
crystallographic analysis of $>50$ project atropisomers revealed the more potent isomer to consistently position its larger ortho substituent toward the cryptic (Y96/H95/Q99) pocket.

\section{Compound 10}

4-(4-Acryloylpiperazin-1-yl)-6-chloro-1-(2-isopropylphenyl)-7-(3-hydroxynaphthalen-1-yl)quinazolin-2(1H)-one was prepared according to the procedure described for Compound $(R)-14$, using (3-methoxynaphthalen-1-yl)boronic acid (Ark Pharm, Inc.) and SPhos Pd G3 in DME in Step 6, followed by the procedure for Step 9 from Compound 9 (20\% yield for the two steps) to afford Compound $\mathbf{1 0}$ as a white solid (mixture of 4 diastereomers; 89.5\% LCAP @ $215 \mathrm{~nm}$ ). ${ }^{1} \mathrm{H}$ NMR $\left(400 \mathrm{MHz}, \mathrm{CDCl}_{3}\right) \delta \mathrm{ppm} 7.91(\mathrm{~d}, J=3.3 \mathrm{~Hz}, 1 \mathrm{H}), 7.70(\mathrm{dd}, J=8.3,2.6 \mathrm{~Hz}, 1 \mathrm{H}), 7.34-7.49(\mathrm{~m}, 3 \mathrm{H}), 7.28-7.32(\mathrm{~m}, 1 \mathrm{H})$, 7.24-7.26 (m, $1 \mathrm{H}), 7.17-7.23(\mathrm{~m}, 2 \mathrm{H}), 7.09-7.14(\mathrm{~m}, 1 \mathrm{H}), 6.81-6.92(\mathrm{~m}, 1 \mathrm{H}), 6.57-6.67(\mathrm{~m}, 2 \mathrm{H}), 6.37-6.44$ (m, $1 \mathrm{H})$, $5.81(\mathrm{dd}, J=10.6,1.6 \mathrm{~Hz}, 1 \mathrm{H}), 3.81-4.09$ (m, $8 \mathrm{H}), 2.64-2.73(\mathrm{~m}, 1 \mathrm{H}), 1.18-1.25(\mathrm{~m}, 3 \mathrm{H}), 0.95-1.14$ (m, $3 \mathrm{H})$. m/z (ESI, +ve) $579.2(\mathrm{M}+\mathrm{H})^{+}$.

\section{Compound $(R)-11$}

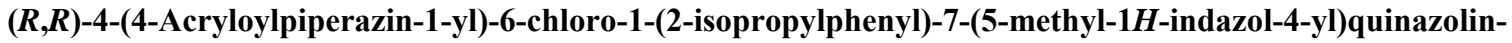
$\mathbf{2}(\mathbf{1 H})$-one was prepared according to the procedure described for Compound $(R)$-18, using 4-bromo-5-chloro-2fluorobenzoic acid (OxChem Corporation) in Step 1 (used in the next step without purification), Boc-piperazine in Step 4b (used in the next step without purification), and 5-methyl-1H-indazol-4-yl boronic acid (Ark Pharm, Inc.) and SPhos Pd G3 in DME in Step 5 (52\% yield) to afford the title compound (a mixture of two diastereomeric atropisomers) as the second eluting isomers from silica gel chromatography (the undesired first eluting pair of diastereomeric atropisomers can be racemized by heating in dioxane at $90{ }^{\circ} \mathrm{C}$ for $1 \mathrm{~h}$ and then re-separated to obtain additional desired material). Atropisomer separation following Step 6 (chiral SFC: OD, $150 \times 30 \mathrm{~mm}, 5 \mu \mathrm{m}, 25 \% \mathrm{MeOH}\left(\mathrm{w} / 20 \mathrm{mM} \mathrm{NH}\right.$ ) $/ \mathrm{CO}_{2}, 140 \mathrm{~g} / \mathrm{min}, 102 \mathrm{bar}$ ) gave Compound $(R)-11$ as the second-eluting isomer and a white solid. ${ }^{1} \mathrm{H} \mathrm{NMR}\left(400 \mathrm{MHz}, \mathrm{CDCl}_{3}\right) \delta \mathrm{ppm} 7.94(1 \mathrm{H}, \mathrm{s})$ $7.50(1 \mathrm{H}, \mathrm{s}) 7.42-7.47(2 \mathrm{H}, \mathrm{m}) 7.35-7.41(1 \mathrm{H}, \mathrm{m}) 7.26-7.31(2 \mathrm{H}, \mathrm{m}) 7.13(1 \mathrm{H}, \mathrm{dd}, J=7.67,0.83 \mathrm{~Hz}) 6.65(1 \mathrm{H}, \mathrm{dd}, J$ $=16.79,10.57 \mathrm{~Hz}) 6.55(1 \mathrm{H}, \mathrm{s}) 6.41(1 \mathrm{H}, \mathrm{dd}, J=16.79,1.66 \mathrm{~Hz}) 5.81(1 \mathrm{H}, \mathrm{dd}, J=10.57,1.87 \mathrm{~Hz}) 3.82-4.10(8 \mathrm{H}, \mathrm{m})$ $2.70(1 \mathrm{H}, \mathrm{spt}, J=6.84 \mathrm{~Hz}) 2.13(3 \mathrm{H}, \mathrm{s}) 1.23(3 \mathrm{H}, \mathrm{d}, J=6.84 \mathrm{~Hz}) 1.03(3 \mathrm{H}, \mathrm{d}, J=6.84 \mathrm{~Hz}) . \mathrm{m} / \mathrm{z}(\mathrm{ESI},+\mathrm{ve}) 567.2(\mathrm{M}+\mathrm{H})^{+}$. Atropisomer configuration ( $R$ vs. $S$ ) assigned crystallographically.

\section{Compound (R)-12}

(R)-4-(4-Acryloylpiperazin-1-yl)-6-chloro-7-(2-fluorophenyl)-1-(2-isopropylphenyl)quinazolin-2(1H)-one was prepared according to the procedure described for Compound $(R)-14$, using Boc-piperazine (Combi-Blocks, Inc.) in Step 5a and 2-fluorobenzeneboronic acid (TCI America) and SPhos Pd G3 in DME in Step 6 (35\% yield) to afford the title compound. Atropisomer separation following Step 6 (chiral SFC: ID, $250 \times 21 \mathrm{~mm}, 5 \mu \mathrm{m}, 50 \% \mathrm{MeOH}(\mathrm{w} / 20 \mathrm{mM}$ $\left.\mathrm{NH}_{3}\right) / \mathrm{CO}_{2}, 50 \mathrm{~mL} / \mathrm{min}, 227$ bar) gave Compound $(R)-12$ as the first-eluting isomer and a white solid. ${ }^{1} \mathrm{H} \mathrm{NMR}(400 \mathrm{MHz}$, $\left.\mathrm{CDCl}_{3}\right) \delta$ ppm $7.86(1 \mathrm{H}, \mathrm{s}) 7.30-7.51(4 \mathrm{H}, \mathrm{m}) 7.08-7.19(4 \mathrm{H}, \mathrm{m}) 6.63(1 \mathrm{H}, \mathrm{dd}, J=16.79,10.37 \mathrm{~Hz}) 6.51(1 \mathrm{H}, \mathrm{s}) 6.39(1$ $\mathrm{H}, \mathrm{dd}, J=16.79,1.87 \mathrm{~Hz}) 5.80(1 \mathrm{H}, \mathrm{dd}, J=10.57,1.87 \mathrm{~Hz}) 3.80-4.06(8 \mathrm{H}, \mathrm{m}) 2.66(1 \mathrm{H}, \mathrm{spt}, J=6.84 \mathrm{~Hz}) 1.22(3 \mathrm{H}, \mathrm{d}$, $J=6.84 \mathrm{~Hz}) 1.07(3 \mathrm{H}, \mathrm{d}, J=6.84 \mathrm{~Hz}) . m / z(\mathrm{ESI},+\mathrm{ve}) 531.0(\mathrm{M}+\mathrm{H})^{+}$. Atropisomer configuration $(R$ vs. $S)$ assigned by analogy. ${ }^{17}$

\section{Compound $(R)-13$}

(R)-(S)-4-(4-Acryloyl-2-methylpiperazin-1-yl)-6-chloro-7-(2-fluorophenyl)-1-(2-isopropylphenyl)quinazolin$\mathbf{2}(\mathbf{1 H})$-one was prepared according to the procedure described for Compound 32 using 4-bromo-5-chloro-2-fluorobenzoic acid (OxChem Corporation) in Step 1 and 2-fluorobenzeneboronic acid (TCI America) and SPhos Pd G3 in DME in Step 5 (62\% yield) to afford the title compound. Atropisomer separation following Step 5 (chiral SFC: Whelk-01 $(S, S), 250 \times 21$ $\mathrm{mm}, 5 \mu \mathrm{m}, 40 \% \mathrm{MeOH}\left(\mathrm{w} / 20 \mathrm{mM} \mathrm{NH}\right.$ ) $/ \mathrm{CO}_{2}, 50 \mathrm{~mL} / \mathrm{min}, 165$ bar) gave Compound $(R)-13$ as the second-eluting isomer and a white solid. ${ }^{1} \mathrm{H} \mathrm{NMR}\left(400 \mathrm{MHz}, \mathrm{CDCl}_{3}\right) \delta \mathrm{ppm} 7.80(1 \mathrm{H}, \mathrm{br} \mathrm{s}) 7.30-7.50(4 \mathrm{H}, \mathrm{m}) 7.09-7.19$ (4 H, m) 6.54-6.70 (1 $\mathrm{H}, \mathrm{m}) 6.51(1 \mathrm{H}, \mathrm{s}) 6.40(1 \mathrm{H}, \mathrm{dd}, J=16.79,1.45 \mathrm{~Hz}) 5.80(1 \mathrm{H}, \mathrm{dd}, J=10.60,1.20 \mathrm{~Hz}) 2.56-5.16(8 \mathrm{H}, \mathrm{m}) 1.41-1.53(3$ $\mathrm{H}, \mathrm{m}) 1.22(3 \mathrm{H}, \mathrm{d}, J=6.63 \mathrm{~Hz}) 1.07(3 \mathrm{H}, \mathrm{d}, J=6.84 \mathrm{~Hz}) . \mathrm{m} / \mathrm{z}(\mathrm{ESI},+\mathrm{ve}) 545.0(\mathrm{M}+\mathrm{H})^{+}$. Atropisomer configuration $(R$ vs. $S)$ assigned by analogy. ${ }^{17}$

\section{Compound $(R)-14$}

(R)-(S)-4-(4-Acryloyl-2-methylpiperazin-1-yl)-6-chloro-7-(2-chlorophenyl)-1-(2-isopropylphenyl)quinazolin2(1H)-one 

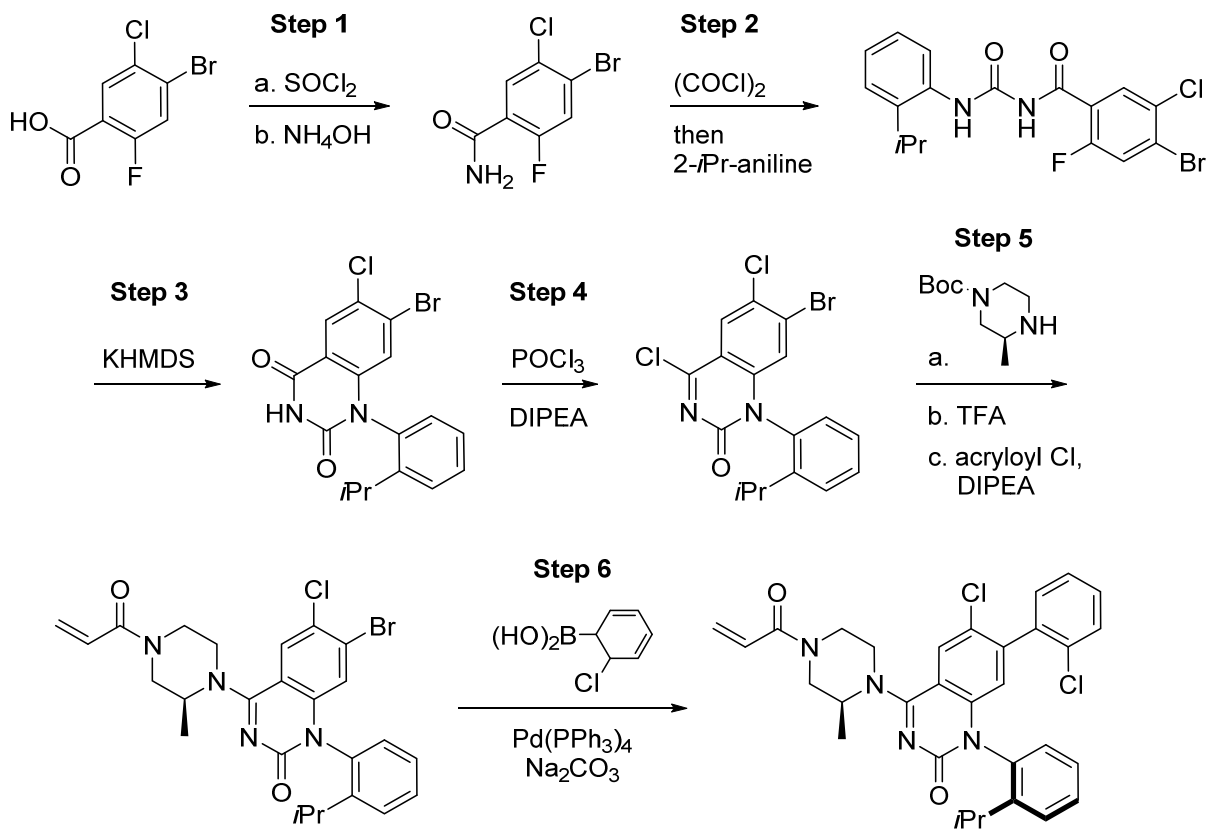

Compound $(R)-14$

Step 1: 4-Bromo-5-chloro-2-fluorobenzamide. A mixture of 4-bromo-5-chloro-2-fluorobenzoic acid (5.01 g, 19.8 mmol, Ark Pharm, Inc.) in thionyl chloride $(20 \mathrm{~mL}, 330 \mathrm{mmol})$ was stirred at $75{ }^{\circ} \mathrm{C}$ for $3 \mathrm{~h}$. The reaction mixture was concentrated in vacuo. The resulting residue was taken up in 1,4-dioxane $(100 \mathrm{~mL})$ and cooled to $0{ }^{\circ} \mathrm{C}$ before ammonium hydroxide $(30 \%$ aqueous, $20 \mathrm{~mL}, 158 \mathrm{mmol})$ was added slowly. The reaction mixture was stirred at $0{ }^{\circ} \mathrm{C}$ for $15 \mathrm{~min}$. The reaction mixture was concentrated in vacuo to give crude 4-bromo-5-chloro-2-fluorobenzamide as an off-white solid that was used directly in the next step. $\mathrm{m} / \mathrm{z}(\mathrm{ESI},+\mathrm{ve}) 251.9(\mathrm{M}+\mathrm{H})^{+}$.

Step 2: 4-Bromo-5-chloro-2-fluoro- $\mathrm{N}$-((2-isopropylphenyl)carbamoyl)benzamide. A mixture of 4-bromo-5-chloro2-fluorobenzamide (4.99 g, $19.8 \mathrm{mmol})$ and oxalyl chloride (2.0 M in DCM, 16.8 mL, $33.6 \mathrm{mmol})$ in 1,2-dichloroethane (99 $\mathrm{mL}$ ) was stirred under a reflux condenser and drying tube at $80^{\circ} \mathrm{C}$ for $70 \mathrm{~min}$ before being cooled to rt and concentrated in vacuo. A mixture of the resulting residue and 2-isopropylaniline $(2.94 \mathrm{~mL}, 20.8 \mathrm{mmol})$ in acetonitrile $(99 \mathrm{~mL})$ was stirred at $80{ }^{\circ} \mathrm{C}$ for $10 \mathrm{~min}$. The reaction mixture was cooled to $\mathrm{rt}$ and filtered. The solid was washed with water $(100 \mathrm{~mL})$ then dried in vacuo to give 4-bromo-5-chloro-2-fluoro- $N$-((2-isopropylphenyl)carbamoyl)benzamide (6.30 g, $77 \%$ yield over 2 steps) as a white solid. ${ }^{1} \mathrm{H}$ NMR $\left(400 \mathrm{MHz}, \mathrm{DMSO}-d_{6}\right) \delta 11.06$ (br. s., $\left.1 \mathrm{H}\right), 10.31(\mathrm{~s}, 1 \mathrm{H}) 7.97-8.05(\mathrm{~m}, 2 \mathrm{H}), 7.82(\mathrm{~d}, J=$ $7.2 \mathrm{~Hz}, 1 \mathrm{H}), 7.32-7.38(\mathrm{~m}, 1 \mathrm{H}), 7.14-7.25(\mathrm{~m}, 2 \mathrm{H}), 3.11$ (spt, $J=6.8 \mathrm{~Hz}, 1 \mathrm{H}), 1.24(\mathrm{~d}, J=6.8 \mathrm{~Hz}, 6 \mathrm{H}) .{ }^{19} \mathrm{~F} \mathrm{NMR}(376$ $\left.\mathrm{MHz}, \mathrm{DMSO}-d_{6}\right) \delta-113.55(\mathrm{~s}, 1 \mathrm{~F}) . \mathrm{m} / \mathrm{z}(\mathrm{ESI},+\mathrm{ve}) 413.0(\mathrm{M}+\mathrm{H})^{+}$.

Step 3: 7-Bromo-6-chloro-1-(2-isopropylphenyl)quinazoline-2,4(1H,3H)-dione. KHMDS (0.91 M in THF, $18.2 \mathrm{~mL}$, $16.8 \mathrm{mmol})$ was added to a stirred mixture of 4-bromo-5-chloro-2-fluoro- $\mathrm{N}$-((2-isopropylphenyl)carbamoyl)benzamide $(6.30 \mathrm{~g}, 15.2 \mathrm{mmol})$ in tetrahydrofuran $(76 \mathrm{~mL})$ at $-20{ }^{\circ} \mathrm{C}$. The mixture was stirred at $-20{ }^{\circ} \mathrm{C}$ for $15 \mathrm{~min}$. Additional KHMDS (0.91 M in THF, $18.2 \mathrm{~mL}, 16.8 \mathrm{mmol})$ was added, and the reaction mixture was stirred at $-20{ }^{\circ} \mathrm{C}$ for $10 \mathrm{~min}$ then at $\mathrm{rt}$ for $30 \mathrm{~min}$. The reaction mixture was quenched with saturated aqueous ammonium chloride $(100 \mathrm{~mL})$ and stirred at $\mathrm{rt}$ for $15 \mathrm{~min}$. The organic layer was separated, and the aqueous layers was extracted with EtOAc (100 mL). The combined organic layers were dried over anhydrous $\mathrm{Na}_{2} \mathrm{SO}_{4}$, filtered, and concentrated in vacuo. The resulting crude product was slurried in DCM $(50 \mathrm{~mL})$ for $1 \mathrm{~h}$ and filtered to give 7-bromo-6-chloro-1-(2-isopropylphenyl)quinazoline- $2,4(1 \mathrm{H}, 3 \mathrm{H})$-dione (5.73 g, 96\% yield) as a white solid. ${ }^{1} \mathrm{H}$ NMR (400 MHz, DMSO-d6) $\delta$ ppm 11.57-11.89 (1 H, br s), 8.12 (1 H, s), $7.55-$ $7.65(2 \mathrm{H}, \mathrm{m}), 7.41-7.47(1 \mathrm{H}, \mathrm{m}), 7.32-7.37(1 \mathrm{H}, \mathrm{m}), 6.53(1 \mathrm{H}, \mathrm{s}), 2.73(1 \mathrm{H}, \mathrm{sept}, J=6.75 \mathrm{~Hz}), 1.11(3 \mathrm{H}, \mathrm{d}, J=6.85$ $\mathrm{Hz}), 1.05(3 \mathrm{H}, \mathrm{d}, J=6.85 \mathrm{~Hz}) . \mathrm{m} / \mathrm{z}(\mathrm{ESI},+\mathrm{ve}) 392.9(\mathrm{M}+\mathrm{H})^{+}$.

Step 4: 7-Bromo-4,6-dichloro-1-(2-isopropylphenyl)quinazolin-2(1H)-one. ${ }^{\mathbf{1 6}}$ To a stirred mixture of 7-bromo-6chloro-1-(2-isopropylphenyl)quinazoline-2,4(1H,3H)-dione $(470 \mathrm{mg}, 1.19 \mathrm{mmol})$ and DIPEA $(0.6 \mathrm{~mL}, 4 \mathrm{mmol})$ in acetonitrile $(11 \mathrm{~mL})$ was added phosphorus oxychloride $(0.9 \mathrm{~mL}, 6 \mathrm{mmol})$. The reaction mixture was stirred at $80{ }^{\circ} \mathrm{C}$ for 2 $\mathrm{h}$, cooled to $\mathrm{rt}$, and concentrated in vacuo to give crude 7-bromo-4,6-dichloro-1-(2-isopropylphenyl)quinazolin-2(1H)-one that was used directly in the next step. $\mathrm{m} / \mathrm{z}(\mathrm{ESI},+\mathrm{ve}) 413.0(\mathrm{M}+\mathrm{H})^{+}$.

Step 5: (S)-4-(4-Acryloyl-2-methylpiperazin-1-yl)-7-bromo-6-chloro-1-(2-isopropylphenyl)quinazolin-2(1H)-one. A mixture of 7-bromo-4,6-dichloro-1-(2-isopropylphenyl)quinazolin-2(1H)-one (492 mg, $1.19 \mathrm{mmol})$, (S)-4-Boc-2-methyl piperazine (478 mg, $2.38 \mathrm{mmol}$, CNH Technologies, Inc.) and DIPEA (0.62 mL, $3.58 \mathrm{mmol})$ in DMF (2 mL) was stirred at 
rt for $10 \mathrm{~min}$. Ice water $(10 \mathrm{~mL})$ was added, and the mixture was stirred for $15 \mathrm{~min}$. The resulting precipitate was filtered and washed with water to give $(S)$-tert-butyl 4-(7-bromo-6-chloro-1-(2-isopropylphenyl)-2-oxo-1,2-dihydroquinazolin-4yl)-3-methylpiperazine-1-carboxylate $\left(690 \mathrm{mg}\right.$, quantitative over 2 steps) as a yellow solid. $\mathrm{m} / \mathrm{z}(\mathrm{ESI},+\mathrm{ve}) 577.1(\mathrm{M}+\mathrm{H})^{+}$.

A solution of (S)-tert-butyl 4-(7-bromo-6-chloro-1-(2-isopropylphenyl)-2-oxo-1,2-dihydroquinazolin-4-yl)-3methylpiperazine-1-carboxylate $(297 \mathrm{mg}, 0.52 \mathrm{mmol})$ in DCM $(2.0 \mathrm{~mL})$ was treated with trifluoroacetic acid $(2.0 \mathrm{~mL}, 27$ $\mathrm{mmol}$ ) and stirred for $15 \mathrm{~min}$ at rt. The reaction mixture was concentrated in vacuo to afford crude (S)-7-bromo-6-chloro1-(2-isopropylphenyl)-4-(2-methylpiperazin-1-yl)quinazolin-2(1H)-one. $\mathrm{m} / \mathrm{z}(\mathrm{ESI},+\mathrm{ve}) 477.0(\mathrm{M}+\mathrm{H})^{+}$.

To a stirred mixture of crude $(S)$-7-bromo-6-chloro-1-(2-isopropylphenyl)-4-(2-methylpiperazin-1-yl)quinazolin-2(1H)one, and DIPEA $(200 \mathrm{mg}, 0.269 \mathrm{~mL}, 1.55 \mathrm{mmol})$ in DCM $(2 \mathrm{~mL})$ at $0{ }^{\circ} \mathrm{C}$ was added acryloyl chloride $(0.26 \mathrm{M}$ in DCM, 4.0 $\mathrm{mL}, 1.0 \mathrm{mmol})$. The reaction mixture was stirred at $0{ }^{\circ} \mathrm{C}$ for $20 \mathrm{~min}$ then concentrated in vacuo. Chromatographic purification of the residue (silica gel, 0-50\% (3:1) EtOAc-EtOH/heptane) gave (S)-4-(4-acryloyl-2-methylpiperazin-1-yl)7-bromo-6-chloro-1-(2-isopropylphenyl)quinazolin-2(1H)-one $(223 \mathrm{mg}, 82 \%$ yield over $2 \mathrm{steps})$ as a light yellow solid. ${ }^{1} \mathrm{H}$ NMR (400 MHz, DMSO-d 6 ) $\delta$ ppm 7.91-8.08 (m, $1 \mathrm{H}), 7.49-7.67$ (m, $2 \mathrm{H}), 7.41$ (br d, J = 5.8 Hz, $1 \mathrm{H}), 7.21$ (br s, $1 \mathrm{H})$, 6.76-6.98 (m, 1 H), 6.52-6.67 (m, 1 H), 6.09-6.29 (m, $1 \mathrm{H}), 5.75$ (br s, 1 H), 4.61-4.96 (m, $1 \mathrm{H}), 4.23-4.48$ (m, $1 \mathrm{H}), 3.93-$ $4.21(\mathrm{~m}, 2 \mathrm{H}), 3.50-3.77(\mathrm{~m}, 1 \mathrm{H}), 3.33-3.49(\mathrm{~m}, 1 \mathrm{H}), 3.23-3.28(\mathrm{~m}, 1 \mathrm{H}), 2.94-3.24(\mathrm{~m}, 1 \mathrm{H}), 1.27$ (br d, J = 9.3 Hz, $6 \mathrm{H})$, 1.09 (br s, $3 \mathrm{H}) . \quad \mathrm{m} / \mathrm{z}$ (ESI, +ve) $531.1(\mathrm{M}+\mathrm{H})^{+}$.

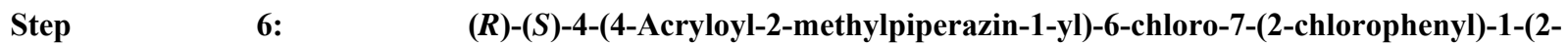

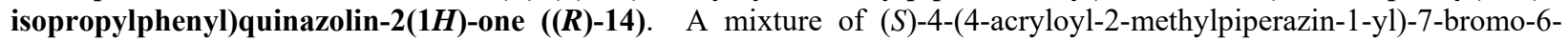
chloro-1-(2-isopropylphenyl)quinazolin-2(1H)-one (45 mg, $0.085 \mathrm{mmol})$, 2-chlorobenzeneboronic acid (45 mg, $0.09 \mathrm{mmol}$, Alfa Aesar), sodium carbonate $(36 \mathrm{mg}, 0.34 \mathrm{mmol})$, and tetrakis(triphenylphosphine)palladium $(9.8 \mathrm{mg}, 8.5 \mu \mathrm{mol}) \mathrm{in} 1,4-$ dioxane $(0.6 \mathrm{~mL})$ and water $(0.15 \mathrm{~mL})$ was stirred at $90^{\circ} \mathrm{C}$ for $1 \mathrm{~h}$. The reaction mixture was concentrated in vacuo to give Compound 14 (30 mg, 63\% yield) as a green solid. Chromatographic purification of the residue (silica gel, 0-50\% (3:1) EtOAc-EtOH/heptane) gave the title compound as a mixture of atropisomers. Atropisomer separation (chiral SFC: Whelk$01(S, S), 250 \times 21 \mathrm{~mm}, 5 \mu \mathrm{m}, 30 \% \mathrm{MeOH} / \mathrm{CO}_{2}(\mathrm{w} / 20 \mathrm{mM} \mathrm{NH}$ ), $50 \mathrm{~mL} / \mathrm{min}, 158$ bar) afforded $(R)-(S)-4-(4-\mathrm{acryloyl}-2-$ methylpiperazin-1-yl)-6-chloro-7-(2-chlorophenyl)-1-(2-isopropylphenyl)quinazolin-2(1H)-one as the second-eluting isomer and a white solid. ${ }^{1} \mathrm{H}$ NMR (400 MHz, DMSO-d $) \delta$ ppm 8.01 (s, $\left.1 \mathrm{H}\right), 7.49-7.59(\mathrm{~m}, 2 \mathrm{H}), 7.31-7.49$ (m, $\left.4 \mathrm{H}\right)$, 7.10-7.26 (m, 2 H), 6.77-6.95 (m, $1 \mathrm{H}), 6.16-6.26$ (m, $2 \mathrm{H}), 5.73-5.82$ (m, $1 \mathrm{H}), 4.90$ (br d, J = 1.7 Hz, $1 \mathrm{H}), 4.21-4.53$ (m, $1 \mathrm{H}), 3.98-4.20(\mathrm{~m}, 2 \mathrm{H}), 3.38-3.85(\mathrm{~m}, 2 \mathrm{H}), 2.98-3.13(\mathrm{~m}, 1 \mathrm{H}), 2.53-2.61(\mathrm{~m}, 1 \mathrm{H}), 1.31(\mathrm{br} \mathrm{d}, J=6.4 \mathrm{~Hz}, 3 \mathrm{H}), 1.11(\mathrm{br}$ $\mathrm{t}, J=6.6 \mathrm{~Hz}, 3 \mathrm{H}), 0.93-1.06(\mathrm{~m}, 3 \mathrm{H}) . \mathrm{m} / \mathrm{z}(\mathrm{ESI},+\mathrm{ve}) 561.2(\mathrm{M}+\mathrm{H})^{+}$. Atropisomer configuration $(R$ vs. $S)$ assigned by analogy. ${ }^{17}$

\section{Compound 15}

(S)-4-(4-Acryloyl-2-methylpiperazin-1-yl)-6-chloro-1-(2-isopropylphenyl)-7-(2-

(trifluoromethyl)phenyl)quinazolin-2(1H)-one was prepared according to the procedure described for Compound 32 using 4-bromo-5-chloro-2-fluorobenzoic acid (OxChem Corporation) in Step 1 and 2-(trifluoromethyl)phenylboronic acid (Combi-Blocks, Inc.) and SPhos Pd G3 (Strem Chemicals, Inc.) in DME in Step 5 (21\% yield) to afford the title compound as an off-white solid. ${ }^{1} \mathrm{H}$ NMR $\left(500 \mathrm{MHz}\right.$, DMSO- $\left.d_{6}\right) \delta \mathrm{ppm} 7.96-8.01(1 \mathrm{H}, \mathrm{m}) 7.80(1 \mathrm{H}, \mathrm{dd}, J=7.85,3.05 \mathrm{~Hz}) 7.72(1$ $\mathrm{H}, \mathrm{q}, J=7.27 \mathrm{~Hz}) 7.61-7.67(1 \mathrm{H}, \mathrm{m}) 7.48-7.52$ (1 H, m) 7.40-7.45 (1 H, m) 7.29-7.35 (1 H, m) 7.24-7.29 (1 H, m) 7.10$7.18(1 \mathrm{H}, \mathrm{m}) 6.81-6.93(1 \mathrm{H}, \mathrm{m}) 6.17-6.24(2 \mathrm{H}, \mathrm{m}) 5.76(1 \mathrm{H}, \mathrm{dd}, J=10.38,2.21 \mathrm{~Hz}) 2.48-4.91(9 \mathrm{H}, \mathrm{m}) 1.30-1.36(3 \mathrm{H}$, m) 1.07-1.11 (3 H, m) 0.93-0.99 (3 H, m). m/z (ESI, +ve) $595.2(\mathrm{M}+\mathrm{H})^{+}$.

\section{Compound (R)-16}

(R)-4-((S)-4-Acryloyl-2-methylpiperazin-1-yl)-6-chloro-7-(2-fluoro-6-hydroxyphenyl)-1-(2-

isopropylphenyl)quinazolin-2(1H)-one was prepared according to the procedure described for Compound $(R)-\mathbf{9}$, using $(S)$ tert-butyl 3-methylpiperazine-1-carboxylate in Step 6 (38\% yield) to afford the title compound as a mixture of atropisomers. Atropisomer separation following Step 9 (chiral SFC: Whelk-01 (S,S), $250 \times 21 \mathrm{~mm}, 5 \mu \mathrm{m}, 30 \% \mathrm{EtOH}(\mathrm{w} / 20 \mathrm{mM}$ $\left.\mathrm{NH}_{3}\right) / \mathrm{CO}_{2}, 70 \mathrm{~g} / \mathrm{min}, 187$ bar) gave Compound $(R)-\mathbf{1 6}$ as the second-eluting isomer and an off-white solid. ${ }^{1} \mathrm{H} \mathrm{NMR}(400$ $\left.\mathrm{MHz}_{2} \mathrm{CDCl}_{3}\right) \delta 7.79$ (br s, $\left.1 \mathrm{H}\right) 7.35-7.48(\mathrm{~m}, 2 \mathrm{H}) 7.21-7.32(\mathrm{~m}, 1 \mathrm{H}) 7.04-7.17$ (m, $\left.2 \mathrm{H}\right) 6.68(\mathrm{~d}, \mathrm{~J}=8.3 \mathrm{~Hz}, 1 \mathrm{H}) 6.49-$ $6.66(\mathrm{~m}, 3 \mathrm{H}) 6.36(\mathrm{br} \mathrm{d}, J=16.6 \mathrm{~Hz}, 1 \mathrm{H}) 5.78(\mathrm{dd}, J=10.4,1.9 \mathrm{~Hz}, 1 \mathrm{H}) 4.29-5.11(\mathrm{~m}, 2 \mathrm{H}) 3.46-4.02(\mathrm{~m}, 3 \mathrm{H}) 2.93-$ $3.29(\mathrm{~m}, 2 \mathrm{H}) 2.49-2.68(\mathrm{~m}, 1 \mathrm{H}) 1.48(\mathrm{dd}, J=14.5,2.1 \mathrm{~Hz}, 6 \mathrm{H}) 1.03$ (br d, $J=6.0 \mathrm{~Hz}, 3 \mathrm{H}) .{ }^{19} \mathrm{~F} \mathrm{NMR}\left(377 \mathrm{MHz}, \mathrm{CDCl}_{3}\right)$ $\delta-113.4--113.3(\mathrm{~m}, 1 \mathrm{~F})-114.0--113.8(\mathrm{~m}, 1 \mathrm{~F}) . \mathrm{m} / \mathrm{z}(\mathrm{ESI},+\mathrm{ve}) 561.2(\mathrm{M}+\mathrm{H})^{+}$. Atropisomer configuration $(R$ vs. $S)$ assigned by analogy. ${ }^{17}$ 


\section{Compound $(R)-17$}

(R)-4-(4-Acryloylpiperazin-1-yl)-6-chloro-7-(2-fluoro-6-hydroxyphenyl)-1-(2-isopropylphenyl)pyrido[2,3d]pyrimidin-2(1H)-one was prepared according to the procedure described for Compound $(R)-\mathbf{1 4}$, using 2,5,6trichloronicotinic acid (Combi-Blocks, Inc.) in Step 1, 1-(tert-butoxycarbonyl)-piperazine (Sigma-Aldrich) in Step 5, and 2fluoro-6-hydroxyphenylboronic acid (Combi-Blocks, Inc.) in Step 6 (21\% yield) to afford the title compound as a mixture of atropisomers. Separation of atropisomers (chiral SFC: IC, $150 \times 21 \mathrm{~mm}, 5 \mu \mathrm{m}, 40 \% \mathrm{MeOH}\left(\mathrm{w} / 20 \mathrm{mM} \mathrm{NH}_{3}\right) / \mathrm{CO}_{2}, 80$ $\mathrm{g} / \mathrm{min}, 102 \mathrm{bar}$ ) afforded Compound $(R)-17$ as the first eluting isomer, light yellow solid. ${ }^{1} \mathrm{H}$ NMR (400 MHz, DMSO- $\left.d_{6}\right)$ $\delta$ ppm $10.04($ br s, $1 \mathrm{H}), 8.46(\mathrm{~s}, 1 \mathrm{H}), 7.36-7.43(\mathrm{~m}, 1 \mathrm{H}), 7.29-7.35(\mathrm{~m}, 1 \mathrm{H}), 7.16-7.27$ (m, $2 \mathrm{H}), 7.07$ (br d, $J=7.9 \mathrm{~Hz}$, $1 \mathrm{H}), 6.83(\mathrm{dd}, J=16.8,10.4 \mathrm{~Hz}, 1 \mathrm{H}), 6.69(\mathrm{~d}, J=8.3 \mathrm{~Hz}, 1 \mathrm{H}), 6.64(\mathrm{brt}, J=8.7 \mathrm{~Hz}, 1 \mathrm{H}), 6.19(\mathrm{dd}, J=16.7,2.4 \mathrm{~Hz}, 1$ H), 5.71-5.79 (m, $1 \mathrm{H}), 3.90-4.10(\mathrm{~m}, 4 \mathrm{H}), 3.68-3.89(\mathrm{~m}, 4 \mathrm{H}), 2.53-2.59(\mathrm{~m}, 1 \mathrm{H}), 1.06(\mathrm{~d}, J=6.8 \mathrm{~Hz}, 3 \mathrm{H}), 0.96(\mathrm{~d}, J=$ $6.8 \mathrm{~Hz}, 3 \mathrm{H}) .{ }^{19} \mathrm{~F}$ NMR $\left(376 \mathrm{MHz}, \mathrm{DMSO}-d_{6}\right) \delta \mathrm{ppm}-115.36(\mathrm{br} \mathrm{s}, 1 \mathrm{~F}) . \mathrm{m} / \mathrm{z}(\mathrm{ESI},+\mathrm{ve}) 548.2(\mathrm{M}+\mathrm{H})^{+}$. Atropisomer configuration ( $R$ vs. $S$ ) assigned crystallographically.

\section{Compound $(R)-18$}

(R)-4-((S)-4-Acryloyl-2-methylpiperazin-1-yl)-6-chloro-7-(2-fluoro-6-hydroxyphenyl)-1-(2isopropylphenyl)pyrido[2,3-d]pyrimidin-2(1H)-one.
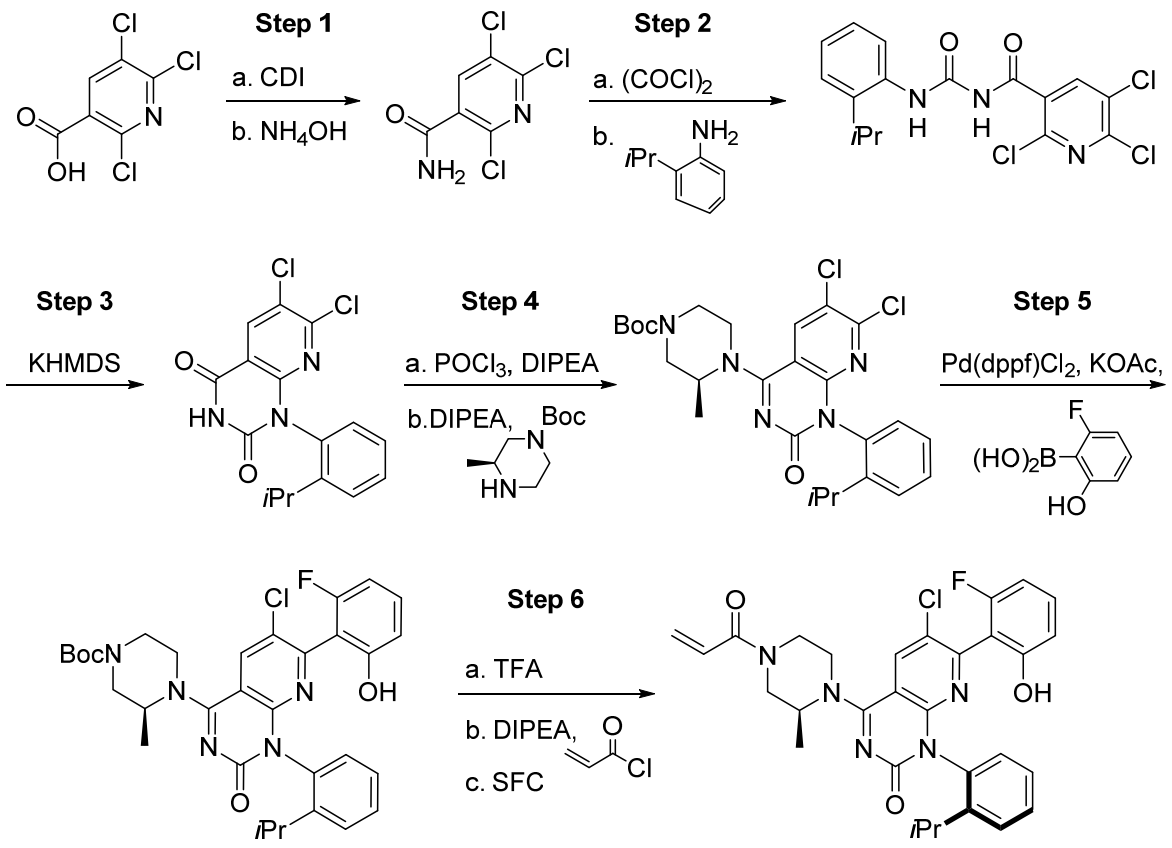

Compound $(R)-18$

Step 1: 2,5,6-Trichloronicotinamide. A 5-L reactor was charged with 2,5,6-trichloronicotinic acid (183 g, $808 \mathrm{mmol}$; Combi-Blocks, Inc.) and 2-methyltetrahydrofuran $(1.8 \mathrm{~L})$; the light orange solution was stirred at $18{ }^{\circ} \mathrm{C}$, then $\mathrm{CDI}(138 \mathrm{~g}$, $848 \mathrm{mmol}$ ) was added over 5 portions allowing the slurry to reach a maximum temperature of $22^{\circ} \mathrm{C}$. The reaction mixture was stirred at $40{ }^{\circ} \mathrm{C}$ for $90 \mathrm{~min}$, cooled to $5{ }^{\circ} \mathrm{C}$, then ammonium hydroxide $(0.315 \mathrm{~L}, 242 \mathrm{mmol})$ was added slowly via addition funnel when the slurry reached a maximum temperature of $18{ }^{\circ} \mathrm{C}$. After stirring at $22{ }^{\circ} \mathrm{C}$ for 45 min, the organic layer was washed with saturated, aqueous ammonium chloride $(3 \times 750 \mathrm{~mL})$ and $1 \mathrm{~N}$ hydrochloric acid $(2 \times 300 \mathrm{~mL})$; the organic layer was separated, dried over anhydrous $\mathrm{Na}_{2} \mathrm{SO}_{4}$, and concentrated in vacuo. The crude solids were recrystallized in $\sim 75 \mathrm{~g}$ batches from ethyl acetate $(2 \mathrm{~mL} / \mathrm{g})$ at $70{ }^{\circ} \mathrm{C}$, cooled to $\mathrm{rt}$, and washed with cold ethyl acetate. The combined mother liquors were evaporated to dryness under reduced pressure and recrystallized from ethyl acetate. The solids were combined and dried in a vacuum oven at $50{ }^{\circ} \mathrm{C}$ with a nitrogen bleed to give 2,5,6-trichloronicotinamide. $\mathrm{m} / \mathrm{z}(\mathrm{ESI},+\mathrm{ve}$ ion): $224.9 / 227.0(\mathrm{M}+\mathrm{H})^{+}$.

Step-2: $\quad$ 2,5,6-Trichloro- $N$-((2-isopropylphenyl)carbamoyl)nicotinamide. $\quad$ A $\quad$ suspension of 2,5,6trichloronicotinamide $(6.70 \mathrm{~g}, 29.7 \mathrm{mmol})$ in 1,2-dichloroethane $(100 \mathrm{~mL})$ was treated with oxalyl chloride $(3.02 \mathrm{~mL}, 35.7$ $\mathrm{mmol})$ at rt. The reaction mixture was stirred at $80^{\circ} \mathrm{C}$ for $30 \mathrm{~min}$. The resulting white suspension solution was evaporated to leave a slurry to which was added acetonitrile $(100 \mathrm{~mL})$ then 2-isopropylaniline $(4.63 \mathrm{~mL}, 32.7 \mathrm{mmol}$, Sigma-Aldrich) at rt. The resulting suspension was stirred for $15 \mathrm{~min}$; the white solid was collected by filtration, washed with acetonitrile, and 
dried in vacuo to give 2,5,6-trichloro- $N$-((2-isopropylphenyl)carbamoyl)nicotinamide ( $8.55 \mathrm{~g}, 74 \%$ yield). $\mathrm{m} / \mathrm{z}$ (ESI, +ve) 386.0/388.0 $(\mathrm{M}+\mathrm{H})^{+}$.

Step-3: 7-Dichloro-1-(2-isopropylphenyl)pyrido[2,3-d]pyrimidine-2,4(1H,3H)-dione. A mixture of 2,5,6-trichloro$\mathrm{N}$-((2-isopropylphenyl)carbamoyl)nicotinamide $(8.55 \mathrm{~g}, 22.1 \mathrm{mmol})$ in tetrahydrofuran $(73.8 \mathrm{~mL})$ at $0{ }^{\circ} \mathrm{C}$ was treated with potassium bis(trimethylsilyl)amide $(1 \mathrm{M}$ in THF, $44.3 \mathrm{~mL}, 44.3 \mathrm{mmol})$. The resulting mixture was stirred at $0{ }^{\circ} \mathrm{C}$ for $10 \mathrm{~min}$ and at $\mathrm{rt}$ for $30 \mathrm{~min}$. The reaction mixture was quenched with saturated aqueous $\mathrm{NH} 4 \mathrm{Cl}(100 \mathrm{~mL})$ and extracted with EtOAc $(200 \mathrm{~mL})$. The organic layer was separated, washed with brine $(150 \mathrm{~mL})$, dried over $\mathrm{Na}_{2} \mathrm{SO}_{4}$, filtered, and concentrated in vacuo. The crude product was sonicated in $\mathrm{MeOH}(20 \mathrm{~mL})$. The resulting solid was collected by filtration, washed with $\mathrm{MeOH}$ and dried to give pure 6,7-dichloro-1-(2-isopropylphenyl)pyrido[2,3-d]pyrimidine-2,4(1H,3H)-dione (7.17 g, 92\% yield) as a tan solid. ${ }^{1} \mathrm{H}$ NMR $\left(400 \mathrm{MHz}\right.$, DMSO- $\left.d_{6}\right) \delta \mathrm{ppm} 12.10(\mathrm{~s}, 1 \mathrm{H}), 8.52(\mathrm{~s}, 1 \mathrm{H}), 7.38-7.60(\mathrm{~m}, 2 \mathrm{H}), 7.12-7.38(\mathrm{~m}$, $2 \mathrm{H}), 2.74(\mathrm{dt}, J=13.5,6.8 \mathrm{~Hz}, 1 \mathrm{H}), 1.08(\mathrm{~d}, J=6.8 \mathrm{~Hz}, 3 \mathrm{H}), 1.03(\mathrm{~d}, J=6.8 \mathrm{~Hz}, 3 \mathrm{H}) . \mathrm{m} / \mathrm{z}(\mathrm{ESI},+\mathrm{ve}) 350.0(\mathrm{M}+\mathrm{H})^{+}$.

Step-4: (S)-tert-Butyl 4-(6,7-dichloro-1-(2-isopropylphenyl)-2-oxo-1,2-dihydropyrido[2,3-d]pyrimidin-4-yl)-3methylpiperazine-1-carboxylate. ${ }^{16}$ To a mixture of 6,7-dichloro-1-(2-isopropylphenyl)pyrido[2,3- $d$ ]pyrimidine2,4(1H,3H)-dione $(2.04 \mathrm{~g}, 5.83 \mathrm{mmol})$ and DIPEA $(3.0 \mathrm{~mL}, 18 \mathrm{mmol})$ in acetonitrile $(39 \mathrm{~mL})$ was added POCl $\mathrm{P}_{3}(2.7 \mathrm{~mL}$, $18 \mathrm{mmol}$ ) at $\mathrm{rt}$; the resulting solution was stirred at $80{ }^{\circ} \mathrm{C}$ for $30 \mathrm{~min}$ and concentrated in vacuo to give the crude $4,6,7-$ trichloro-1-(2-isopropylphenyl)pyrido[2,3-d]pyrimidin-2(1H)-one as a brown solid. $\mathrm{m} / \mathrm{z}(\mathrm{ESI},+\mathrm{ve}) 370.0(\mathrm{M}+\mathrm{H})^{+}$.

To a mixture of the above crude 4,6,7-trichloro-1-(2-isopropylphenyl)pyrido[2,3-d]pyrimidin-2(1H)-one $(5.83 \mathrm{mmol})$, (S)-4-N-Boc-2-methyl piperazine (1.75 g, $8.75 \mathrm{mmol}$, CNH Technologies, Inc.) and DIPEA (3.0 mL, $18 \mathrm{mmol}) \mathrm{in} \mathrm{DMF} \mathrm{(19}$ $\mathrm{mL})$ was stirred at $\mathrm{rt}$ for $10 \mathrm{~min}$. Ice water $(40 \mathrm{~mL})$ was added to the reaction mixture and stirred for $15 \mathrm{~min}$. The resulting precipitate was collected by filtration, washed with water, and dried to give (S)-tert-butyl 4-(6,7-dichloro-1-(2isopropylphenyl)-2-oxo-1,2-dihydropyrido[2,3-d]pyrimidin-4-yl)-3-methylpiperazine-1-carboxylate (3.02 g, 97\% yield) as a light orange solid . ${ }^{1} \mathrm{H}$ NMR $(400 \mathrm{MHz}$, DMSO-d $) \delta 8.39(\mathrm{~d}, J=19.9 \mathrm{~Hz}, 1 \mathrm{H}), 7.37-7.54(\mathrm{~m}, 2 \mathrm{H}), 7.22-7.33(\mathrm{~m}, 1 \mathrm{H})$, 7.06-7.15 (m, $1 \mathrm{H}), 4.66-4.96(\mathrm{~m}, 1 \mathrm{H}), 4.02-4.25(\mathrm{~m}, 1 \mathrm{H}), 3.88-4.01(\mathrm{~m}, 1 \mathrm{H}), 3.77-3.86(\mathrm{~m}, 1 \mathrm{H}), 3.55-3.77(\mathrm{~m}, 1 \mathrm{H})$, 2.89-3.17 (m, 2 H), 2.44 (m, $1 \mathrm{H}), 1.45$ (s, $9 \mathrm{H}), 1.07$ (br d, $J=6.8 \mathrm{~Hz}, 3 \mathrm{H}), 1.01$ (br d, $J=6.8 \mathrm{~Hz}, 6 \mathrm{H}) . m / z($ ESI, +ve) $532.2(\mathrm{M}+\mathrm{H})^{+}$.

Step-5: $\quad$ (3S)-tert-Butyl 4-(6-chloro-7-(2-fluoro-6-hydroxyphenyl)-1-(2-isopropylphenyl)-2-oxo-1,2dihydropyrido[2,3-d]pyrimidin-4-yl)-3-methylpiperazine-1-carboxylate. To a solution of (S)-tert-butyl 4-(6,7-dichloro1-(2-isopropylphenyl)-2-oxo-1,2-dihydropyrido[2,3-d]pyrimidin-4-yl)-3-methylpiperazine-1-carboxylate (1.20 g, 2.25 $\mathrm{mmol})$ in 1,4-dioxane $(15 \mathrm{~mL})$ was added 2-fluoro-6-hydroxyphenylboronic acid (1.05 g, $6.76 \mathrm{mmol}$, Combi-Blocks Inc.), potassium acetate $(1.11 \mathrm{~g}, 11.3 \mathrm{mmol})$, and (1,1'-bis(diphenylphosphino)ferrocene)dichloropalladium (0.17 $\mathrm{g}, 0.23 \mathrm{mmol})$. The mixture was degassed with $\mathrm{N}_{2}$ for $5 \mathrm{~min}$ and then stirred at $80{ }^{\circ} \mathrm{C}$ for $40 \mathrm{~min}$. The resulting mixture was diluted with $\mathrm{H}_{2} \mathrm{O}(50 \mathrm{~mL})$ and extracted with EtOAc $(2 \times 150 \mathrm{~mL})$. The combined organic extracts were dried over $\mathrm{Na}_{2} \mathrm{SO}_{4}$ and concentrated. Chromatographic purification (silica gel; 0-15\% MeOH/DCM) gave (3S)-tert-butyl 4-(6-chloro-7-(2-fluoro6-hydroxyphenyl)-1-(2-isopropylphenyl)-2-oxo-1,2-dihydropyrido[2,3-d]pyrimidin-4-yl)-3-methylpiperazine-1-

carboxylate $\left(1.31 \mathrm{~g}, 96 \%\right.$ yield) as a yellow solid. ${ }^{1} \mathrm{H}$ NMR $\left(400 \mathrm{MHz}, \mathrm{MeOH}-\mathrm{d}_{4}\right) \delta 8.29(\mathrm{~d}, J=4.6 \mathrm{~Hz}, 1 \mathrm{H}), 7.28-7.38(\mathrm{~m}$, $2 \mathrm{H}), 7.19(\mathrm{dt}, J=1.6,7.5 \mathrm{~Hz}, 1 \mathrm{H}), 7.13(\mathrm{dt}, J=6.7,8.3 \mathrm{~Hz}, 1 \mathrm{H}), 7.02(\mathrm{~d}, J=7.9 \mathrm{~Hz}, 1 \mathrm{H}), 6.56(\mathrm{~d}, J=8.3 \mathrm{~Hz}, 1 \mathrm{H}), 6.50$ $(\mathrm{t}, J=8.8 \mathrm{~Hz}, 1 \mathrm{H}), 4.83-4.95(\mathrm{~m}, 1 \mathrm{H}), 4.24-4.34(\mathrm{~m}, 1 \mathrm{H}), 4.05(\mathrm{br} \mathrm{d}, J=13.1 \mathrm{~Hz}, 1 \mathrm{H}), 3.89-3.94(\mathrm{~m}, 1 \mathrm{H}), 3.63-3.77(\mathrm{~m}$, $1 \mathrm{H}), 3.28-3.37(\mathrm{~m}, 1 \mathrm{H}), 3.04-3.22(\mathrm{~m}, 1 \mathrm{H}), 2.44-2.63(\mathrm{~m}, 1 \mathrm{H}), 1.41-1.47(\mathrm{~m}, 12 \mathrm{H}), 1.10(\mathrm{dd}, J=1.2,6.8 \mathrm{~Hz}, 3 \mathrm{H}), 0.96(\mathrm{~d}$, $J=6.8 \mathrm{~Hz}, 3 \mathrm{H}) ;-\mathrm{OH}$ was not observed. $\mathrm{m} / \mathrm{z}(\mathrm{ESI},+\mathrm{ve}) 608.2(\mathrm{M}+\mathrm{H})^{+}$.

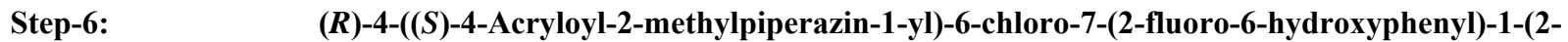
isopropylphenyl)pyrido[2,3-d]pyrimidin-2(1H)-one $((\boldsymbol{R})-18)$. A solution of (3S)-tert-butyl 4-(6-chloro-7-(2-fluoro-6hydroxyphenyl)-1-(2-isopropylphenyl)-2-oxo-1,2-dihydropyrido[2,3-d]pyrimidin-4-yl)-3-methylpiperazine-1-carboxylate $(130 \mathrm{mg}, 0.21 \mathrm{mmol})$ in DCM $(2 \mathrm{~mL})$ was treated with trifluoroacetic acid $(1.0 \mathrm{~mL}, 13 \mathrm{mmol})$ at $\mathrm{rt}$ and stirred for $30 \mathrm{~min}$. The reaction was concentrated to afford 6-chloro-7-(2-fluoro-6-hydroxyphenyl)-1-(2-isopropylphenyl)-4-((S)-2methylpiperazin-1-yl)pyrido[2,3-d]pyrimidin-2(1H)-one. $\mathrm{m} / \mathrm{z}(\mathrm{ESI},+\mathrm{ve}) 508.2(\mathrm{M}+\mathrm{H})^{+}$.

To a mixture of 6-chloro-7-(2-fluoro-6-hydroxyphenyl)-1-(2-isopropylphenyl)-4-((S)-2-methylpiperazin-1yl)pyrido[2,3-d]pyrimidin-2(1H)-one and DIPEA $(0.2 \mathrm{~mL}, 1.07 \mathrm{mmol})$ in DCM $(2.0 \mathrm{~mL})$ was added acryloyl chloride $(0.26$ $\mathrm{M}$ in DCM, $0.5 \mathrm{~mL}, 0.13 \mathrm{mmol})$ at $0{ }^{\circ} \mathrm{C}$; the solution was stirred for $1 \mathrm{~h}$ at $0{ }^{\circ} \mathrm{C}$ and was concentrated in vacuo. The crude material was adsorbed onto a plug of silica gel and chromatographed (silica gel; 0-5\% MeOH/DCM) to give 4-((S)-4acryloyl-2-methylpiperazin-1-yl)-6-chloro-7-(2-fluoro-6-hydroxyphenyl)-1-(2-isopropylphenyl)pyrido[2,3-d]pyrimidin$2(1 \mathrm{H})$-one (92 mg, 76\% yield) as a mixture of atropisomers (light-yellow solid). $\mathrm{m} / \mathrm{z}(\mathrm{ESI},+\mathrm{ve}) 562.2(\mathrm{M}+\mathrm{H})^{+}$.

Atropisomer separation following Step 6b (chiral SFC: IC, $20 \times 150 \mathrm{~mm}, 5 \mu \mathrm{m}, 25 \% \mathrm{MeOH}\left(\mathrm{w} / \mathrm{NH}_{3}\right) / \mathrm{CO}_{2}, 80 \mathrm{~g} / \mathrm{min}$, 102 bar) gave Compound $(R)-\mathbf{1 8}(62.9 \mathrm{mg})$ as the first-eluting isomer as a yellow solid. ${ }^{1} \mathrm{H} \mathrm{NMR}\left(400 \mathrm{MHz}, \mathrm{DMSO}-d_{6}\right) \delta$ ppm 9.95-10.21 (m, 1 H), 8.31-8.47 (m, 1 H), 7.36-7.44 (m, 1 H), 7.29-7.36 (m, 1 H), 7.17-7.27 (m, 2 H), 7.09 (br d, J = $7.9 \mathrm{~Hz}, 1 \mathrm{H}), 6.80-6.95(\mathrm{~m}, 1 \mathrm{H}), 6.57-6.74(\mathrm{~m}, 2 \mathrm{H}), 6.21(\mathrm{br} \mathrm{d}, J=17.0 \mathrm{~Hz}, 1 \mathrm{H}), 5.70-5.82(\mathrm{~m}, 1 \mathrm{H}), 4.96(\mathrm{br} \mathrm{s}, 1 \mathrm{H})$, 4.24-4.47 (m, 1 H), 3.97-4.22 (m, $2 \mathrm{H}), 3.73-3.89(\mathrm{~m}, 1 \mathrm{H}), 3.61-3.69(\mathrm{~m}, 1 \mathrm{H}), 2.93-3.12(\mathrm{~m}, 1 \mathrm{H}), 2.53-2.60$ (m, $1 \mathrm{H})$, 
$1.30(\mathrm{br} \mathrm{d}, J=6.4 \mathrm{~Hz}, 3 \mathrm{H}), 1.06(\mathrm{~d}, J=6.8 \mathrm{~Hz}, 3 \mathrm{H}), 0.96(\mathrm{~d}, J=6.8 \mathrm{~Hz}, 3 \mathrm{H}) .{ }^{19} \mathrm{~F}$ NMR $\left(376 \mathrm{MHz}, \mathrm{DMSO}-d_{6}\right) \delta \mathrm{ppm}-$ $115.72--115.04(\mathrm{~m}, 1 \mathrm{~F}) . \mathrm{m} / \mathrm{z}(\mathrm{ESI},+\mathrm{ve}) 562.2(\mathrm{M}+\mathrm{H})^{+}$. Atropisomer configuration $(R$ vs. $S)$ assigned crystallographically.

\section{Compound $(R)-19$}

(R)-(S)-4-(4-Acryloyl-2-methylpiperazin-1-yl)-6-chloro-7-(2-fluorophenyl)-1-(2-isopropylphenyl)pyrido[2,3d]pyrimidin-2(1H)-one was prepared according to the procedure described for Compound (R)-18, using 2fluorobenzeneboronic acid (TCI America) in Step 5 (88\% yield) to afford the title compound as a mixture of atropisomers. Separation of atropisomers (chiral SFC: Whelk-01 (S,S), $250 \times 21 \mathrm{~mm}, 5 \mu \mathrm{m}, 45 \% \mathrm{MeOH} / \mathrm{CO}_{2}(\mathrm{w} / 20 \mathrm{mM} \mathrm{NH} 3), 75 \mathrm{~g} / \mathrm{min}$, 102 bar) gave Compound $(R)-19$ as the second eluting isomer, light yellow solid. ${ }^{1} \mathrm{H}$ NMR $\left(400 \mathrm{MHz}, \mathrm{DMSO}-d_{6}\right) \delta \mathrm{ppm}$ 8.42 (br s, $1 \mathrm{H}), 7.46-7.55(\mathrm{~m}, 1 \mathrm{H}), 7.39-7.44(\mathrm{~m}, 1 \mathrm{H}), 7.16-7.37(\mathrm{~m}, 5 \mathrm{H}), 7.12(\mathrm{dd}, J=7.8,0.9 \mathrm{~Hz}, 1 \mathrm{H}), 6.80-6.95(\mathrm{~m}$, $1 \mathrm{H}), 6.21$ (br d, $J=16.4 \mathrm{~Hz}, 1 \mathrm{H}), 5.73-5.79(\mathrm{~m}, 1 \mathrm{H}), 4.97$ (br s, $1 \mathrm{H}), 4.24-4.49(\mathrm{~m}, 1 \mathrm{H}), 3.98-4.23$ (m, $2 \mathrm{H}), 3.37-3.86$ $(\mathrm{m}, 2 \mathrm{H}), 2.97-3.25(\mathrm{~m}, 1 \mathrm{H}), 2.53-2.58(\mathrm{~m}, 1 \mathrm{H}), 1.31(\mathrm{br} \mathrm{d}, J=6.6 \mathrm{~Hz}, 3 \mathrm{H}), 1.08(\mathrm{~d}, J=6.8 \mathrm{~Hz}, 3 \mathrm{H}), 0.98(\mathrm{~d}, J=6.8$ $\mathrm{Hz}, 3 \mathrm{H}) .{ }^{19} \mathrm{~F}$ NMR $\left(376 \mathrm{MHz}\right.$, DMSO-d $d_{6} \delta \mathrm{ppm}-113.76(\mathrm{~s}, 1 \mathrm{~F}) . \mathrm{m} / \mathrm{z}(\mathrm{ESI},+\mathrm{ve}) 546.2(\mathrm{M}+\mathrm{H})^{+}$. Atropisomer configuration $(R$ vs. $S)$ assigned by analogy. ${ }^{17}$

\section{Compound $(R)-20$}

(R)-(S)-4-(4-Acryloyl-2-methylpiperazin-1-yl)-6-chloro-7-(2-chlorophenyl)-1-(2-isopropylphenyl)pyrido[2,3d]pyrimidin-2(1H)-one was prepared according to the procedure described for Compound $(R)-18$, using 2chlorobenzeneboronic acid (Alfa Aesar) in Step 5 (90\% yield) to afford the title compound as a mixture of atropisomers. Separation of atropisomers (chiral SFC: OD, $150 \times 21 \mathrm{~mm}, 5 \mu \mathrm{m}, 25 \% \mathrm{iPrOH} / \mathrm{MeCN}(1: 1) / \mathrm{CO}_{2}, 80 \mathrm{~g} / \mathrm{min}, 140 \mathrm{bar}$ ) gave Compound $(R)-20$ as the second eluting isomer, light yellow solid. ${ }^{1} \mathrm{H}$ NMR $\left(400 \mathrm{MHz}, \mathrm{DMSO}-d_{6}\right) \delta \mathrm{ppm} 8.45$ (br s, $\left.1 \mathrm{H}\right)$, 7.51-7.57 (m, 1 H), 7.46 (td, $J=7.7,1.9 \mathrm{~Hz}, 1 \mathrm{H}), 7.37-7.43(\mathrm{~m}, 2 \mathrm{H}), 7.30-7.36(\mathrm{~m}, 1 \mathrm{H}), 7.17-7.26$ (m, 2 H), 7.04-7.15 $(\mathrm{m}, 1 \mathrm{H}), 6.79-6.94(\mathrm{~m}, 1 \mathrm{H}), 6.22(\mathrm{br} \mathrm{d}, J=16.6 \mathrm{~Hz}, 1 \mathrm{H}), 5.73-5.80(\mathrm{~m}, 1 \mathrm{H}), 4.97$ (br s, $1 \mathrm{H}), 4.27-4.46$ (m, $1 \mathrm{H}), 4.01-$ 4.23 (m, 2 H), 3.59-3.90 (m, 2 H), 2.98-3.28 (m, $1 \mathrm{H}), 2.54-2.60(\mathrm{~m}, 1 \mathrm{H}), 1.32$ (br d, J = 6.6 Hz, $3 \mathrm{H}), 1.08(\mathrm{~d}, J=6.8 \mathrm{~Hz}$, $3 \mathrm{H}), 0.99(\mathrm{~d}, \mathrm{~J}=6.8 \mathrm{~Hz}, 3 \mathrm{H}) . \mathrm{m} / \mathrm{z}(\mathrm{ESI},+\mathrm{ve}) 562.2(\mathrm{M}+\mathrm{H})^{+}$. Atropisomer configuration $(R$ vs. $S)$ assigned by analogy. ${ }^{17}$

\section{Compound $(R)-21$}

(R)-(S)-4-(4-Acryloyl-2-methylpiperazin-1-yl)-6-chloro-7-(2-hydroxyphenyl)-1-(2-isopropylphenyl)pyrido[2,3d]pyrimidin-2(1H)-one was prepared according to the procedure described for Compound $(R)-18$, using (2hydroxyphenyl)boronic acid (Frontier Scientific, Inc.) in Step 5 (99\% yield) to afford (S)-4-(4-acryloyl-2-methylpiperazin1-yl)-6-chloro-7-(2-hydroxyphenyl)-1-(2-isopropylphenyl)pyrido[2,3-d]pyrimidin-2(1H)-one. Atropisomer separation following Step 6 (chiral SFC: Whelk-01 $(R, R), 250 \times 21 \mathrm{~mm}, 5 \mu \mathrm{m}, 50 \% \mathrm{MeOH} / \mathrm{CO}_{2}, 65 \mathrm{~g} / \mathrm{min}, 102$ bar) gave Compound $(R)-21$ as the second-eluting isomer and as a yellow solid. ${ }^{1} \mathrm{H}$ NMR $\left(400 \mathrm{MHz}, \mathrm{DMSO}-d_{6}\right) \delta 9.79(\mathrm{br} \mathrm{s}, 1 \mathrm{H}), 8.32(\mathrm{br} \mathrm{s}, 1 \mathrm{H})$, 7.40-7.44 (m, 1H), $7.34(\mathrm{t}, \mathrm{J}=7.57 \mathrm{~Hz}, 1 \mathrm{H}), 7.22(\mathrm{q}, \mathrm{J}=6.77 \mathrm{~Hz}, 2 \mathrm{H}), 7.12(\mathrm{~d}, \mathrm{~J}=7.88 \mathrm{~Hz}, 1 \mathrm{H}), 7.00(\mathrm{br} d, \mathrm{~J}=6.43 \mathrm{~Hz}$ $1 \mathrm{H}), 6.85$ (br d, J = 8.09 Hz, 1H), 6.76-6.81 (m, 1H), 6.15-6.27 (m, 1H), 5.72-5.80 (m, 1H), 4.95 (br s, 1H), 4.26-4.48 (m, $1 \mathrm{H}), 4.00-4.23(\mathrm{~m}, 2 \mathrm{H}), 3.39-3.86(\mathrm{~m}, 2 \mathrm{H}), 2.95-3.25(\mathrm{~m}, 1 \mathrm{H}), 2.53-2.72(\mathrm{~m}, 1 \mathrm{H}), 1.31$ (br d, J = 6.43 Hz, 3H), $1.08(\mathrm{~d}, \mathrm{~J}$ $=6.84 \mathrm{~Hz}, 3 \mathrm{H}), 1.01(\mathrm{br} \mathrm{d}, \mathrm{J}=6.84 \mathrm{~Hz}, 3 \mathrm{H}) . \mathrm{m} / \mathrm{z}(\mathrm{ESI},+\mathrm{ve}) 543.8(\mathrm{M}+\mathrm{H})^{+}$. Atropisomer configuration $(R$ vs. $S)$ assigned by analogy. ${ }^{17}$

\section{Compound 22}

4-((S)-4-Acryloyl-2-methylpiperazin-1-yl)-6-chloro-1-(2-cyclopropylphenyl)-7-(2-fluoro-6-

hydroxyphenyl)pyrido[2,3-d]pyrimidin-2(1H)-one was prepared according to the procedure described for Compound $(R)$ 18, using 2-cyclopropaneaniline (ChemBridge Corporation) in Step $2 \mathrm{~b}$ (80\% yield) to afford the title compound as a tan solid. ${ }^{1} \mathrm{H}$ NMR $(400 \mathrm{MHz}$, DMSO-d6) $\delta \mathrm{ppm} 10.08(\mathrm{~s}, 1 \mathrm{H}), 8.37$ (br d, $J=17.0 \mathrm{~Hz}, 1 \mathrm{H}), 7.19-7.30$ (m, $\left.3 \mathrm{H}\right), 7.15$ (br s, 1 H), 7.06 (br d, $J=5.2 \mathrm{~Hz}, 1 \mathrm{H}), 6.78-6.92(\mathrm{~m}, 1 \mathrm{H}), 6.61-6.74(\mathrm{~m}, 2 \mathrm{H}), 6.21$ (br d, $J=16.6 \mathrm{~Hz}, 1 \mathrm{H}), 5.76(\mathrm{dd}, J=10.5$, $2.2 \mathrm{~Hz}, 1 \mathrm{H}), 4.73-5.02(\mathrm{~m}, 1 \mathrm{H}), 3.97-4.47(\mathrm{~m}, 3 \mathrm{H}), 3.40-3.86(\mathrm{~m}, 2 \mathrm{H}), 3.03-3.28(\mathrm{~m}, 1 \mathrm{H}), 1.42-1.61(\mathrm{~m}, 1 \mathrm{H}), 1.33(\mathrm{br}$ dd, $J=16.9,6.3 \mathrm{~Hz}, 3 \mathrm{H}), 0.47-0.67(\mathrm{~m}, 3 \mathrm{H}), 0.41$ (br d, $J=1.5 \mathrm{~Hz}, 1 \mathrm{H}) .{ }^{19} \mathrm{~F}$ NMR $(376 \mathrm{MHz}$, DMSO-d $) \delta-115.37(\mathrm{~s}$, $1 \mathrm{~F}) . \mathrm{m} / \mathrm{z}(\mathrm{ESI},+\mathrm{ve}) 560(\mathrm{M}+\mathrm{H})^{+}$.

\section{Compound $(R)-23$}

(R)-4-((S)-4-Acryloyl-2-methylpiperazin-1-yl)-1-(2-(tert-butyl)phenyl)-6-chloro-7-(2-fluoro-6hydroxyphenyl)pyrido[2,3-d]pyrimidin-2(1H)-one was prepared according to the procedure described for Compound $(R)$ 18, using 2-(tert-butyl)aniline (Ark Pharm, Inc.) in Step 2b (70\% yield) to afford the title compound. Atropisomer separation following Step $6 \mathrm{~b}$ (chiral SFC: IF, $150 \times 4.6 \mathrm{~mm}, 5 \mu \mathrm{m}), 50 \% \mathrm{iPrOH} / \mathrm{CO}_{2}, 4 \mathrm{~mL} / \mathrm{min}, 100 \mathrm{bar}$ ), gave Compound $(R)-23 \mathrm{as}$ 
the second eluting isomer as a yellow solid. ${ }^{1} \mathrm{H}$ NMR (400 MHz, DMSO-d 6 ) $\delta 10.07$ (br s, 1H), 8.37 (br s, $\left.1 \mathrm{H}\right), 7.54$ (br d, $J=7.88 \mathrm{~Hz}, 1 \mathrm{H}), 7.25-7.33(\mathrm{~m}, 1 \mathrm{H}), 7.17-7.25(\mathrm{~m}, 2 \mathrm{H}), 6.96($ br d, $J=6.01 \mathrm{~Hz}, 1 \mathrm{H}), 6.77-6.90(\mathrm{~m}, 1 \mathrm{H}), 6.71(\mathrm{~d}, J=8.29$ $\mathrm{Hz}, 1 \mathrm{H}), 6.65$ (br t, $J=8.71 \mathrm{~Hz}, 1 \mathrm{H}), 6.20$ (br d, $J=16.59 \mathrm{~Hz}, 1 \mathrm{H}), 5.72-5.80(\mathrm{~m}, 1 \mathrm{H}), 4.85(\mathrm{br} \mathrm{s}, 1 \mathrm{H}), 4.18-4.43(\mathrm{~m}, 2 \mathrm{H})$, 3.96-4.17 (m, 1H), 3.70 (br s, 1H), 3.41-3.64 (m, 1H), 3.22 (br s, 1H), 1.33 (br d, J =6.22 Hz, 3H), $1.08-1.14$ (m, 9H). ${ }^{19}$ F NMR $\left(376 \mathrm{MHz}, \mathrm{DMSO}-d_{6}\right) \delta-115.43(\mathrm{~s}, 1 \mathrm{~F}) . \mathrm{m} / \mathrm{z}(\mathrm{ESI},+\mathrm{ve}) 576(\mathrm{M}+\mathrm{H})^{+}$. Atropisomer configuration $(R$ vs. $S)$ assigned crystallographically.

\section{Compound $(R)-24$}

(R)-4-((S)-4-Acryloyl-2-methylpiperazin-1-yl)-6-chloro-7-(2-fluoro-6-hydroxyphenyl)-1-(2-isopropyl-6methylphenyl)pyrido[2,3-d]pyrimidin-2(1H)-one was prepared according to the procedure described for Compound $(R)$ 18, using 2-(1-methylethyl)-6-methylaniline (Enamine, LLC) in Step 2b (99\% yield) to afford the title compound. Atropisomer separation following Step 6 (chiral SFC: OD-H, $21 \times 250 \mathrm{~mm}, 5 \mu \mathrm{m}, 30 \% \mathrm{MeOH} / \mathrm{CO}_{2}, 50 \mathrm{~mL} / \mathrm{min}, 165 \mathrm{bar}$ ) gave Compound $(R)-24$ as the first-eluting isomer and as a light yellow solid. ${ }^{1} \mathrm{H}$ NMR (400 MHz, DMSO- $\left.d_{6}\right) \delta 10.07(\mathrm{~s}$, 1H), 9.96-10.13 (m, 1H), 8.39 (br s, 1H), 7.17-7.26 (m, 3H), 7.09 (br d, J=5.86 Hz, 1H), $6.84($ br s, 1H), 6.60-6.71 (m, 2H), 6.20 (br d, $J=17.21 \mathrm{~Hz}, 1 \mathrm{H}), 5.74-5.78(\mathrm{~m}, 1 \mathrm{H}), 4.77-4.99(\mathrm{~m}, 1 \mathrm{H}), 4.26($ br s, 3H), 3.58-3.86 (m, $1 \mathrm{H}), 3.57(\mathrm{~s}, 1 \mathrm{H})$, 3.13 (br d, $J=1.66 \mathrm{~Hz}, 1 \mathrm{H}), 1.85$ (br s, 3H), 1.34 (br d, $J=6.43 \mathrm{~Hz}, 3 \mathrm{H}), 1.05$ (d, $J=6.63 \mathrm{~Hz}, 3 \mathrm{H}), 0.92(\mathrm{~d}, J=6.63 \mathrm{~Hz}$, $3 \mathrm{H}) .{ }^{19} \mathrm{~F}$ NMR $\left(377 \mathrm{MHz}, \mathrm{CDCl}_{3}\right) \delta-104.54$ (br d, $\left.J=10.40 \mathrm{~Hz}, 1 \mathrm{~F}\right) . \quad \mathrm{m} / \mathrm{z}$ (ESI, +ve) $576(\mathrm{M}+\mathrm{H})^{+}$. Atropisomer configuration ( $R$ vs. $S$ ) assigned crystallographically.

\section{Compound 25}

4-((S)-4-Acryloyl-2-methylpiperazin-1-yl)-6-chloro-1-(2-ethyl-6-methylphenyl)-7-(2-fluoro-6-

hydroxyphenyl)pyrido[2,3-d]pyrimidin-2(1H)-one was prepared according to the procedure described for Compound $(R)$ 18, using 2-amino-3-ethyltoluene (Sigma-Aldrich) in Step $2 \mathrm{~b}\left(92 \%\right.$ yield) to afford the title compound as a yellow solid. ${ }^{1} \mathrm{H}$ NMR (400 MHz, $\left.\mathrm{CDCl}_{3}\right) \delta 8.62($ br s, 1H), $8.14(\mathrm{~s}, 1 \mathrm{H}), 7.36-7.42(\mathrm{~m}, 1 \mathrm{H}), 7.28-7.33(\mathrm{~m}, 2 \mathrm{H}), 7.23-7.26(\mathrm{~m}, 1 \mathrm{H}), 6.54-$ $6.74(\mathrm{~m}, 3 \mathrm{H}), 6.42(\mathrm{dd}, J=1.45,16.79 \mathrm{~Hz}, 1 \mathrm{H}), 5.83(\mathrm{dd}, J=1.76,10.47 \mathrm{~Hz}, 1 \mathrm{H}), 4.23-5.26(\mathrm{~m}, 3 \mathrm{H}), 3.51-4.09(\mathrm{~m}, 3 \mathrm{H})$, 2.93-3.37 (m, 1H), 2.23-2.47 (m, 2H), 1.99-2.06 (m, 3H), 1.42-1.62 (m, 3H), 1.08-1.17 (m, 3H). ${ }^{19} \mathrm{~F} \mathrm{NMR} \mathrm{(377} \mathrm{MHz,}$ $\left.\mathrm{CDCl}_{3}\right) \delta-105.18--104.05(\mathrm{~m}, 1 \mathrm{~F}) . \mathrm{m} / \mathrm{z}(\mathrm{ESI},+\mathrm{ve}) 562(\mathrm{M}+\mathrm{H})^{+}$.

\section{Compound 26}

4-((S)-4-Acryloyl-2-methylpiperazin-1-yl)-6-chloro-7-(2-fluoro-6-hydroxyphenyl)-1-(3-isopropylpyridin-2yl)pyrido[2,3-d]pyrimidin-2(1H)-one was prepared according to the procedure described for Compound $(R)$-18, using 3(propan-2-yl)pyridin-2-amine (Enamine, LLC) in Step 2b (29\% yield) to afford the title compound as a light brown solid. ${ }^{1} \mathrm{H}$ NMR (400 MHz, DMSO-d $) \delta 10.09$ (br s, 1H), 8.31-8.47 (m, 2H), 7.89 (br d, $\left.J=7.67 \mathrm{~Hz}, 1 \mathrm{H}\right), 7.40$ (dd, $J=4.77,7.67$ $\mathrm{Hz}, 1 \mathrm{H}), 7.17-7.28(\mathrm{~m}, 1 \mathrm{H}), 6.77-6.94(\mathrm{~m}, 1 \mathrm{H}), 6.60-6.74(\mathrm{~m}, 2 \mathrm{H}), 6.21$ (br d, J = 16.59 Hz, 1H), 5.73-5.80 (m, 1H), 4.72$5.12(\mathrm{~m}, 1 \mathrm{H}), 3.95-4.49(\mathrm{~m}, 3 \mathrm{H}), 3.46-3.92(\mathrm{~m}, 2 \mathrm{H}), 2.95-3.26(\mathrm{~m}, 1 \mathrm{H}), 2.54($ br s, $1 \mathrm{H}), 1.26-1.43(\mathrm{~m}, 3 \mathrm{H}), 1.10(\mathrm{~d}, J=$ $6.84 \mathrm{~Hz}, 3 \mathrm{H}), 1.00$ (br d, $J=6.84 \mathrm{~Hz}, 3 \mathrm{H}) .{ }^{19} \mathrm{~F}$ NMR $\left(376 \mathrm{MHz}, \mathrm{DMSO}-d_{6}\right) \delta-115.46(\mathrm{~s}, 1 \mathrm{~F}) . \mathrm{m} / \mathrm{z}(\mathrm{ESI},+\mathrm{ve}) 563(\mathrm{M}+\mathrm{H})^{+}$.

\section{Compound 27}

4-((S)-4-Acryloyl-2-methylpiperazin-1-yl)-6-chloro-7-(2-fluoro-6-hydroxyphenyl)-1-(1-isopropyl-1H-pyrazol-5yl)pyrido[2,3-d]pyrimidin-2(1H)-one was prepared according to the procedure described for Compound $(R)-18$, using 1 isopropyl-1H-pyrazol-5-amine (Enamine, LLC) in Step $2 \mathrm{~b}(45 \%$ yield), to afford the title compound as a light-yellow solid. ${ }^{1} \mathrm{H}$ NMR (400 MHz, DMSO-d $) \delta$ ppm 10.09 (br s, $\left.1 \mathrm{H}\right), 8.43$ (br s, $\left.1 \mathrm{H}\right), 7.48$ (d, $\left.J=1.7 \mathrm{~Hz}, 1 \mathrm{H}\right), 7.26(\mathrm{q}, J=8.0$ $\mathrm{Hz}, 1 \mathrm{H}), 6.78-6.90(\mathrm{~m}, 1 \mathrm{H}), 6.65-6.76(\mathrm{~m}, 2 \mathrm{H}), 6.20(\mathrm{br} \mathrm{d}, J=17.2 \mathrm{~Hz}, 1 \mathrm{H}), 6.12$ (s, $1 \mathrm{H}), 5.73-5.78$ (m, $1 \mathrm{H}), 5.05$ (br s, $1 \mathrm{H}), 4.37(\mathrm{br} \mathrm{d}, J=11.2 \mathrm{~Hz}, 1 \mathrm{H}), 4.15(\mathrm{br} \mathrm{s}, 1 \mathrm{H}), 3.97-4.10(\mathrm{~m}, 2 \mathrm{H}), 3.51-3.70(\mathrm{~m}, 1 \mathrm{H}), 3.16(\mathrm{~d}, J=5.0 \mathrm{~Hz}, 2 \mathrm{H})$, 1.38 (br d, $J=6.4 \mathrm{~Hz}, 1 \mathrm{H}), 1.23-1.31(\mathrm{~m}, 5 \mathrm{H}), 1.19$ (br d, $J=6.2 \mathrm{~Hz}, 3 \mathrm{H}) . \quad \mathrm{m} / \mathrm{z}(\mathrm{ESI},+\mathrm{ve}) 551.9(\mathrm{M}+\mathrm{H})^{+}$.

\section{Compound 28}

4-((S)-4-Acryloyl-2-methylpiperazin-1-yl)-6-chloro-7-(2-fluoro-6-hydroxyphenyl)-1-(4-isopropylthiazol-5yl)pyrido[2,3-d]pyrimidin-2(1H)-one was prepared according to the procedure described for Compound $(R)-18$, using 4(propan-2-yl)-1,3-thiazol-5-amine (Enamine, LLC) in Step 2b (quantitative) to afford the title compound as a light brown foam. ${ }^{1} \mathrm{H}$ NMR $\left(400 \mathrm{MHz}, \mathrm{DMSO}-d_{6}\right) \delta \mathrm{ppm} 10.10(\mathrm{~s}, 1 \mathrm{H}), 9.00(\mathrm{~s}, 1 \mathrm{H}), 8.37$ (br s, $\left.1 \mathrm{H}\right), 7.22-7.31$ (m, $\left.1 \mathrm{H}\right), 6.78-6.92$ $(\mathrm{m}, 1 \mathrm{H}), 6.66-6.77(\mathrm{~m}, 2 \mathrm{H}), 6.20(\mathrm{br} \mathrm{d}, J=16.2 \mathrm{~Hz}, 1 \mathrm{H}), 5.76(\mathrm{dd}, J=10.0,2.7 \mathrm{~Hz}, 1 \mathrm{H}), 4.92(\mathrm{br} \mathrm{dd}, J=11.5,5.3 \mathrm{~Hz}, 1$ H), 4.07-4.45 (m, 3 H), 3.68-3.89 (m, $1 \mathrm{H}), 3.62$ (br d, $J=13.7 \mathrm{~Hz}, 1 \mathrm{H}), 3.01-3.26(\mathrm{~m}, 1 \mathrm{H}), 2.58-2.71$ (m, $1 \mathrm{H}), 1.33$ (br 
$\mathrm{d}, J=5.8 \mathrm{~Hz}, 3 \mathrm{H}), 1.09$ (br d, $J=6.2 \mathrm{~Hz}, 3 \mathrm{H}), 1.01$ (br d, $J=6.4 \mathrm{~Hz}, 3 \mathrm{H}) .{ }^{19} \mathrm{~F}$ NMR $\left(376 \mathrm{MHz}, \mathrm{DMSO}-d_{6}\right) \delta-115.41(\mathrm{~s}$, $1 \mathrm{~F}) . \mathrm{m} / \mathrm{z}(\mathrm{ESI},+\mathrm{ve}) 569(\mathrm{M}+\mathrm{H})^{+}$.

\section{Compound $(R)-29$}

(R)-4-((S)-4-Acryloyl-2-methylpiperazin-1-yl)-6-chloro-7-(2-fluoro-6-hydroxyphenyl)-1-(1-isopropyl-4-methyl$1 H$-pyrazol-5-yl)pyrido[2,3-d]pyrimidin-2(1H)-one was prepared according to the procedure described for Compound (R)-18, using 1-isopropyl-4-methyl-1H-pyrazol-5-amine (ChemBridge Corporation) in Step 2b (84\% yield) to afford 6chloro-7-(2-fluoro-6-hydroxyphenyl)-1-(4-methyl-1-(2-propanyl)-1H-pyrazol-5-yl)-4-((2S)-2-methyl-4-(2-propenoyl)-1piperazinyl)pyrido[2,3-d]pyrimidin-2(1H)-one as a light-yellow solid. Atropisomer separation following Step 6c (chiral SFC: Whelk-01 $\left.(S, S), 21 \times 250 \mathrm{~mm}, 5 \mu \mathrm{m}, 30 \% \mathrm{MeOH} / \mathrm{CO}_{2}, 80 \mathrm{~g} / \mathrm{min}, 175 \mathrm{bar}\right)$ gave Compound $(R)-29$ as the first-eluting isomer and a light-yellow solid. ${ }^{1} \mathrm{H}$ NMR $\left(400 \mathrm{MHz}, \mathrm{DMSO}-d_{6}\right) \delta \mathrm{ppm} 10.12$ (br s, $\left.1 \mathrm{H}\right), 8.42(\mathrm{br} \mathrm{s}, 1 \mathrm{H}), 7.32(\mathrm{~s}, 1 \mathrm{H})$, 7.22-7.31 (m, 1 H), 6.78-6.93 (m, $1 \mathrm{H}), 6.66-6.77(\mathrm{~m}, 2 \mathrm{H}), 6.21$ (br d, $J=16.4 \mathrm{~Hz}, 1 \mathrm{H}), 5.76(\mathrm{dd}, J=10.4,2.1 \mathrm{~Hz}, 1 \mathrm{H})$, 4.98 (br s, 1 H), 3.94-4.46 (m, 4 H), 3.81 (br s, 1 H), 3.37-3.69 (m, 1 H), 2.99-3.29 (m, 1 H), 1.69 (br s, 3 H), 1.33 (br d, J $=6.4 \mathrm{~Hz}, 3 \mathrm{H}), 1.20$ (br dd, $J=39.1,6.3 \mathrm{~Hz}, 6 \mathrm{H}) .{ }^{19} \mathrm{~F} \mathrm{NMR}\left(376 \mathrm{MHz}, \mathrm{DMSO}-d_{6}\right) \delta \mathrm{ppm}-115.65(\mathrm{br} \mathrm{d}, J=80.6 \mathrm{~Hz}, 1 \mathrm{~F})$. $\mathrm{m} / \mathrm{z}(\mathrm{ESI},+\mathrm{ve}) 565.8(\mathrm{M}+\mathrm{H})^{+}$. Atropisomer configuration $(R$ vs. $S)$ assigned crystallographically.

\section{Compound 30}

4-((S)-4-Acryloyl-2-methylpiperazin-1-yl)-6-chloro-1-(2,6-dimethylphenyl)-7-(2-fluoro-6-

hydroxyphenyl)pyrido[2,3-d]pyrimidin-2(1H)-one was prepared according to the procedure described for Compound $(R)$ 18, using 2,6-dimethylaniline (Sigma-Aldrich) in Step $2 \mathrm{~b}\left(36 \%\right.$ yield) to afford the Compound 30 as an off-white solid. ${ }^{1} \mathrm{H}$ NMR (400 MHz, $\left.\mathrm{CDCl}_{3}\right) \delta 8.69(\mathrm{~s}, 1 \mathrm{H}) 8.13(\mathrm{~s}, 1 \mathrm{H}) 7.30-7.36(\mathrm{~m}, 1 \mathrm{H}) 7.25-7.29(\mathrm{~m}, 2 \mathrm{H}) 7.24(\mathrm{~s}, 1 \mathrm{H}) 6.72(\mathrm{~d}, J=8.5$ $\mathrm{Hz}, 1 \mathrm{H}) 6.68(\mathrm{dd}, J=10.2,8.5 \mathrm{~Hz}, 1 \mathrm{H}) 6.54-6.65(\mathrm{~m}, 1 \mathrm{H}) 6.42(\mathrm{dd}, J=16.8,1.5 \mathrm{~Hz}, 1 \mathrm{H}) 5.82(\mathrm{dd}, J=10.5,1.8 \mathrm{~Hz}, 1$ H) 4.27-5.25 (m, 3 H) 3.85-4.09 (m, 1 H) 3.50-3.85 (m, 2 H) 2.99-3.32 (m, 1 H) 2.05 (br d, J=2.3 Hz, 6 H) 1.51 (br d, J $=18.7 \mathrm{~Hz}, 3 \mathrm{H}) .{ }^{19} \mathrm{~F}$ NMR $\left(377 \mathrm{MHz}, \mathrm{CDCl}_{3}\right) \delta-104.7(\mathrm{~s}, 1 \mathrm{~F})-104.8(\mathrm{~s}, 1 \mathrm{~F}) . \mathrm{m} / \mathrm{z}(\mathrm{ESI},+\mathrm{ve}) 547.8(\mathrm{M}+\mathrm{H})^{+}$.

\section{Compound 31}

4-((S)-4-Acryloyl-2-methylpiperazin-1-yl)-6-chloro-1-(2,6-diethylphenyl)-7-(2-fluoro-6hydroxyphenyl)pyrido[2,3-d]pyrimidin-2(1H)-one was prepared according to the procedure described for Compound 32 , using 2,6-diethylaniline (Sigma-Aldrich) in Step $2 \mathrm{~b}$ (quantitative yield) to afford Compound 31 as a light yellow solid. ${ }^{1} \mathrm{H}$ NMR $\left(400 \mathrm{MHz}, \mathrm{CDCl}_{3}\right) \delta 8.58(\mathrm{~s}, 1 \mathrm{H}) 8.13(\mathrm{~s}, 1 \mathrm{H}) 7.41-7.50(\mathrm{~m}, 1 \mathrm{H}) 7.32(\mathrm{~s}, 1 \mathrm{H}) 7.30(\mathrm{~s}, 1 \mathrm{H}) 7.22-7.30(\mathrm{~m}, 1 \mathrm{H})$ 6.53-6.75 (m, $3 \mathrm{H}) 6.42(\mathrm{dd}, J=16.8,1.7 \mathrm{~Hz}, 1 \mathrm{H}) 5.77-5.86(\mathrm{~m}, 1 \mathrm{H}) 3.53-5.25(\mathrm{~m}, 6 \mathrm{H}) 2.98-3.34(\mathrm{~m}, 1 \mathrm{H}) 2.16-2.49$ $(\mathrm{m}, 4 \mathrm{H}) 1.52(\mathrm{br} \mathrm{d}, J=19.5 \mathrm{~Hz}, 3 \mathrm{H}) 1.07-1.17(\mathrm{~m}, 6 \mathrm{H}) .{ }^{19} \mathrm{~F}$ NMR $\left(377 \mathrm{MHz}, \mathrm{CDCl}_{3}\right) \delta-104.9--104.7(\mathrm{~m}, 1 \mathrm{~F}) . \quad \mathrm{m} / \mathrm{z}$ (ESI, +ve ion) $575.9(\mathrm{M}+\mathrm{H})^{+}$.

\section{Compound 32}

4-((S)-4-Acryloyl-2-methylpiperazin-1-yl)-6-chloro-1-(4,6-dicyclopropylpyrimidin-5-yl)-7-(2-fluoro-6hydroxyphenyl)pyrido[2,3-d]pyrimidin-2(1H)-one. 

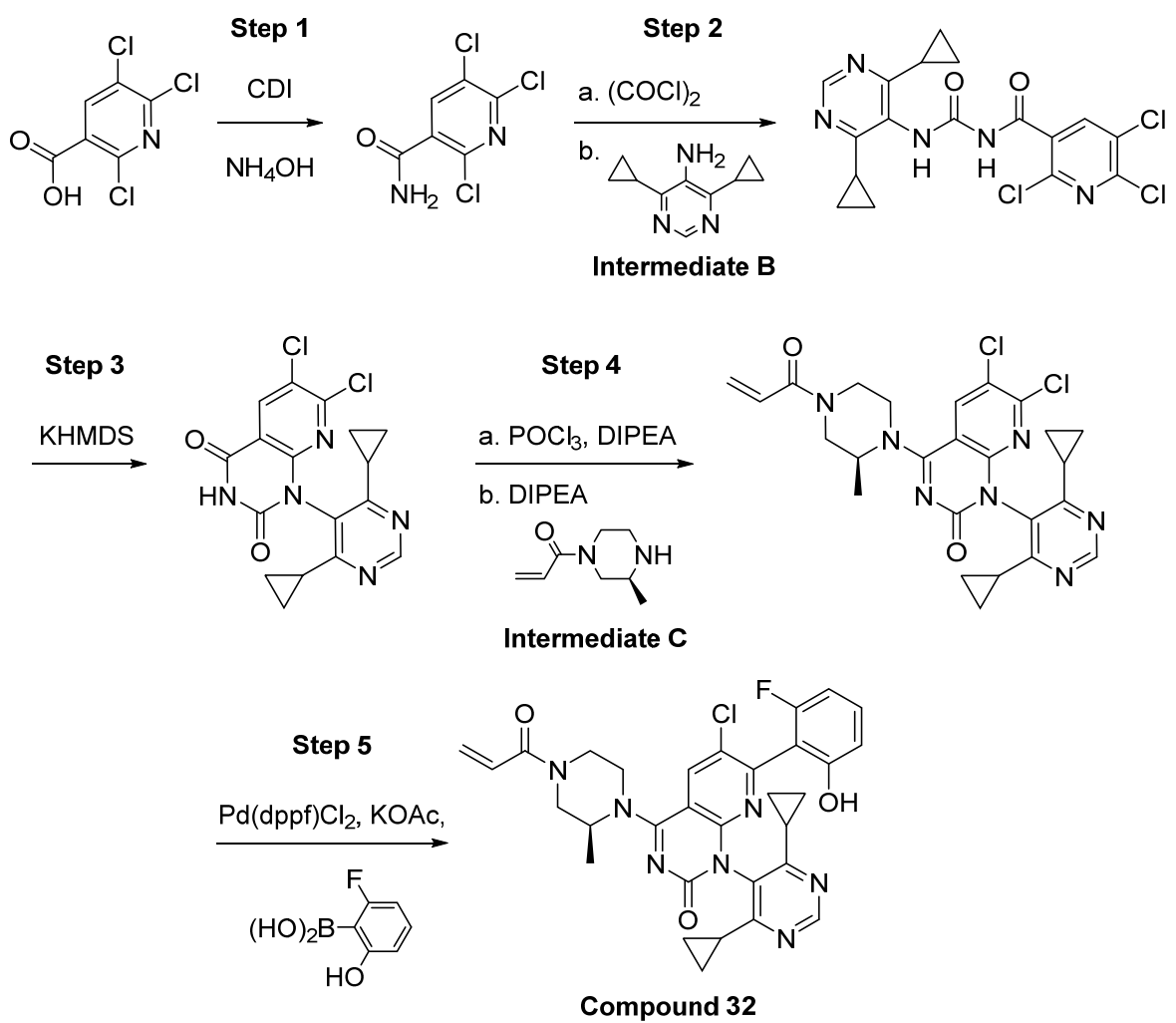

Step 1: 2,5,6-Trichloronicotinamide. A 5-L reactor was charged with 2,5,6-trichloronicotinic acid (183 g, $808 \mathrm{mmol}$; Combi-Blocks, Inc.) and 2-methyltetrahydrofuran $(1.8 \mathrm{~L})$; the light orange solution was stirred at $18{ }^{\circ} \mathrm{C}$, then $\mathrm{CDI}(138 \mathrm{~g}$, $848 \mathrm{mmol}$ ) was added over 5 portions allowing the slurry to reach a maximum temperature of $22^{\circ} \mathrm{C}$. The reaction mixture was stirred at $40{ }^{\circ} \mathrm{C}$ for $90 \mathrm{~min}$, cooled to $5{ }^{\circ} \mathrm{C}$, then ammonium hydroxide $(315 \mathrm{~mL}, 242$ mmol) was added slowly via addition funnel when the slurry reached a maximum temperature of $18{ }^{\circ} \mathrm{C}$. After stirring at $22{ }^{\circ} \mathrm{C}$ for 45 min, the organic layer was washed with saturated, aqueous ammonium chloride $(3 \times 750 \mathrm{~mL})$ and 1 N hydrochloric acid $(2 \times 300 \mathrm{~mL})$; the organic layer was separated, dried over anhydrous $\mathrm{Na}_{2} \mathrm{SO}_{4}$, and concentrated in vacuo. The crude solids were recrystallized in $\sim 75 \mathrm{~g}$ batches from ethyl acetate $(2 \mathrm{~mL} / \mathrm{g})$ at $70{ }^{\circ} \mathrm{C}$, cooled to $\mathrm{rt}$, and washed with cold ethyl acetate. The combined mother liquors were evaporated to dryness under reduced pressure and recrystallized from ethyl acetate. The solids were combined and dried in a vacuum oven at $50{ }^{\circ} \mathrm{C}$ with a nitrogen bleed to give 2,5,6-trichloronicotinamide. $\mathrm{m} / \mathrm{z}$ (ESI, $+\mathrm{ve}$ ion): 224.9/227.0 $(\mathrm{M}+\mathrm{H})^{+}$.

Step 2: 2,5,6-Trichloro- $N$-((4,6-dicyclopropylpyrimidin-5-yl)carbamoyl)nicotinamide. Oxalyl chloride (2.0 $\mathrm{M}$ in DCM; $2.67 \mathrm{~mL}, 5.33 \mathrm{mmol})$ was added to a mixture of 2,5,6-trichloronicotinamide $(1.15 \mathrm{~g}, 5.08 \mathrm{mmol})$ in tetrahydrofuran $(20 \mathrm{~mL})$. The reaction mixture was stirred at $60{ }^{\circ} \mathrm{C}$ for $15 \mathrm{~min}$ then was cooled to $0{ }^{\circ} \mathrm{C}$. 4,6-Dicyclopropylpyrimidin-5amine $\left(890 \mathrm{mg}, 5.08 \mathrm{mmol}\right.$; Intermediate B) in THF $(5 \mathrm{~mL})$ was added, and the reaction mixture was stirred at $0{ }^{\circ} \mathrm{C}$ for 35 min. The reaction mixture was partitioned between saturated aqueous $\mathrm{NaHCO}_{3}(60 \mathrm{~mL})$ and EtOAc $(80 \mathrm{~mL})$. The organic layer was separated, washed with brine $(50 \mathrm{~mL})$, dried over $\mathrm{MgSO}_{4}$, filtered, and concentrated in vacuo to give 2,5,6trichloro- $N$-((4,6-dicyclopropylpyrimidin-5-yl)carbamoyl)nicotinamide $(2.00 \mathrm{~g}, 92 \%$ yield $)$ as a light yellow solid which was used without further purification. $\mathrm{m} / \mathrm{z}\left(\mathrm{ESI},+\mathrm{ve}\right.$ ion): $425.9(\mathrm{M}+\mathrm{H})^{+}$.

Step 3: 6,7-Dichloro-1-(4,6-dicyclopropylpyrimidin-5-yl)pyrido[2,3-d]pyrimidine-2,4(1H,3H)-dione. Potassium bis(trimethylsilyl)amide (1 M solution in tetrahydrofuran; $9.37 \mathrm{~mL}, 9.37 \mathrm{mmol}$ ) was added to a stirred solution of 2,5,6trichloro- $N$-((4,6-dicyclopropylpyrimidin-5-yl)carbamoyl)nicotinamide (2.00 g, $4.69 \mathrm{mmol})$ in tetrahydrofuran $(40 \mathrm{~mL})$ at $0{ }^{\circ} \mathrm{C}$. The reaction mixture was stirred at $0{ }^{\circ} \mathrm{C}$ for $40 \mathrm{~min}$. The reaction mixture was quenched with saturated aqueous $\mathrm{NH}_{4} \mathrm{Cl}(75 \mathrm{~mL})$ and extracted with EtOAc $(100 \mathrm{~mL})$. The organic layer was separated, washed with brine $(75 \mathrm{~mL}), \mathrm{dried}$ over $\mathrm{MgSO}_{4}$, filtered, and concentrated in vacuo. Chromatographic purification of the residue (silica gel, 0-50\% (3:1 EtOAc/EtOH)/heptane) gave 6,7-dichloro-1-(4,6-dicyclopropylpyrimidin-5-yl)pyrido[2,3-d]pyrimidine-2,4(1H,3H)-dione (352 mg, 19\% yield) as a white solid. ${ }^{1} \mathrm{H}$ NMR (400 MHz, $\left.\mathrm{CDCl}_{3}\right) \delta 8.88(1 \mathrm{H}, \mathrm{s}) 8.54(1 \mathrm{H}, \mathrm{s}) 8.50(1 \mathrm{H}$, br s) $1.54-1.70$ (2 H, m) 1.17-1.35 (4 H, m) 0.98-1.07 (2 H, m) 0.85-0.95 (2 H, m). m/z (ESI, +ve ion): $390.0(\mathrm{M}+\mathrm{H})^{+}$.

Step 4: (S)-4-(4-Acryloyl-2-methylpiperazin-1-yl)-6,7-dichloro-1-(4,6-dicyclopropylpyrimidin-5-yl)pyrido[2,3d]pyrimidin-2(1H)-one. Phosphorus oxychloride $(0.101 \mathrm{~mL}, 1.08 \mathrm{mmol})$ was added to a stirred mixture of 6,7-dichloro1-(4,6-dicyclopropylpyrimidin-5-yl)pyrido[2,3-d]pyrimidine-2,4(1H,3H)-dione (352 mg, $0.902 \mathrm{mmol})$ and DIPEA (0.205 
$\mathrm{mL}, 1.17 \mathrm{mmol})$ in acetonitrile $(4 \mathrm{~mL})$. The reaction mixture was stirred at $80{ }^{\circ} \mathrm{C}$ for $30 \mathrm{~min}$. The reaction mixture was cooled to $0^{\circ} \mathrm{C}$, then DIPEA $(1.03 \mathrm{~mL}, 5.87 \mathrm{mmol})$ and $(S)-1$-(3-methylpiperazin-1-yl)prop-2-en-1-one 2,2,2-trifluoroacetate (543 mg, $0.902 \mathrm{mmol}$; Intermediate $\mathrm{C}$ ) were added. The reaction mixture was stirred at $0{ }^{\circ} \mathrm{C}$ for $40 \mathrm{~min}$. Water $(50 \mathrm{~mL})$ was added, and the aqueous suspension was extracted with EtOAc $(75 \mathrm{~mL})$. The organic layer was separated, washed with brine $(50 \mathrm{~mL})$, dried over $\mathrm{MgSO}_{4}$, filtered, and concentrated in vacuo. Chromatographic purification of the residue (silica gel, $\quad 0-75 \% \quad(3: 1 \quad$ EtOAc/EtOH)/heptane $)$ gave (S)-4-(4-acryloyl-2-methylpiperazin-1-yl)-6,7-dichloro-1-(4,6dicyclopropylpyrimidin-5-yl)pyrido[2,3-d]pyrimidin-2 $(1 \mathrm{H})$-one $\left(153 \mathrm{mg}, 32 \%\right.$ yield) as a yellow solid. ${ }^{1} \mathrm{H} \mathrm{NMR}(400 \mathrm{MHz}$, $\left.\mathrm{CDCl}_{3}\right) \delta 8.85(1 \mathrm{H}, \mathrm{s}) 8.06(1 \mathrm{H}, \mathrm{s}) 6.51-6.67(1 \mathrm{H}, \mathrm{m}) 6.36-6.45(1 \mathrm{H}, \mathrm{m}) 5.81(1 \mathrm{H}, \mathrm{dd}, J=10.37,1.87 \mathrm{~Hz}) 2.94-5.17(7$ $\mathrm{H}, \mathrm{m})$ 1.41-1.64 (5 H, m) 1.23-1.33 (2 H, m) 1.12-1.22 (2 H, m) 0.90-1.02 (2 H, m) 0.78-0.89 (2 H, m). m/z (ESI, +ve ion): $526.1(\mathrm{M}+\mathrm{H})^{+}$. NOTE: this procedure employs an optimized $\mathrm{POCl}_{3}$ procedure intended to mitigate risks associated with a potential latent exotherm during aqueous quenching. ${ }^{18}$

Step 5: 4-((S)-4-Acryloyl-2-methylpiperazin-1-yl)-6-chloro-1-(4,6-dicyclopropylpyrimidin-5-yl)-7-(2-fluoro-6hydroxyphenyl)pyrido[2,3-d]pyrimidin-2(1H)-one (32). (S)-4-(4-acryloyl-2-methylpiperazin-1-yl)-6,7-dichloro-1-(4,6dicyclopropylpyrimidin-5-yl)pyrido[2,3-d]pyrimidin-2(1H)-one $(50 \mathrm{mg}, 0.095 \mathrm{mmol}), \quad(1,1$ '-bis(diphenylphosphino) ferrocene) dichloropalladium $(7 \mathrm{mg}, 10 \mu \mathrm{mol})$, and potassium acetate $(0.024 \mathrm{~mL}, 0.38 \mathrm{mmol})$ in 1,4 -dioxane $(0.5 \mathrm{~mL}) \mathrm{was}$ stirred at $90{ }^{\circ} \mathrm{C}$ for $5 \mathrm{~min}$, then (2-fluoro-6-hydroxyphenyl)boronic acid (22 mg, $0.14 \mathrm{mmol}$; Combi-Blocks, Inc.) and water $(0.050 \mathrm{~mL})$ were added. The reaction mixture was stirred at $90^{\circ} \mathrm{C}$ for $30 \mathrm{~min}$. The reaction mixture was diluted with EtOAc $(75 \mathrm{~mL})$ and washed with water $(50 \mathrm{~mL})$. The organic layer was separated, washed with brine $(50 \mathrm{~mL})$, dried over MgSO 4 , filtered, and concentrated in vacuo. Chromatographic purification of the residue (silica gel, $0-70 \%$ (3:1 EtOAc/EtOH)/heptane) gave 4-((S)-4-acryloyl-2-methylpiperazin-1-yl)-6-chloro-1-(4,6-dicyclopropylpyrimidin-5-yl)-7(2-fluoro-6-hydroxyphenyl)pyrido[2,3-d]pyrimidin-2(1H)-one (30 mg, 53\% yield) as a yellow solid. ${ }^{1} \mathrm{H} \mathrm{NMR}(400 \mathrm{MHz}$, $\left.\mathrm{CDCl}_{3}\right) \delta 8.85(1 \mathrm{H}, \mathrm{s}) 8.18(1 \mathrm{H}, \mathrm{s}) 8.07(1 \mathrm{H}$, br s) $7.26-7.34(1 \mathrm{H}, \mathrm{m}) 6.54-6.80(3 \mathrm{H}, \mathrm{m}) 6.42(1 \mathrm{H}, \mathrm{d}, \mathrm{J}=16.59 \mathrm{~Hz}) 5.83$ $(1 \mathrm{H}, \mathrm{d}, J=10.20 \mathrm{~Hz}) 2.99-5.27(7 \mathrm{H}, \mathrm{m}) 1.43-1.75(5 \mathrm{H}, \mathrm{m}) 1.16-1.31(4 \mathrm{H}, \mathrm{m})$ 0.95-1.06 (2 H, m) $0.79-0.90$ (2 H, m). $\mathrm{m} / \mathrm{z}$ (ESI, +ve ion): $602.2(\mathrm{M}+\mathrm{H})^{+}$.

Intermediate B: 4,6-Dicyclopropylpyrimidin-5-amine.

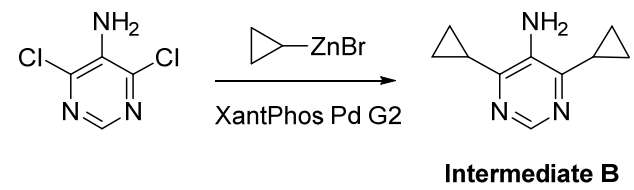

Cyclopropylzinc bromide $(0.5 \mathrm{M}$ in THF; $75 \mathrm{~mL}, 38 \mathrm{mmol})$ was added to a mixture of 5-amine-4,6-dichloropyrimidine (2.05 g, 12.5 mmol; Combi-Blocks, Inc.) and XantPhos Pd G2 (1.19 g, 1.25 mmol) under an argon atmosphere. The reaction mixture was stirred at $40{ }^{\circ} \mathrm{C}$ for $2.5 \mathrm{~h}$, quenched with saturated aqueous $\mathrm{NaHCO}_{3}(200 \mathrm{~mL})$, and extracted with EtOAc $(2 \times$ $200 \mathrm{~mL})$. The combined organic layers were washed with brine $(200 \mathrm{~mL})$, dried over $\mathrm{MgSO}_{4}$, filtered, and concentrated in vacuo. Chromatographic purification of the residue (silica gel, 0-100\% EtOAc/heptane) gave 4,6-dicyclopropylpyrimidin5-amine $\left(1.795 \mathrm{~g}, 82 \%\right.$ yield; Intermediate B) as an orange solid. ${ }^{1} \mathrm{H} \mathrm{NMR}\left(400 \mathrm{MHz}, \mathrm{CDCl}_{3}\right) \delta 8.40(1 \mathrm{H}, \mathrm{s}) 3.91(2 \mathrm{H}$, br s) 1.81-1.89 (2 H, m) 1.00-1.12 (8 H, m). m/z (ESI, +ve ion): $176.1(\mathrm{M}+\mathrm{H})^{+}$.

Intermediate C: (S)-1-(3-Methylpiperazin-1-yl)prop-2-en-1-one TFA salt.<smiles>CC1CNCCN1C(=O)O</smiles><smiles>C=CC(=O)N1CC(C)NC(C(=O)NCCC(=O)OCC)C1</smiles>

Step a: (S)-tert-Butyl 4-acryloyl-2-methylpiperazine-1-carboxylate. Acryloyl chloride (1.3 $\mathrm{mL}, 16.5 \mathrm{mmol}) \mathrm{was}$ added to a solution of (S)-1-Boc-2-methyl-piperazine (3.00 g, $15.0 \mathrm{mmol}$; AstaTech, Inc.) in THF $(30 \mathrm{~mL})$ at $-10{ }^{\circ} \mathrm{C}$, and the resulting mixture was stirred at $-10{ }^{\circ} \mathrm{C}$ for $5 \mathrm{~min}$. Triethylamine $(6.3 \mathrm{~mL}, 45 \mathrm{mmol})$ was then slowly added, and the resulting mixture was stirred at $-10^{\circ} \mathrm{C}$ for $15 \mathrm{~min}$, then allowed to warm to rt. The reaction mixture was partitioned between EtOAc and saturated aqueous $\mathrm{NaHCO}_{3}$. The aqueous layer was extracted with EtOAc, and the organic layers were then combined, dried over $\mathrm{MgSO}_{4}$, filtered, and concentrated in vacuo. The crude product was purified by silica gel chromatography (eluent: $0-100 \%$ EtOAc/heptane) to provide (S)-tert-butyl 4-acryloyl-2-methylpiperazine-1-carboxylate. ${ }^{1} \mathrm{H}$ NMR (400 MHz, DMSO-d 6 ) $\delta$ 6.72-6.85 (m, 1H) 6.10-6.18 (m, 1H) 5.68-5.76 (m, 1H) 4.08-4.32 (m, 2H) 3.68-4.03 $(\mathrm{m}, 2 \mathrm{H}) 2.86-3.14(\mathrm{~m}, 2 \mathrm{H}) 2.66-2.80(\mathrm{~m}, 1 \mathrm{H})$ 1.38-1.43 (s, 9H) 0.96-1.04 (m, 3H). m/z (ESI, +ve ion): $277.3(\mathrm{M}+\mathrm{Na})^{+}$. 
Step b: (S)-1-(3-Methylpiperazin-1-yl)prop-2-en-1-one 2,2,2-trifluoroacetate (Intermediate C). A mixture of (S)tert-butyl 4-acryloyl-2-methylpiperazine-1-carboxylate $(3.21 \mathrm{~g}, 12.6 \mathrm{mmol})$ and TFA $(4.7 \mathrm{~mL}, 63.1 \mathrm{mmol}) \mathrm{in} \mathrm{DCM}(16 \mathrm{~mL})$ was stirred at $\mathrm{rt}$ for $24 \mathrm{~h}$. The reaction mixture was then concentrated in vacuo to give (S)-1-(3-methylpiperazin-1-yl)prop2-en-1-one TFA salt (Intermediate C) as a brown oil. ${ }^{1} \mathrm{H}$ NMR $\left(400 \mathrm{MHz}, \mathrm{DMSO}-\mathrm{d}_{6}\right) \delta 8.70-8.99(\mathrm{~m}, 1 \mathrm{H}) 6.74-6.91(\mathrm{~m}$, 1H) 6.12-6.26 (m, 1H) 5.70-5.84 (m, 1H) 4.25-4.44 (m, 1H) 4.07-4.25 (m, 1H) 3.49-3.53 (m, 1H) 3.22-3.32 (m, 2H) 2.92$3.08(\mathrm{~m}, 2 \mathrm{H}) 1.14-1.29(\mathrm{~m}, 3 \mathrm{H}) . \mathrm{m} / \mathrm{z}$ (ESI, +ve ion): $155.1(\mathrm{M}+\mathrm{H})^{+}$.

\section{Compound 33}

4-((S)-4-Acryloyl-2-methylpiperazin-1-yl)-6-chloro-1-(4,6-diisopropylpyrimidin-5-yl)-7-(2-fluoro-6-

hydroxyphenyl)pyrido[2,3-d]pyrimidin-2(1H)-one was prepared according to the procedure described for Compound $(R)$ 18, using 4,6-diisopropylpyrimidin-5-amine (Intermediate D) in Step 2 (32\% yield), to afford the title compound as a lightyellow solid. ${ }^{1} \mathrm{H}$ NMR (400 MHz, DMSO-d $) \delta$ ppm 9.97-10.41 (m, $\left.1 \mathrm{H}\right) 9.03$ (br s, 1 H) 8.25-8.65 (m, $\left.1 \mathrm{H}\right) 7.22$ (br s, 1 H) 6.78-6.94 (m, 1 H) 6.67 (br s, 2 H) 6.09-6.31 (m, 1 H) 5.68-5.85 (m, 1 H) 4.88-5.05 (m, 1 H) 4.36 (br s, 2 H) 3.80 (br s, 2 H) 3.62 (br s, 2 H) 2.64-2.74 (m, 2 H) 1.33 (br s, 3 H) 1.06 (br s, 6 H) 0.91 (br s, 6 H). m/z (ESI, +ve) $607.3(\mathrm{M}+\mathrm{H})^{+}$.

Intermediate D: 4,6-Diisopropylpyrimidin-5-amine.

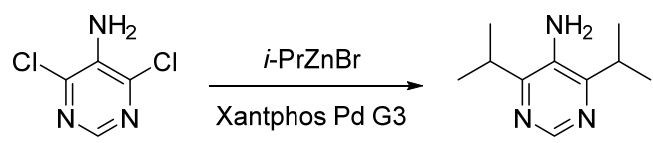

Intermediate D

To a 250-mL round-bottomed flask was added 4,6-dichloro-5-aminopyrimidine (2.50 g, 15.2 mmol; Combi-Blocks, Inc.) in tetrahydrofuran $(31 \mathrm{~mL})$. The reaction mixture was sparged with argon for $5 \mathrm{~min}$, then 2-propylzinc bromide $(0.5 \mathrm{M}$ in THF; $67.1 \mathrm{~mL}, 33.5 \mathrm{mmol})$ and XantPhos Pd G3 $(0.43 \mathrm{~g}, 0.46 \mathrm{mmol})$ were added. The reaction mixture was stirred at $60{ }^{\circ} \mathrm{C}$ for $2 \mathrm{~h}$. The reaction mixture was quenched with saturated aqueous $\mathrm{NH}_{4} \mathrm{Cl}(30 \mathrm{~mL})$ and diluted with EtOAc and brine $(10$ $\mathrm{mL}$ ). The layers were separated and the aqueous layer was extracted with EtOAc. The combined organic extracts were dried over $\mathrm{MgSO}_{4}$, filtered, and concentrated in vacuo. Chromatographic purification of the residue (silica gel; 0-15\% $2 \mathrm{M}$ $\left.\mathrm{NH}_{3} \cdot \mathrm{MeOH} / \mathrm{DCM}\right)$ provided 4,6-diisopropylpyrimidin-5-amine (0.878 g, 32\% yield; Intermediate D) as tan solid. ${ }^{1} \mathrm{H} \mathrm{NMR}$ $\left(400 \mathrm{MHz}, \mathrm{DMSO}-d_{6}\right) \delta \mathrm{ppm}$ 8.26-8.35 (m, $\left.1 \mathrm{H}\right)$ 4.94-5.08 (m, $\left.2 \mathrm{H}\right) 3.16-3.26(\mathrm{~m}, 2 \mathrm{H}) 1.14(\mathrm{~d}, \mathrm{~J}=6.63 \mathrm{~Hz}, 12 \mathrm{H}) . \mathrm{m} / \mathrm{z}$ (ESI, +ve ion): $180.2(\mathrm{M}+\mathrm{H})^{+}$.

\section{Compound (R)-34}

(R)-4-((S)-4-Acryloyl-2-methylpiperazin-1-yl)-6-chloro-7-(2-fluoro-6-hydroxyphenyl)-1-(2-isopropyl-4methylpyridin-3-yl)pyrido[2,3-d]pyrimidin-2(1H)-one was prepared according to the procedure described for Compound (R)-18, using 2-isopropyl-4-methylpyridin-3-amine (Intermediate E) in Step 2b (85\% yield), to afford the title compound. Atropisomer separation following Step 6c (chiral SFC: IC $\left.(21 \times 150,50 \mu \mathrm{m}) 50 \% \mathrm{MeOH} / \mathrm{CO}_{2}, 50 \mathrm{~mL} / \mathrm{min}, 186 \mathrm{bar}\right) \mathrm{gave}$ Compound $(R)-34$ as the first-eluting isomer and a light-yellow solid. ${ }^{1} \mathrm{H}$ NMR $\left(400 \mathrm{MHz}, \mathrm{CDCl}_{3}\right) \delta \mathrm{ppm} 8.59(\mathrm{~s}, 1 \mathrm{H}), 8.36$ (br s, $1 \mathrm{H}), 8.16(\mathrm{~s}, 2 \mathrm{H}), 7.28-7.35(\mathrm{~m}, 1 \mathrm{H}), 6.61-6.76(\mathrm{~m}, 4 \mathrm{H}), 6.44(\mathrm{~d}, J=1.7 \mathrm{~Hz}, 1 \mathrm{H}), 4.96-5.14(\mathrm{~m}, 1 \mathrm{H}), 4.71-4.84$ (m, $1 \mathrm{H}), 4.42-4.60(\mathrm{~m}, 1 \mathrm{H}), 3.89-4.16(\mathrm{~m}, 1 \mathrm{H}), 3.65$ (br s, $3 \mathrm{H}), 3.49$ (s, $2 \mathrm{H}), 3.07-3.27$ (m, $1 \mathrm{H}), 2.86$ (br s, $1 \mathrm{H}), 2.08$ $(\mathrm{br} \mathrm{s}, 3 \mathrm{H}), 1.29(\mathrm{br} \mathrm{s}, 3 \mathrm{H}), 1.12(\mathrm{br} \mathrm{s}, 3 \mathrm{H}) . \mathrm{m} / \mathrm{z}(\mathrm{ESI},+\mathrm{ve}) 577.0(\mathrm{M}+\mathrm{H})^{+}$. Atropisomer configuration $(R$ vs. $S)$ assigned by analogy. ${ }^{17}$

Intermediate E: 2-Isopropyl-4-methylpyridin-3-amine.

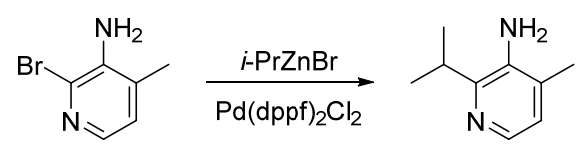

Intermediate $\mathrm{E}$

To a slurry of 3-amino-2-bromo-4-picoline (360 mg, $1.9 \mathrm{mmol}$; Combi-Blocks, Inc.) in THF (4 mL) was added [1,1'bis(diphenylphosphino)ferrocene]dichloropalladium(II), complex with DCM (79 $\mathrm{mg}, 0.10 \mathrm{mmol})$. The resulting slurry was deoxygenated with argon, then 2-propylzinc bromide $(0.5 \mathrm{M}$ solution in THF, $5.4 \mathrm{~mL}, 2.7 \mathrm{mmol})$ was added. The resulting solution was stirred at $60{ }^{\circ} \mathrm{C}$ for $17 \mathrm{~h}$, then the reaction was allowed to cool to ambient temperature. Water $(10 \mathrm{~mL})$ and 1 $\mathrm{N} \mathrm{NaOH}$ solution $(20 \mathrm{~mL})$ were sequentially added, and the resulting mixture was extracted with EtOAc $(2 \times)$. The combined organic extracts were dried over anhydrous sodium sulfate and concentrated in vacuo. Chromatographic purification of the residue (silica gel; 0-15\% MeOH/DCM) provided 2-isopropyl-4-methylpyridin-3-amine (284 mg, $98 \%$ yield; Intermediate 
E) as a brown solid. ${ }^{1} \mathrm{H}$ NMR $\left(400 \mathrm{MHz}, \mathrm{DMSO}-\mathrm{d}_{6}\right) \delta \mathrm{ppm} 7.66(\mathrm{~d}, J=4.6 \mathrm{~Hz}, 1 \mathrm{H}), 6.78(\mathrm{~d}, J=4.8 \mathrm{~Hz}, 1 \mathrm{H}), 4.72(\mathrm{br}$ s, $2 \mathrm{H}), 3.14-3.25(\mathrm{~m}, 1 \mathrm{H}), 2.08(\mathrm{~s}, 3 \mathrm{H}), 1.14(\mathrm{~d}, \mathrm{~J}=6.8 \mathrm{~Hz}, 6 \mathrm{H}) . \mathrm{m} / \mathrm{z}\left(\mathrm{ESI},+\right.$ ve ion): $151.1(\mathrm{M}+\mathrm{H})^{+}$.

\section{Compound (S)-35}

(S)-4-((S)-4-Acryloyl-2-methylpiperazin-1-yl)-6-chloro-7-(2-fluoro-6-hydroxyphenyl)-1-(4-isopropyl-2-

methylpyridin-3-yl)pyrido[2,3-d]pyrimidin-2(1H)-one was prepared according to the procedure described for Compound (R)-18, using 4-isopropyl-2-methylpyridin-3-amine (Intermediate $\mathrm{H}$ ) in Step 2 (51\% yield) to afford Compound 35. Atropisomer separation following Step 6 (chiral SFC: IC, $250 \times 20 \mathrm{~mm}, 10 \mu \mathrm{m}$ ) $70 \% \mathrm{MeOH} / \mathrm{CO}_{2}, 70 \mathrm{~g} / \mathrm{min}, 103 \mathrm{bar}$ ) gave Compound (S)-35 as the second-eluting isomer and a white solid. ${ }^{1} \mathrm{H}$ NMR $\left(400 \mathrm{MHz}, \mathrm{DMSO}-d_{6}\right) \delta 10.11(\mathrm{br} \mathrm{s}, 1 \mathrm{H}), 8.43$ (br s, 1H), 8.34 (d, $J=5.18 \mathrm{~Hz}, 1 \mathrm{H}), 7.20-7.29(\mathrm{~m}, 2 \mathrm{H}), 6.78-6.93(\mathrm{~m}, 1 \mathrm{H}), 6.63-6.73(\mathrm{~m}, 2 \mathrm{H}), 6.23$ (br s, $1 \mathrm{H}), 5.76(\mathrm{dd}, J$ $=2.18,10.47 \mathrm{~Hz}, 1 \mathrm{H}), 4.94$ (br s, $1 \mathrm{H}), 3.40-4.46(\mathrm{~m}, 6 \mathrm{H}), 3.17(\mathrm{~d}, J=5.18 \mathrm{~Hz}, 1 \mathrm{H}), 2.07$ (br s, 3H), 1.35 (br d, $J=6.43 \mathrm{~Hz}$, $3 \mathrm{H}), 1.07(\mathrm{~d}, J=6.84 \mathrm{~Hz}, 3 \mathrm{H}), 0.93(\mathrm{br} \mathrm{d}, J=6.43 \mathrm{~Hz}, 3 \mathrm{H}) . \mathrm{m} / \mathrm{z}(\mathrm{ESI},+\mathrm{ve}) 577.3(\mathrm{M}+\mathrm{H})^{+}$. Atropisomer configuration $(R$ vs. $S)$ assigned crystallographically.

\section{Compound $(R)-36$}

(R)-4-((S)-4-Acryloyl-2-methylpiperazin-1-yl)-6-chloro-7-(2-fluoro-6-hydroxyphenyl)-1-(4-isopropyl-6methylpyrimidin-5-yl)pyrido[2,3-d]pyrimidin-2(1H)-one was prepared according to the procedure described for Compound $(R)-18$, using 4-isopropyl-6-methylpyrimidin-5-amine (Intermediate F) in Step 2b (82\% yield) to afford the title compound. Atropisomer separation following Step $6 \mathrm{~b}$ (chiral SFC: Whelk-01 $(R, R), 250 \times 21 \mathrm{~mm}, 5 \mu \mathrm{m}, 35 \% \mathrm{MeOH} / \mathrm{CO}$, $110 \mathrm{~mL} / \mathrm{min}$ ) gave Compound $(R)-36$ as the second eluting isomer as a light yellow solid. ${ }^{1} \mathrm{H}$ NMR (400 MHz, DMSO-d $)$ $\delta$ ppm $10.15(\mathrm{~s}, 1 \mathrm{H}), 8.95(\mathrm{~s}, 1 \mathrm{H}), 8.45$ (br s, $1 \mathrm{H}), 7.25$ (br d, J = 7.5 Hz, $1 \mathrm{H}), 6.79-6.94(\mathrm{~m}, 1 \mathrm{H}), 6.63-6.76$ (m, 2 H), 6.16-6.27 (m, 1 H), 5.74-5.81 (m, $1 \mathrm{H}), 4.96$ (br d, $J=4.4 \mathrm{~Hz}, 1 \mathrm{H}), 4.24-4.46(\mathrm{~m}, 2 \mathrm{H}), 3.99-4.22(\mathrm{~m}, 1 \mathrm{H}), 3.87-3.97(\mathrm{~m}$, $1 \mathrm{H}), 3.78$ (br d, $J=5.2 \mathrm{~Hz}, 1 \mathrm{H}), 3.45-3.70(\mathrm{~m}, 1 \mathrm{H}), 2.75(\mathrm{br} \mathrm{d}, J=5.2 \mathrm{~Hz}, 1 \mathrm{H}), 2.11(\mathrm{br} \mathrm{d}, J=10.6 \mathrm{~Hz}, 3 \mathrm{H}), 1.36(\mathrm{br}$ $\mathrm{d}, J=6.6 \mathrm{~Hz}, 3 \mathrm{H}), 1.11(\mathrm{~s}, 3 \mathrm{H}), 1.05(\mathrm{~d}, J=6.2 \mathrm{~Hz}, 3 \mathrm{H}) .{ }^{19} \mathrm{~F}$ NMR $\left(376 \mathrm{MHz}, \mathrm{DMSO}-d_{6}\right) \delta \mathrm{ppm}-115.90(\mathrm{br} \mathrm{d}, J=209$ $\mathrm{Hz}, 1 \mathrm{~F}) . \mathrm{m} / \mathrm{z}(\mathrm{ESI},+\mathrm{ve}): 578(\mathrm{M}+\mathrm{H})^{+}$. Atropisomer configuration $(R$ vs. $S)$ assigned by analogy. ${ }^{17}$

Intermediate F: 4-Isopropyl-6-methylpyrimidin-5-amine
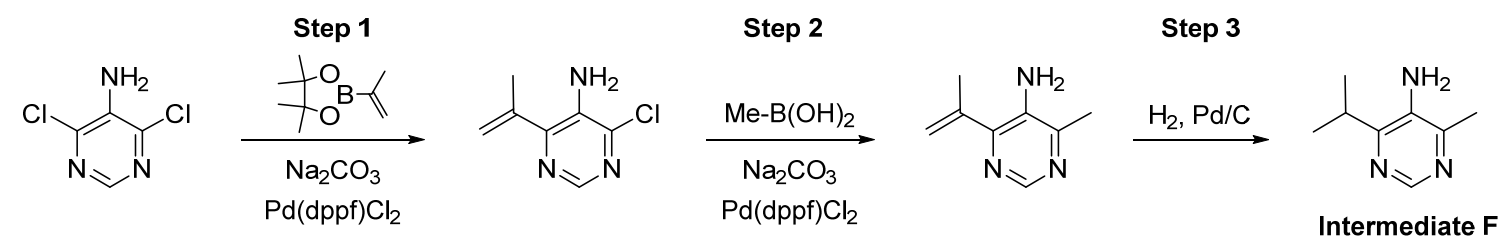

Step 1: 4-Chloro-6-(prop-1-en-2-yl)pyrimidin-5-amine. A mixture of 4,6-dichloro-5-aminopyrimidine (5.00 g, 30.5 mmol; Combi-Blocks, Inc.), 2-isopropenylboronic acid, pinacol ester (6.15 g, $36.6 \mathrm{mmol}), \mathrm{Pd}(\mathrm{dppf}) \mathrm{Cl}_{2}(2.23 \mathrm{~g}, 3.05 \mathrm{mmol})$, and sodium carbonate $(9.69 \mathrm{~g}, 91 \mathrm{mmol})$ in 1,4 -dioxane/water $(4: 1 ; 50 \mathrm{~mL})$ was sparged with $\mathrm{N}_{2}$ then stirred at $95{ }^{\circ} \mathrm{C}$ for 2 h. The mixture was cooled to rt, saturated aqueous $\mathrm{NaHCO}_{3}$ was added, and the resulting mixture was extracted with EtOAc. The combined organic extracts were concentrated in vacuo; chromatographic purification of the residue (silica gel; 0-40\% EtOAc/heptane) provided 4-chloro-6-(prop-1-en-2-yl)pyrimidin-5-amine (1.24 g, 24\% yield) as a yellow oil. $\mathrm{m} / \mathrm{z}$ (ESI, +ve) $170.0(\mathrm{M}+\mathrm{H})^{+}$.

Step 2: 4-Methyl-6-(prop-1-en-2-yl)pyrimidin-5-amine. A mixture of 4-chloro-6-(prop-1-en-2-yl)pyrimidin-5-amine $(2.0 \mathrm{~g}, 11.8 \mathrm{mmol})$, methylboronic acid $(3.53 \mathrm{~g}, 59.0 \mathrm{mmol}), \mathrm{Pd}(\mathrm{dppf}) \mathrm{Cl}_{2}(0.86 \mathrm{~g}, 1.18 \mathrm{mmol})$ and sodium carbonate $(6.3 \mathrm{~g}$, $59 \mathrm{mmol})$ in 1,4-dioxane/water $(4: 1 ; 50 \mathrm{~mL})$ was sparged with $\mathrm{N}_{2}$, then stirred at $95{ }^{\circ} \mathrm{C}$ for $17 \mathrm{~h}$. The mixture was then cooled to rt, diluted with saturated aqueous $\mathrm{NaHCO}_{3}$, and extracted with EtOAc. The combined extracts were concentrated in vacuo; chromatographic purification of the residue (silica gel; 0-5\% MeOH/DCM) provided 4-methyl-6-(prop-1-en-2yl)pyrimidin-5-amine (1.3 g, 74\% yield). m/z (ESI, +ve) $150.2(\mathrm{M}+\mathrm{H})^{+}$.

Step 3: 4-Isopropyl-6-methylpyrimidin-5-amine (Intermediate F). Palladium (10\% on activated carbon; $0.522 \mathrm{~g}$, $0.491 \mathrm{mmol})$ was added to a solution of 4-methyl-6-(prop-1-en-2-yl)pyrimidin-5-amine (1.46 g, $9.81 \mathrm{mmol}) \mathrm{in} \mathrm{EtOH} \mathrm{(30}$ $\mathrm{mL})$; the resulting suspension was stirred under hydrogen gas $(30 \mathrm{psig})$ for $1.5 \mathrm{~h}$. The resulting mixture was subsequently filtered through Celite ${ }^{\circledR}$, and the filtrate was concentrated in vacuo to provide 4-isopropyl-6-methylpyrimidin-5-amine (1.48 $\mathrm{g}$, quantitative; Intermediate F) as a brown oil. ${ }^{1} \mathrm{H}$ NMR (400 MHz, DMSO-d $) \delta 7.96-8.30(\mathrm{~m}, 1 \mathrm{H}), 4.94-5.11(\mathrm{~m}, 2 \mathrm{H})$, 3.12-3.27 (m, 1H), 2.22-2.31 (m, 3H), 1.13-1.16 (m, 6H). m/z (ESI, +ve) $152.2(\mathrm{M}+\mathrm{H})^{+}$. 


\section{Compound $(R)-37$}

(R)-4-((S)-4-Acryloyl-2-methylpiperazin-1-yl)-6-fluoro-7-(2-fluoro-6-hydroxyphenyl)-1-(2-isopropyl-6methylphenyl)pyrido[2,3-d]pyrimidin-2(1H)-one was prepared according to the procedure described for Compound $(R)-$ 18, using 2,6-dichloro-5-fluoro-nicotinic acid (AstaTech, Inc.) in Step 1, and 2-isopropyl-6-methylaniline (Enamine, LLC) in Step 2b, to afford the title compound. Atropisomer separation following Step 6 (chiral SFC: AD, $250 \times 30 \mathrm{~mm}, 5 \mu \mathrm{m}$, $40 \% \mathrm{iPrOH} / \mathrm{CO}_{2}, 95 \mathrm{~g} / \mathrm{min}, 103 \mathrm{bar}$ ) gave Compound $(R)-37$ as the first-eluting isomer and an off-white solid. ${ }^{1} \mathrm{H}$ NMR $\left(400 \mathrm{MHz}, \mathrm{CDCl}_{3}\right) \delta \mathrm{ppm} 9.44(1 \mathrm{H}$, br s) $7.87(1 \mathrm{H}, \mathrm{d}, J=9.33 \mathrm{~Hz}) 7.41(1 \mathrm{H}, \mathrm{t}, J=7.46 \mathrm{~Hz}) 7.34(1 \mathrm{H}, \mathrm{d}, J=7.67 \mathrm{~Hz})$ 7.20-7.28 (2 H, m) 6.52-6.69 (3 H, m) $6.38(1 \mathrm{H}, \mathrm{d}, J=16.59 \mathrm{~Hz}) 5.79(1 \mathrm{H}, \mathrm{d}, J=10.37 \mathrm{~Hz}) 2.98-5.11(7 \mathrm{H}, \mathrm{m}) 2.50-$ $2.69(1 \mathrm{H}, \mathrm{m}) 1.90-2.03(3 \mathrm{H}, \mathrm{m}) 1.42-1.59(3 \mathrm{H}, \mathrm{m}) 1.18(3 \mathrm{H}, \mathrm{d}, J=6.22 \mathrm{~Hz}) 0.99(3 \mathrm{H}, \mathrm{d}, J=6.01 \mathrm{~Hz}) . m / z(\mathrm{ESI},+\mathrm{ve})$ $560.0(\mathrm{M}+\mathrm{H})^{+}$. Atropisomer configuration $(R$ vs. $S)$ assigned by analogy. ${ }^{17}$

\section{Compound $(R)-38$ - AMG 510}

(1R)-6-Fluoro-7-(2-fluoro-6-hydroxyphenyl)-1-[4-methyl-2-(1-methylethyl)-3-pyridinyl]-4-[(2S)-2-methyl-4-(1oxo-2-propen-1-yl)-1-piperazinyl]-pyrido[2,3-d]pyrimidin-2(1H)-one

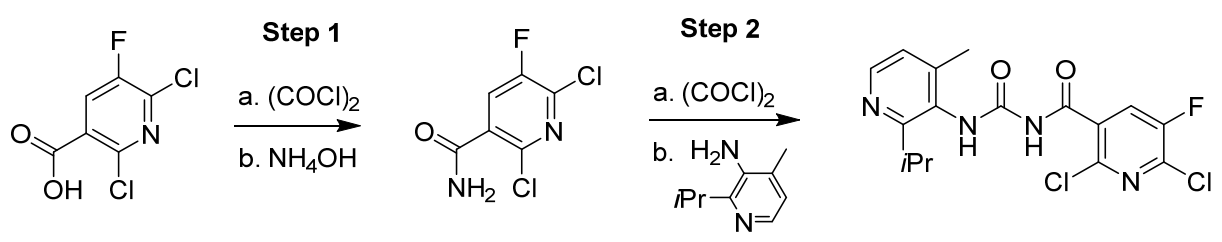

Intermediate $\mathrm{E}$
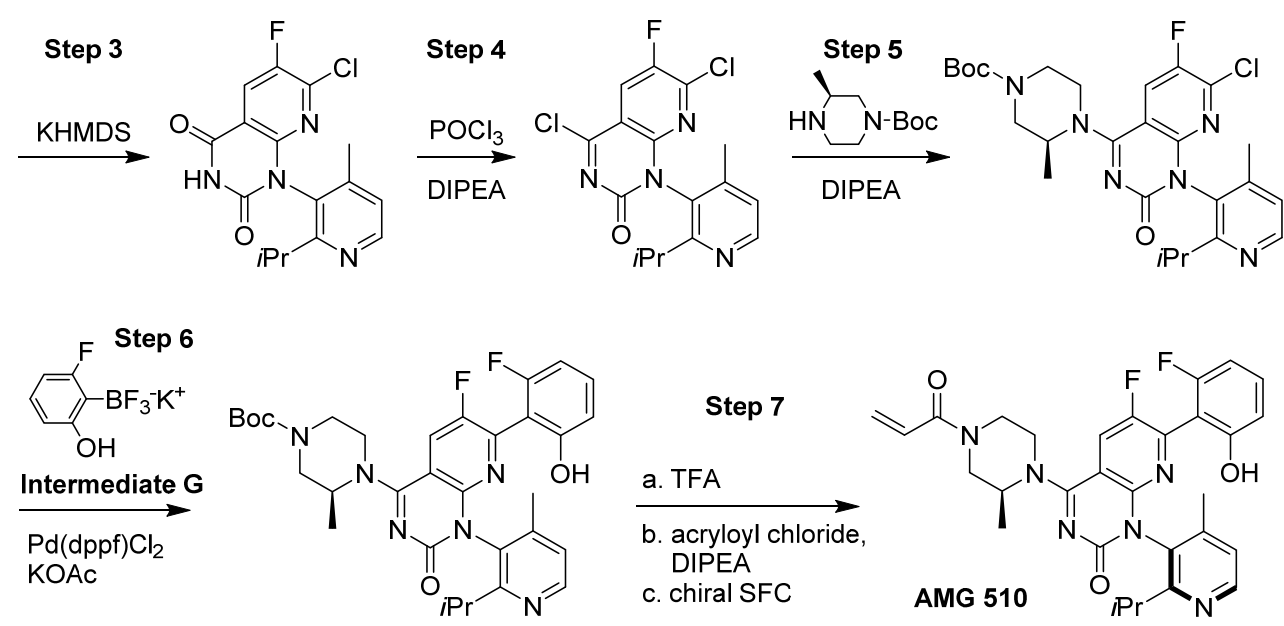

Step 1: 2,6-Dichloro-5-fluoronicotinamide. Oxalyl chloride (2 M solution in DCM, $11.9 \mathrm{~mL}, 23.8 \mathrm{mmol})$ and DMF $(0.05 \mathrm{~mL})$ were sequentially added to 2,6-dichloro-5-fluoro-nicotinic acid (4.0 g, $19.1 \mathrm{mmol}$, AstaTech, Inc.) in DCM (48 $\mathrm{mL}$ ), and the resulting mixture was stirred at ambient temperature for $16 \mathrm{~h}$. The reaction mixture was then concentrated in vacuo, and the residue was dissolved in 1,4-dioxane $(48 \mathrm{~mL})$ and cooled to $0{ }^{\circ} \mathrm{C}$. Ammonium hydroxide solution $(28-30 \%$ $\mathrm{NH}_{3}$ basis, $3.6 \mathrm{~mL}, 28.6 \mathrm{mmol}$ ) was slowly added, and the resulting mixture was stirred at $0{ }^{\circ} \mathrm{C}$ for 30 min. The mixture was then concentrated in vacuo, and the residue diluted with 1:1 EtOAc/heptane, agitated for 5 min, and filtered. The filtrate was concentrated to half-volume and re-filtered. The combined collected solids were washed with heptane and dried overnight in a reduced-pressure oven $\left(45^{\circ} \mathrm{C}\right)$ to provide 2,6-dichloro-5-fluoronicotinamide $(2.0 \mathrm{~g}, 50 \%$ yield $)$. ${ }^{1} \mathrm{H}$ NMR $\left(400 \mathrm{MHz}, \mathrm{DMSO}-d_{6}\right) \delta 8.23$ (d, $\left.J=7.9 \mathrm{~Hz}, 1 \mathrm{H}\right) 8.09$ (br s, $\left.1 \mathrm{H}\right) 7.93$ (br s, $\left.1 \mathrm{H}\right) .{ }^{19} \mathrm{~F}$ NMR $\left(376 \mathrm{MHz}, \mathrm{DMSO}-d_{6}\right) \delta:-$ 122.39 (s, $1 \mathrm{~F}) . \mathrm{m} / \mathrm{z}$ (ESI, +ve ion): $208.9(\mathrm{M}+\mathrm{H})^{+}$.

Step 2: 2,6-Dichloro-5-fluoro- $N$-((2-isopropyl-4-methylpyridin-3-yl)carbamoyl)nicotinamide. To an ice-cooled slurry of 2,6-dichloro-5-fluoronicotinamide $(5.0 \mathrm{~g}, 23.9 \mathrm{mmol})$ in THF $(20 \mathrm{~mL})$ was slowly added oxalyl chloride (2 M solution in DCM, $14.4 \mathrm{~mL}, 28.8 \mathrm{mmol}$ ). The resulting mixture was stirred at $75^{\circ} \mathrm{C}$ for $1 \mathrm{~h}$, then allowed to cool and concentrated in vacuo to half volume. The concentrate was cooled to $0{ }^{\circ} \mathrm{C}$ and diluted with THF $(20 \mathrm{~mL})$. A solution of $2-$ isopropyl-4-methylpyridin-3-amine (3.59 g, $23.9 \mathrm{mmol}$; Intermediate E) in THF $(10 \mathrm{~mL})$ was added dropwise via cannula. The resulting mixture was stirred at $0{ }^{\circ} \mathrm{C}$ for $1 \mathrm{~h}$, diluted with a $1: 1$ mixture of brine and saturated aqueous ammonium chloride, and extracted with EtOAc $(3 \times)$. The combined organic extracts were dried over anhydrous sodium sulfate and 
concentrated in vacuo to provide 2,6-dichloro-5-fluoro- $N$-((2-isopropyl-4-methylpyridin-3-yl)carbamoyl)nicotinamide, which was used without further purification. $\mathrm{m} / \mathrm{z}$ (ESI, +ve ion): $385.1(\mathrm{M}+\mathrm{H})^{+}$.

Step 3: 7-Chloro-6-fluoro-1-(2-isopropyl-4-methylpyridin-3-yl)pyrido[2,3-d]pyrimidine-2,4(1H,3H)-dione. To an ice-cooled solution of 2,6-dichloro-5-fluoro- $N$-((2-isopropyl-4-methylpyridin-3-yl)carbamoyl)nicotinamide (9.2 g, 24.0 $\mathrm{mmol}$ ) in THF (40 mL) was slowly added KHMDS (1 M solution in THF, $50.2 \mathrm{~mL}, 50.2 \mathrm{mmol}$ ). The ice bath was removed, and the resulting mixture was stirred for $40 \mathrm{~min}$ at ambient temperature. Saturated aqueous ammonium chloride solution was added, and the resulting mixture was extracted with EtOAc $(3 \times)$. The combined organic extracts were dried over anhydrous sodium sulfate and concentrated in vacuo. Chromatographic purification of the residue (silica gel; 0-50\% 3:1 EtOAc-EtOH/heptane) provided 7-chloro-6-fluoro-1-(2-isopropyl-4-methylpyridin-3-yl)pyrido[2,3-d]pyrimidine2,4(1H,3H)-dione (9.24 g, quantitative yield). ${ }^{1} \mathrm{H}$ NMR (400 MHz, DMSO-d $) \delta 12.27$ (br s, $\left.1 \mathrm{H}\right), 8.48-8.55$ (m, $\left.2 \mathrm{H}\right), 7.29$ $(\mathrm{d}, J=4.8 \mathrm{~Hz}, 1 \mathrm{H}), 2.87$ (quin, $J=6.6 \mathrm{~Hz}, 1 \mathrm{H}), 1.99-2.06(\mathrm{~m}, 3 \mathrm{H}), 1.09(\mathrm{~d}, J=6.6 \mathrm{~Hz}, 3 \mathrm{H}), 1.01(\mathrm{~d}, J=6.6 \mathrm{~Hz}, 3 \mathrm{H}) .{ }^{19} \mathrm{~F}$ NMR (376 MHz, DMSO-d $) \delta-126.90(\mathrm{~s}, 1 \mathrm{~F}) . \mathrm{m} / \mathrm{z}\left(\mathrm{ESI},+\mathrm{ve}\right.$ ion): $349.1(\mathrm{M}+\mathrm{H})^{+}$.

Step 4: 4,7-Dichloro-6-fluoro-1-(2-isopropyl-4-methylpyridin-3-yl)pyrido[2,3-d]pyrimidin-2(1H)-one. ${ }^{16}$ Phosphorus oxychloride $(1.63 \mathrm{~mL}, 17.5 \mathrm{mmol})$ was added, dropwise, to a solution of 7-chloro-6-fluoro-1-(2-isopropyl-4methylpyridin-3-yl)pyrido[2,3-d]pyrimidine-2,4(1H,3H)-dione $(4.7 \mathrm{~g}, 13.5 \mathrm{mmol})$ and DIPEA $(3.5 \mathrm{~mL}, 20 \mathrm{mmol})$ in acetonitrile $(20 \mathrm{~mL})$, and the resulting mixture was stirred at $80{ }^{\circ} \mathrm{C}$ for $1 \mathrm{~h}$, then cooled to ambient temperature and concentrated in vacuo to provide 4,7-dichloro-6-fluoro-1-(2-isopropyl-4-methylpyridin-3-yl)pyrido[2,3-d]pyrimidin-2(1H)one, which was used without further purification. $m / z$ (ESI, +ve ion): $367.1(\mathrm{M}+\mathrm{H})^{+}$.

Step 5: (S)-tert-Butyl 4-(7-chloro-6-fluoro-1-(2-isopropyl-4-methylpyridin-3-yl)-2-oxo-1,2-dihydropyrido[2,3d]pyrimidin-4-yl)-3-methylpiperazine-1-carboxylate. To an ice-cooled solution of 4,7-dichloro-6-fluoro-1-(2-isopropyl4-methylpyridin-3-yl)pyrido[2,3-d]pyrimidin-2 $(1 H)$-one $(13.5 \mathrm{mmol})$ in acetonitrile $(20 \mathrm{~mL})$ was added DIPEA (7.1 mL, $40.3 \mathrm{mmol}$ ) followed by (S)-4-Boc-2-methyl piperazine (3.23 g, $16.1 \mathrm{mmol}$, Combi-Blocks, Inc.). The resulting mixture was warmed to ambient temperature and stirred for $1 \mathrm{~h}$, then diluted with cold saturated aqueous sodium bicarbonate solution $(200 \mathrm{~mL})$ and EtOAc $(300 \mathrm{~mL})$. The mixture was stirred for an additional $5 \mathrm{~min}$, and the organic layer was collected. The aqueous layer was extracted with additional EtOAc $(1 \times)$, and the combined organic extracts were dried over anhydrous sodium sulfate and concentrated in vacuo. Chromatographic purification of the residue (silica gel; 0-50\% EtOAc/heptane) gave (S)-tert-butyl 4-(7-chloro-6-fluoro-1-(2-isopropyl-4-methylpyridin-3-yl)-2-oxo-1,2-dihydropyrido[2,3-d]pyrimidin-4yl)-3-methylpiperazine-1-carboxylate (5.71 g, 80\% yield). ${ }^{1} \mathrm{H}$ NMR (400 MHz, DMSO-d6) $\delta$ 8.45-8.51 (1 H, m), 8.31-8.41 (1 H, m), 7.23-7.29 (1 H, m), 4.67-5.01 (1 H, m), 4.09-4.25 (1 H, m), 3.88-4.07 (1 H, m), 3.78-3.87 (1 H, m), 3.59-3.74 (1 H, m), 3.04-3.21 (2 H, m), 2.59-2.66 (1 H, m), 1.88-1.98 (3 H, m), 1.43-1.50 (9 H, m), 1.27-1.35 (3 H, m), 1.03-1.10 (3 H, $\mathrm{m}), 0.94-1.03(3 \mathrm{H}, \mathrm{m}) . \mathrm{m} / \mathrm{z}\left(\mathrm{ESI},+\mathrm{ve}\right.$ ion): $531.2(\mathrm{M}+\mathrm{H})^{+}$.

Step 6: (3S)-tert-Butyl 4-(6-fluoro-7-(2-fluoro-6-hydroxyphenyl)-1-(2-isopropyl-4-methylpyridin-3-yl)-2-oxo-1,2dihydropyrido[2,3-d]pyrimidin-4-yl)-3-methylpiperazine-1-carboxylate. A mixture of (S)-tert-butyl 4-(7-chloro-6fluoro-1-(2-isopropyl-4-methylpyridin-3-yl)-2-oxo-1,2-dihydropyrido[2,3-d]pyrimidin-4-yl)-3-methylpiperazine-1-

carboxylate (4.3 g, $8.1 \mathrm{mmol})$, (2-fluoro-6-hydroxyphenyl)potassium trifluoroborate (2.9 g, 10.5 mmol; Intermediate G), potassium acetate $(3.2 \mathrm{~g}, 32.4 \mathrm{mmol})$ and [1,1'-bis(diphenylphosphino)ferrocene]dichloropalladium(II), complex with dichloromethane $(661 \mathrm{mg}, 0.81 \mathrm{mmol})$ in 1,4-dioxane $(80 \mathrm{~mL})$ was sparged with nitrogen for $1 \mathrm{~min}$. De-oxygenated water $(14 \mathrm{~mL})$ was added, and the resulting mixture was heated at $90{ }^{\circ} \mathrm{C}$ for $1 \mathrm{~h}$, then cooled to ambient temperature, diluted with half-saturated aqueous sodium bicarbonate, and sequentially extracted with EtOAc $(2 \times)$ and DCM $(1 \times)$. The combined organic extracts were dried over anhydrous sodium sulfate and concentrated in vacuo. Chromatographic purification of the residue (silica gel; 0-60\% 3:1 EtOAc-EtOH/heptane) furnished (3S)-tert-butyl 4-(6-fluoro-7-(2-fluoro-6-hydroxyphenyl)1-(2-isopropyl-4-methylpyridin-3-yl)-2-oxo-1,2-dihydropyrido[2,3-d]pyrimidin-4-yl)-3-methylpiperazine-1-carboxylate (4.52 g, 92\% yield). ${ }^{1} \mathrm{H}$ NMR (400 MHz, DMSO-d 6 ) $\delta 10.19$ (br s, $\left.1 \mathrm{H}\right), 8.38$ (d, $\left.J=5.0 \mathrm{~Hz}, 1 \mathrm{H}\right), 8.26$ (dd, $J=12.5,9.2$ $\mathrm{Hz}, 1 \mathrm{H}), 7.23-7.28(\mathrm{~m}, 1 \mathrm{H}), 7.18(\mathrm{~d}, J=5.0 \mathrm{~Hz}, 1 \mathrm{H}), 6.72(\mathrm{~d}, J=8.0 \mathrm{~Hz}, 1 \mathrm{H}), 6.68(\mathrm{t}, J=8.9 \mathrm{~Hz}, 1 \mathrm{H}), 4.77-4.98(\mathrm{~m}, 1$ H), 4.24 (br t, $J=14.2 \mathrm{~Hz}, 1 \mathrm{H}), 3.93-4.08(\mathrm{~m}, 1 \mathrm{H}), 3.84$ (br d, $J=12.9 \mathrm{~Hz}, 1 \mathrm{H}), 3.52-3.75(\mathrm{~m}, 1 \mathrm{H}), 3.07-3.28(\mathrm{~m}, 1 \mathrm{H})$, 2.62-2.74 (m, $1 \mathrm{H}), 1.86-1.93(\mathrm{~m}, 3 \mathrm{H}), 1.43-1.48(\mathrm{~m}, 9 \mathrm{H}), 1.35$ (dd, $J=10.8,6.8 \mathrm{~Hz}, 3 \mathrm{H}), 1.26-1.32$ (m, $1 \mathrm{H}), 1.07$ (dd, $J$ $=6.6,1.7 \mathrm{~Hz}, 3 \mathrm{H}), 0.93(\mathrm{dd}, J=6.6,2.1 \mathrm{~Hz}, 3 \mathrm{H}) .{ }^{19} \mathrm{~F}$ NMR $\left(376 \mathrm{MHz}, \mathrm{DMSO}-d_{6}\right) \delta-115.6(\mathrm{~s}, 1 \mathrm{~F}),-128.6(\mathrm{~s}, 1 \mathrm{~F}) . \mathrm{m} / \mathrm{z}$ (ESI, +ve ion): $607.3(\mathrm{M}+\mathrm{H})^{+}$.

Step 7: (1R)-6-Fluoro-7-(2-fluoro-6-hydroxyphenyl)-1-[4-methyl-2-(1-methylethyl)-3-pyridinyl]-4-[(2S)-2methyl-4-(1-oxo-2-propen-1-yl)-1-piperazinyl]-pyrido[2,3-d]pyrimidin-2(1H)-one ((R)-38; AMG 510). Trifluoroacetic acid $(25 \mathrm{~mL}, 320 \mathrm{mmol})$ was added to a solution of (3S)-tert-butyl 4-(6-fluoro-7-(2-fluoro-6-hydroxyphenyl)-1-(2isopropyl-4-methylpyridin-3-yl)-2-oxo-1,2-dihydropyrido[2,3-d]pyrimidin-4-yl)-3-methylpiperazine-1-carboxylate (6.3 g, $10 \mathrm{mmol})$ in DCM $(30 \mathrm{~mL})$, and the resulting mixture was stirred at ambient temperature for $1 \mathrm{~h}$. The mixture was then concentrated in vacuo, and the residue was taken up in DCM $(30 \mathrm{~mL})$, cooled to $0{ }^{\circ} \mathrm{C}$, and sequentially treated with DIPEA $(7.3 \mathrm{~mL}, 42 \mathrm{mmol})$ and a solution of acryloyl chloride $(0.849 \mathrm{~mL}, 10.4 \mathrm{mmol})$ in DCM (3 mL; added dropwise). The resulting mixture was stirred at $0{ }^{\circ} \mathrm{C}$ for $10 \mathrm{~min}$, then diluted with half-saturated aqueous sodium bicarbonate and extracted with DCM $(2 \times)$. The combined extracts were dried over anhydrous sodium sulfate and concentrated in vacuo. 
Chromatographic purification of the residue (silica gel; 0-100\% 3:1 EtOAc-EtOH/heptane) followed by chiral supercritical fluid chromatography (Chiralpak IC, $30 \times 250 \mathrm{~mm}, 5 \mu \mathrm{m}, 55 \% \mathrm{MeOH} / \mathrm{CO}_{2}, 120 \mathrm{~mL} / \mathrm{min}, 102$ bar) provided (1R)-6-Fluoro7-(2-fluoro-6-hydroxyphenyl)-1-[4-methyl-2-(1-methylethyl)-3-pyridinyl]-4-[(2S)-2-methyl-4-(1-oxo-2-propen-1-yl)-1piperazinyl]-pyrido[2,3-d]pyrimidin-2(1H)-one $\left((R)-38\right.$; AMG 510; $2.25 \mathrm{~g}, 43 \%$ yield) as the first-eluting peak. ${ }^{1} \mathrm{H} \mathrm{NMR}$ $\left(600 \mathrm{MHz}, \mathrm{DMSO}-d_{6}\right) \delta \mathrm{ppm} 10.20(\mathrm{~s}, 1 \mathrm{H}), 8.39(\mathrm{~d}, J=4.9 \mathrm{~Hz}, 1 \mathrm{H}), 8.30(\mathrm{~d}, J=8.9 \mathrm{~Hz}, 0.5 \mathrm{H}), 8.27(\mathrm{~d}, J=8.7 \mathrm{~Hz}, 0.5 \mathrm{H})$, $7.27(\mathrm{q}, J=8.4 \mathrm{~Hz}, 1 \mathrm{H}), 7.18(\mathrm{~d}, J=4.9 \mathrm{~Hz}, 1 \mathrm{H}), 6.87(\mathrm{dd}, J=16.2,10.8 \mathrm{~Hz}, 0.5 \mathrm{H}), 6.84(\mathrm{dd}, J=16.2,10.7 \mathrm{~Hz}, 0.5 \mathrm{H})$, $6.74(\mathrm{~d}, J=8.4 \mathrm{~Hz}, 1 \mathrm{H}), 6.68(\mathrm{t}, J=8.4 \mathrm{~Hz}, 1 \mathrm{H}), 6.21(\mathrm{~d}, J=16.2 \mathrm{~Hz}, 0.5 \mathrm{H}), 6.20(\mathrm{~d}, J=16.2 \mathrm{~Hz}, 0.5 \mathrm{H}), 5.76(\mathrm{~d}, J=10.8$ $\mathrm{Hz}, 0.5 \mathrm{H}), 5.76(\mathrm{~d}, J=10.7 \mathrm{~Hz}, 0.5 \mathrm{H}), 4.91(\mathrm{~m}, 1 \mathrm{H}), 4.41(\mathrm{~d}, J=12.2 \mathrm{~Hz}, 0.5 \mathrm{H}), 4.33(\mathrm{~d}, J=12.2 \mathrm{~Hz}, 1 \mathrm{H}), 4.28(\mathrm{~d}, J=12.2$ $\mathrm{Hz}, 0.5 \mathrm{H}), 4.14(\mathrm{~d}, J=12.2 \mathrm{~Hz}, 0.5 \mathrm{H}), 4.02(\mathrm{~d}, J=13.6 \mathrm{~Hz}, 0.5 \mathrm{H}), 3.69(\mathrm{~m}, 1 \mathrm{H}), 3.65(\mathrm{~d}, J=13.6 \mathrm{~Hz}, 0.5 \mathrm{H}), 3.52(\mathrm{t}, J=$ $12.2 \mathrm{~Hz}, 0.5 \mathrm{H}), 3.27(\mathrm{~d}, J=12.2 \mathrm{~Hz}, 0.5 \mathrm{H}), 3.15(\mathrm{t}, J=12.2 \mathrm{~Hz}, 0.5 \mathrm{H}), 2.72(\mathrm{~m}, 1 \mathrm{H}), 1.90(\mathrm{~s}, 3 \mathrm{H}), 1.35(\mathrm{~d}, J=6.7 \mathrm{~Hz}, 3 \mathrm{H})$, $1.08(\mathrm{~d}, J=6.7 \mathrm{~Hz}, 3 \mathrm{H}), 0.94(\mathrm{~d}, J=6.7 \mathrm{~Hz}, 3 \mathrm{H}) .{ }^{19} \mathrm{~F}$ NMR $\left(376 \mathrm{MHz}, \mathrm{DMSO}-d_{6}\right) \delta-115.6(\mathrm{~d}, J=5.2 \mathrm{~Hz}, 1 \mathrm{~F}),-128.6$ (br. s., $1 \mathrm{~F}) .{ }^{13} \mathrm{C}$ NMR (151 MHz, DMSO-d $) \delta$ ppm 165.0 (1C), 163.4 (1C), 162.5 (1C), $160.1(1 \mathrm{C}), 156.8$ (1C), 153.7 (1C), 151.9 (1C), 149.5 (1C), 148.3 (1C), 145.2 (1C), 144.3 (1C), 131.6 (1C), 130.8 (1C), 127.9 (0.5C), 127.9 (0.5C), 127.8 (0.5C), 127.7 (0.5C), 123.2 (1C), 122.8 (1C), 111.7 (1C), 109.7 (1C), 105.7 (1C), $105.3(1 \mathrm{C}), 51.4(0.5 \mathrm{C}), 51.0(0.5 \mathrm{C}), 48.9$ (0.5C), 45.4 (0.5C), 44.6 (0.5C), 43.7 (0.5C), 43.5 (0.5C), 41.6 (0.5C), 29.8 (1C), 21.9 (1C), 21.7 (1C), 17.0 (1C), 15.5 (0.5C), 14.8 (0.5C). FTMS (ESI) m/z: [M+H] ${ }^{+}$Calcd for $\mathrm{C}_{30} \mathrm{H}_{30} \mathrm{~F}_{2} \mathrm{~N}_{6} \mathrm{O}_{3}$ 561.24202; Found 561.24150. Atropisomer configuration $(R$ vs. $S)$ assigned crystallographically.

Intermediate G: (2-Fluoro-6-hydroxyphenyl)potassium trifluoroborate.

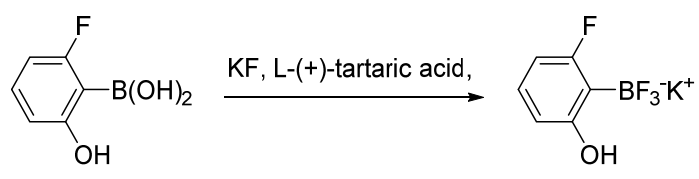

Intermediate G

A solution of potassium fluoride $(44.7 \mathrm{~g}, 770 \mathrm{mmol})$ in water $(75 \mathrm{~mL})$ was added to a suspension of (2-fluoro-6hydroxyphenyl)boronic acid (30 g, $192 \mathrm{mmol}$, Combi-Blocks, Inc.) in acetonitrile (750 mL). After 2 min of stirring, a solution of L-(+)-tartaric acid $(72.2 \mathrm{~g}, 481 \mathrm{mmol})$ in THF $(375 \mathrm{~mL})$ was added over $10 \mathrm{~min}$. The resulting mixture was mechanically stirred for $1 \mathrm{~h}$. Suspended solids were removed by filtration and washed with a small amount of THF. The combined filtrate was then partially concentrated in vacuo until solids began to precipitate. The filtrate was cooled to -20 ${ }^{\circ} \mathrm{C}$ and stirred for $16 \mathrm{~h}$, then slowly warmed to ambient temperature. 2-Propanol $(20 \mathrm{~mL})$ was added, and the precipitated solid was collected by filtration and washed with 2-propanol to provide $27.5 \mathrm{~g}$ of solid. The filtrate was again partially concentrated (until precipitation was observed), cooled to $-20{ }^{\circ} \mathrm{C}$, and stirred for $20 \mathrm{~min}$. Additional 2-propanol was added, and the precipitated solid was collected by filtration and washed with 2-propanol. The two batches of solid were combined to provide 2-fluoro-6-hydroxyphenyl)potassium trifluoroborate (34.6 g, 82\% yield; Intermediate G). ${ }^{1} \mathrm{H} \mathrm{NMR}(400 \mathrm{MHz}$, DMSO-d $)) \delta .07(\mathrm{q}, J=14.7 \mathrm{~Hz}, 1 \mathrm{H}) 6.93(\mathrm{q}, J=7.5 \mathrm{~Hz}, 1 \mathrm{H}) 6.30-6.38(\mathrm{~m}, 2 \mathrm{H})$.

\section{Compound (S)-39}

(S)-4-((S)-4-Acryloyl-2-methylpiperazin-1-yl)-6-fluoro-7-(2-fluoro-6-hydroxyphenyl)-1-(4-isopropyl-2methylpyridin-3-yl)pyrido[2,3-d]pyrimidin-2(1H)-one was prepared according to the procedure described for Compound (R)-18, using 4-isopropyl-2-methylpyridin-3-amine (Intermediate H) in Step 2b (carried on to the next step) to afford 4-((S)4-acryloyl-2-methylpiperazin-1-yl)-6-fluoro-7-(2-fluoro-6-hydroxyphenyl)-1-(4-isopropyl-2-methylpyridin-3-

yl)pyrido[2,3-d]pyrimidin-2(1H)-one. Atropisomer separation following Step 6 (chiral SFC: Whelk-01 $(R, R), 250 \times 21 \mathrm{~mm}$, $\left.5 \mu \mathrm{m}, 65 \% \mathrm{MeOH} / \mathrm{CO}_{2}, 80 \mathrm{~g} / \mathrm{min}, 102 \mathrm{bar}\right)$ gave Compound $(S)-39$ as the second-eluting isomer. ${ }^{1} \mathrm{H} \mathrm{NMR}(400 \mathrm{MHz}$, DMSO-d $) \delta 10.20($ br s, $1 \mathrm{H}), 8.35(\mathrm{~d}, \mathrm{~J}=4.98 \mathrm{~Hz}, 1 \mathrm{H}), 8.23-8.33(\mathrm{~m}, 1 \mathrm{H}), 7.19-7.35(\mathrm{~m}, 2 \mathrm{H}), 6.79-6.95(\mathrm{~m}, 1 \mathrm{H}), 6.64-$ $6.78(\mathrm{~m}, 2 \mathrm{H}), 6.21$ (br d, J = 16.17 Hz, 1H), 5.76 (br d, J = 10.37 Hz, 1H), 4.90 (br s, 1H), 4.24-4.46 (m, 2H), 3.98-4.18 (m, $1 \mathrm{H}), 3.46-3.78(\mathrm{~m}, 2 \mathrm{H}), 3.08-3.26(\mathrm{~m}, 1 \mathrm{H}), 2.55-2.64(\mathrm{~m}, 1 \mathrm{H}), 2.05(\mathrm{~s}, 3 \mathrm{H}), 1.34(\mathrm{br} \mathrm{d}, \mathrm{J}=6.63 \mathrm{~Hz}, 3 \mathrm{H}), 1.07(\mathrm{br} \mathrm{d}, \mathrm{J}=$ $6.63 \mathrm{~Hz}, 3 \mathrm{H}), 0.93$ (br d, J = 6.84 Hz, 3H). ${ }^{19} \mathrm{~F}$ NMR (376 MHz, DMSO-d $) \delta-115.62(\mathrm{~s}, 1 \mathrm{~F}),-128.60(\mathrm{~s}, 1 \mathrm{~F}) . \quad \mathrm{m} / \mathrm{z}(\mathrm{ESI}$, +ve) $561.1(\mathrm{M}+\mathrm{H})^{+}$. Atropisomer configuration ( $R$ vs. $\left.S\right)$ assigned by analogy. ${ }^{17}$ 
Intermediate H: 4-Isopropyl-2-methylpyridin-3-amine.

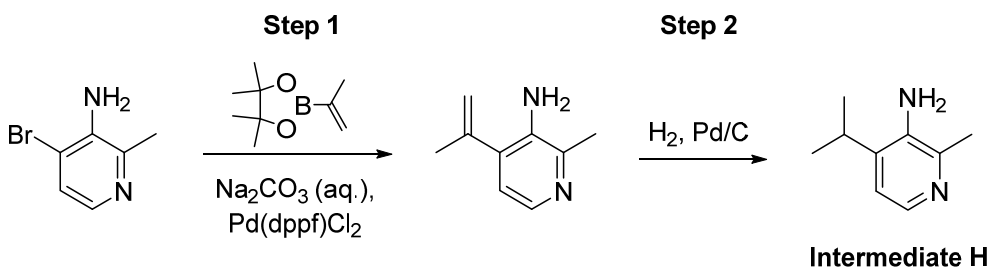

Step 1: 2-Methyl-4-(prop-1-en-2-yl)pyridin-3-amine. A mixture of 4-bromo-2-methylpyridin-3-amine (1.43 g, 7.66 mmol, Chem-Impex International, Inc.), dichloro[1,1'-bis(diphenylphosphino)ferrocene]dichloride palladium(II) DCM adduct $(0.063 \mathrm{~g}, 0.077 \mathrm{mmol})$, 2-isopropenylboronic acid, pinacol ester $(2.32 \mathrm{~g}, 13.8 \mathrm{mmol})$, and aqueous sodium carbonate $(10 \%$ solution in water; $1.62 \mathrm{~g}, 15.3 \mathrm{mmol})$ in 1,4-dioxane $(25 \mathrm{~mL})$ was sparged with nitrogen for $3 \mathrm{~min}$, then stirred at 110 ${ }^{\circ} \mathrm{C}$ for $1 \mathrm{~h}$. The reaction mixture was partitioned between EtOAc and brine. The aqueous layer was extracted with EtOAc, and the combined organic extracts were dried over $\mathrm{Na}_{2} \mathrm{SO}_{4}$, filtered, and concentrated in vacuo. Chromatographic purification of the residue (silica gel; 0-50\% EtOAc-EtOH (3:1)/heptane) provided 2-methyl-4-(prop-1-en-2-yl)pyridin-3amine (1.14 g, quantitative) as light-yellow oil. $\mathrm{m} / \mathrm{z}\left(\mathrm{ESI},+\mathrm{ve}\right.$ ion) $149.1(\mathrm{M}+\mathrm{H})^{+}$.

Step 2: 4-Isopropyl-2-methylpyridin-3-amine (Intermediate H). A mixture of 2-methyl-4-(prop-1-en-2-yl)pyridin-3amine $(1.14 \mathrm{~g}, 7.66 \mathrm{mmol})$ and palladium $(10 \mathrm{wt} \%$ on activated carbon; $407 \mathrm{mg}, 0.383 \mathrm{mmol})$ in ethanol was stirred under hydrogen gas ( $20 \mathrm{psig})$ for $3 \mathrm{~h}$. The reaction mixture was then filtered through a pad of Celite ${ }^{\circledR}$ and concentrated in vacuo to provide 4-isopropyl-2-methylpyridin-3-amine (1.08 g, 94\% yield; Intermediate $\mathbf{H})$ as a light-yellow viscous oil. ${ }^{1} \mathrm{H}$ NMR $\left(400 \mathrm{MHz}, \mathrm{CDCl}_{3}\right) \delta \mathrm{ppm} 7.93(\mathrm{~d}, J=5.18 \mathrm{~Hz}, 1 \mathrm{H}), 6.93(\mathrm{~d}, J=5.18 \mathrm{~Hz}, 1 \mathrm{H}), 3.62(\mathrm{br} \mathrm{s}, 2 \mathrm{H}), 2.89(\mathrm{td}, J=6.82$, $13.53 \mathrm{~Hz}, 1 \mathrm{H}), 2.44(\mathrm{~s}, 3 \mathrm{H}), 1.26(\mathrm{~d}, J=8.0 \mathrm{~Hz}, 6 \mathrm{H}) . \mathrm{m} / \mathrm{z}\left(\mathrm{ESI},+\mathrm{ve}\right.$ ion) $151.1(\mathrm{M}+\mathrm{H})^{+}$.

\section{Compound $(R)-40$}

(R)-4-((S)-4-Acryloyl-2-methylpiperazin-1-yl)-6-fluoro-7-(2-fluoro-6-hydroxyphenyl)-1-(4-isopropyl-6methylpyrimidin-5-yl)pyrido[2,3-d]pyrimidin-2(1H)-one was prepared according to the procedure described for Compound (R)-18, omitting Step 1, using 2,6-dichloro-5-fluoronicotinamide (RennoTech Co., Ltd) in Step 2a (quantitative) and 4-isopropyl-6-methylpyrimidin-5-amine (Intermediate F) in Step 2b, to afford the title compound. Atropisomer separation following Step 6b (chiral SFC: Chiralpak IC $\left.(4.6 \times 150 \mathrm{~mm}, 5 \mu \mathrm{m}), 20 \% \mathrm{EtOH} / \mathrm{CO}_{2}\right)$ gave Compound $(R)-40$ as the first eluting isomer as a light yellow solid. ${ }^{1} \mathrm{H}$ NMR (400 MHz, DMSO-d 6 ) $\delta \mathrm{ppm} 10.24$ (br dd, $\left.J=6.5,2.2 \mathrm{~Hz}, 1 \mathrm{H}\right)$, $8.96(\mathrm{~s}, 1 \mathrm{H}), 8.17-8.44(\mathrm{~m}, 1 \mathrm{H}), 7.17-7.44(\mathrm{~m}, 1 \mathrm{H}), 6.80-6.94(\mathrm{~m}, 1 \mathrm{H}), 6.66-6.76(\mathrm{~m}, 2 \mathrm{H}), 6.16-6.26(\mathrm{~m}, 1 \mathrm{H}), 5.77$ (dd, $J=10.7,2.2 \mathrm{~Hz}, 1 \mathrm{H}), 4.93(\mathrm{br} \mathrm{d}, J=1.5 \mathrm{~Hz}, 1 \mathrm{H}), 4.35(\mathrm{br} \mathrm{d}, J=15.3 \mathrm{~Hz}, 2 \mathrm{H}), 3.98-4.20(\mathrm{~m}, 1 \mathrm{H}), 3.60-3.80(\mathrm{~m}, 2$ H), 3.38-3.60 (m, 1 H), 2.72-2.83 (m, $1 \mathrm{H}), 2.10(\mathrm{~s}, 3 \mathrm{H}), 1.36(\mathrm{~d}, J=6.6 \mathrm{~Hz}, 3 \mathrm{H}), 1.09$ (d, $J=6.6 \mathrm{~Hz}, 3 \mathrm{H}), 0.95(\mathrm{~d}, J=$ $6.6 \mathrm{~Hz}, 3 \mathrm{H}) .{ }^{19} \mathrm{~F}$ NMR $(376 \mathrm{MHz}$, DMSO-d 6 ) $\delta \mathrm{ppm}-115.74$ (br d, J = 4.3 Hz, 1 F), -128.10 (s, $1 \mathrm{~F}) . \mathrm{m} / \mathrm{z}$ (ESI, +ve) 562 $(\mathrm{M}+\mathrm{H})^{+}$. Atropisomer configuration ( $R$ vs. $S$ ) assigned by analogy. ${ }^{17}$

\section{X-ray crystallographic data table}

\section{Compound 2 \& Compound 9}

\section{Data collection and refinement statistics}

\begin{tabular}{lll}
\hline & 2 (6PGO) & 9 (6PGP) \\
\hline $\begin{array}{l}\text { Data collection } \\
\text { Wavelength }(\AA)\end{array}$ & 1.0000 & \\
Space group & $\mathrm{P} 21212$ & 1.0000 \\
Cell dimensions & & $\mathrm{P} 1$ \\
$\quad$ & & \\
$\quad a, c(\AA)$ & $79.57,106.33,33.74$ & $33.42,39.61,62.45$ \\
$\quad \alpha, \beta, \gamma\left({ }^{\circ}\right)$ & $90,90,90$ & $76.91,81.38,77.30$ \\
Resolution $(\AA)$ & $30.0-1.60(1.66-1.60)$ & $35.0-1.5(1.55-1.50)$ \\
Unique reflections & 38777 & 41460 \\
$\mathrm{R}_{\text {sym }}$ & $0.116(0.349)$ & $0.038(0.481)$ \\
$I / \sigma I$ & $9.9(4.05)$ & $12.67(1.55)$ \\
Completeness $(\%)$ & $99.0(95.4)$ & $85.0(46.0)$ \\
\hline
\end{tabular}




\begin{tabular}{|c|c|c|}
\hline Redundancy & $4.7(4.1)$ & $1.8(1.7)$ \\
\hline \multicolumn{3}{|l|}{ Refinement } \\
\hline Resolution $(\AA)$ & $30.00-1.60$ & $35.00-1.50$ \\
\hline Completeness (\%) & 99.11 & 85.49 \\
\hline No. reflections & 36512 & 39365 \\
\hline$R_{\text {work }} / R_{\text {free }}$ & $0.2170 / 0.2311$ & $0.1899 / 0.2165$ \\
\hline No. atoms & 2791 & 3164 \\
\hline Protein & 2500 & 2718 \\
\hline Ligand/ion & 128 & 138 \\
\hline Water & 163 & 308 \\
\hline Average B overall $\left(\AA^{2}\right)$ & 25.11 & 18.43 \\
\hline \multicolumn{3}{|l|}{ R.m.s. deviations } \\
\hline Bond lengths $(\AA)$ & 0.006 & 0.006 \\
\hline Bond angles $\left(^{\circ}\right)$ & 1.171 & 1.186 \\
\hline \multicolumn{3}{|l|}{ Ramachandran ${ }^{\wedge}$} \\
\hline Favored (\%) & 98.7 & 98.2 \\
\hline Allowed (\%) & 1.3 & 1.8 \\
\hline Outliers (\%) & 0 & 0 \\
\hline
\end{tabular}

One crystal data set was collected for each of these structures

*Values in parentheses are for highest-resolution shell.

^ MolProbity Ramachandran Lovell, Davis, et al. Proteins 50:437 (2003)

\section{References}

\footnotetext{
${ }^{1}$ Ostrem, J. M.; Peters, U.; Sos, M. L.; Wells, J. A.; Shokat, K. M., K-Ras(G12C) inhibitors allosterically control GTP affinity and effector interactions. Nature 2013, 503, 548-551.

${ }^{2}$ Schinkel, A. H.; Wagenaar, E.; van Deemter, L.; Mol, C. A.; Borst, P. Absence of the mdr1a P-Glycoprotein in mice affects tissue distribution and pharmacokinetics of dexamethasone, digoxin, and cyclosporin A. J. Clin. Invest. 1995, 96, 1698-1705.

${ }^{3}$ Booth-Genthe, C. L.; Louie, S. W.; Carlini, E. J.; Li, B.; Leake, B. F.; Eisenhandler, R.; Hochman, J. H.; Mei, Q.; Kim, R. B.; Rushmore, T. H.; Yamazaki, M. Development and characterization of LLC-PK1 cells containing Sprague-Dawley rat Abcbla (Mdr1a): comparison of rat P-glycoprotein transport to human and mouse. J Pharmacol. Tox. Met. 2006, 54, 78-89.

${ }^{4}$ Otwinowski, Z.; Minor, W., Processing of X-ray diffraction data collected in oscillation mode. Method. Enzymol. 1997, 276, $307-326$.

${ }^{5}$ Kabsch, W., Xds. Acta Crystallogr. D 2010, 66, 125-132.

${ }^{6}$ McCoy, A. J.; Grosse-Kunstleve, R. W.; Adams, P. D.; Winn, M. D.; Storoni, L. C.; Read, R. J., Phaser crystallographic software. J. Appl. Crystallogr. 2007, 40, 658-674.

${ }^{7}$ Winn, M. D.; Ballard, C. C.; Cowtan, K. D.; Dodson, E. J.; Emsley, P.; Evans, P. R.; Keegan, R. M.; Krissinel, E. B.; Leslie, A. G.; McCoy, A.; McNicholas, S. J.; Murshudov, G. N.; Pannu, N. S.; Potterton, E. A.; Powell, H. R.; Read, R. J.; Vagin, A.; Wilson, K. S., Overview of the CCP4 suite and current developments. Acta Crystallogr. D 2011, 67, 235-242.

${ }^{8}$ Murshudov, G. N.; Skubak, P.; Lebedev, A. A.; Pannu, N. S.; Steiner, R. A.; Nicholls, R. A.; Winn, M. D.; Long, F.; Vagin, A. A., REFMAC5 for the refinement of macromolecular crystal structures. Acta Crystallogr. D 2011, 67, 355-367.

${ }^{9}$ Emsley, P.; Cowtan, K., Coot: model-building tools for molecular graphics. Acta Crystallogr. D 2004, 60, $2126-2132$.

${ }^{10}$ Schuttelkopf, A. W.; van Aalten, D. M., PRODRG: a tool for high-throughput crystallography of protein-ligand complexes. Acta Crystallogr. D 2004, 60, 1355-1363.

${ }^{11}$ Adams, P. D.; Afonine, P. V.; Bunkoczi, G.; Chen, V. B.; Davis, I. W.; Echols, N.; Headd, J. J.; Hung, L. W.; Kapral, G. J.; GrosseKunstleve, R. W.; McCoy, A. J.; Moriarty, N. W.; Oeffner, R.; Read, R. J.; Richardson, D. C.; Richardson, J. S.; Terwilliger, T. C.; Zwart, P. H., PHENIX: a comprehensive Python-based system for macromolecular structure solution. Acta Crystallogr. D 2010, 66, 213-221.

${ }^{12}$ Moriarty, N. W.; Grosse-Kunstleve, R. W.; Adams, P. D., electronic Ligand Builder and Optimization Workbench (eLBOW): a tool for ligand coordinate and restraint generation. Acta Crystallogr. D 2009, 65, 1074-1080.

${ }^{13}$ Rotzler, J.; Gsellinger, H.; Bihlmeier, A.; Gantenbein, M.; Vonlanthen, D.; Haussinger, D.; Klopper, W.; Mayor, M., Atropisomerization of di-para-substituted propyl-bridged biphenyl cyclophanes. Org. Biomol. Chem. 2013, 11, 110-118.

${ }^{14}$ Campuzano, I. D.; San Miguel, T.; Rowe, T.; Onea, D.; Cee, V. J.; Arvedson, T.; McCarter, J. D. High-Throughput Mass Spectrometric Analysis of Covalent Protein-Inhibitor Adducts for the Discovery of Irreversible Inhibitors: A Complete Workflow. J. Biomol. Screen. 2016, 21, 136-144.
} 
${ }^{15}$ Parsons, Z. D.; Gates, K. S., Redox Regulation of Protein Tyrosine Phosphatases: Methods for Kinetic Analysis of Covalent Enzyme Inactivation. Method. Enzymol. 2013, 528, 129-154.

${ }^{16} \mathrm{We}$ have subsequently reported an improved procedure for the workup of $\mathrm{POCl}_{3}$ reactions to mitigate the risk of latent exotherms during aqueous workup: Achmatowicz, M. M.; Thiel, O. R.; Colyer, J. T.; Hu, J.; Elipe, M. V. S.; Tomaskevitch, J.; Tedrow, J. S.; Larsen, R. D., Hydrolysis of Phosphoryl Trichloride ( $\left.\mathrm{POCl}_{3}\right)$ : Characterization, in Situ Detection, and Safe Quenching of Energetic Metastable Intermediates. Org. Process Res. Dev. 2010, 14, 1490-1500. A modified version of this procedure was used in the synthesis of Compound 32 (step 4).

${ }^{17}$ The more potent atropisomer (exchange \& p-ERK assays) was assigned the same arene configuration as Compound (R)-9.

${ }^{18}$ See reference in endnote 16. 